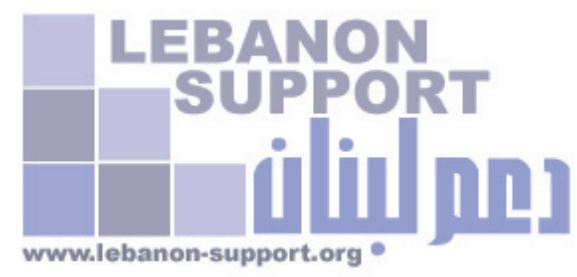

\title{
NAHR EL-BARED STATISTICAL REPORT 2009
}

\section{MAIN TRENDS AND FINDINGS ON THE CONDITIONS AND THE SITUATION OF THE NAHR EL-BARED DISPLACED AND RETURNED POPULATION}

IDPS AND RETURNEES DATABASE (2008 - 2009)

\author{
LEBANON SUPPORT
}




\section{AUTHOR}

BASSEM CHIT

\section{STATISTICAL ANALYSIS}

JOANNA KHATER

\section{REVISED BY}

DAVID LIGNEAU, HANDICAP INTERNATIONAL MARIE-NOËLlE ABIYAGHI, LEBANON SUPPORT

DiA ABOU MOSLEH, LEBANON SUPPORT

\section{COORDINATION AND VALIDATION OF DATA COLLECTION}

WALID TAHA, HIBA ABBANI

\section{FIELD TEAM}

NAEl AbOU-SiAm, HANAA El-SHARIF, AHMAD KHALIL, ISRAR GHANOUMI, MOHAMAD NAJEM, NAHED YASSINE, RAJAA EL-SHAABI, FATMEH EL-HAJJ, JIHANE EL-HAJJ,

SAMER HAMMAD

MAPS CREATED BY: HISHAM ASHKAR

THIS REPORT HAS BEEN REALIZED IN COLLABORATION WITH HANDICAP INTERNATIONAL (HI), UNITED NATIONS DEVELOPMENT PROGRAMME (UNDP), UNITED NATIONS RESIDENT COORDINATOR OFFICE (UNRCO), UNITED NATIONS RELIEF AND WORKS AGENCY (UNRWA)

AND THANKS TO THE FINANCIAL SUPPORT OF

EUROPEAN UNION HUMANITARIAN AID OFFICE, ECHO

\section{PUBLLISHED BY:}

\section{LEBANON SUPPORT}

3RD FLOOR, SHAGHOURI BUILDING,

MEDAWAR STREeT, AdLieH

BEIRUT, LEBANON

TEL/FAX: +961 1397495

EMAIL: CONTACT@DA3EM.ORG

WWW.LEBANON-SUPPORT.ORG 


\section{Table of Contents}

Foreword VI

Background VII

A- Lebanon Support Organization Profile VII

B-Methodology VIII

I- Executive Summary 12

A- Introduction $\quad 12$

$B$ - Key Trends and Findings 13

C-Conclusion and Recommendations 16

II- Palestinian Refugees in Lebanon 17

A- Historical Overview 17

$B$-Camps and Gatherings 18

III-Nahr El-Bared Crisis 20

IV-Displacement and Return 22

A- Patterns of Displacement and Return 23

V-Demographic Composition of the NBC Population 27

A- Family Size 27

$B-$ Age and Sex Characteristics 28

$C$ - Early Marriage 30

D- Civil Status 31

VI- Shelter Characteristics 33

A- NBC IDPs in Beddawi Camp 33

$B$-NBC IDPs in Jabal El-Beddawi 36

$C$-Returnees and Semi-Returnees in NBC Adjacent Area 39

$D$-Comparison of Results between the three areas 43 
VII- State of Services 45

A- NBC IDPs in Beddawi Camp 45

a) Electricity 45

b) Water 46

$B$ - NBC IDPs in Jabal El-Beddawi 48

a) Electricity 48

b) Water 49

C-Returnees and Semi-Returnees in NBC Adjacent Area 52

a) Electricity 52

b) Water 54

D- Comparison of Results 57

VIII- Health Characteristics 58

A-Disability 58

B-Chronic Diseases $\quad 60$

IX-Education $\quad 62$

A- Education Reception by Age Categories 62

B-Education Levels 63

X-Work and Employment 65

A-Employment and Labour Characteristics (Pre \& Post War) 65

B-Income (Pre \& Post War) 71

C-Gender and Employment 73

D- Education and Employment 76

XI- Small and Medium Businesses in Nahr El Bared 78

A- General Characteristics 78

$B$ - Levels of Employment and Income 80

$C$-Obstacles to Growth $\quad 82$

Map of Businesses in Nahr El-Bared Adjacent Area 84 


\section{(C) LEBANON SUPPORT 2009}

\section{DISCLAIMER}

THE FINDINGS, INTERPRETATIONS AND CONCLUSIONS EXPRESSED IN THIS REPGRT ARE ENTIRELY THOSE QF THE AUTHORS AND SHIULD NIT BE ATTRIBUTED TI LEBANIN SUPPGRT, THEIR DONIRS AND PARTNERS.

THIS REPGRT DIES NGT AIM TI PRIVIDE AN EXHAUSTIVE ANALYSIS IF THE SITUATION IN THE NAHR EL-BARED CAMP, BUT RATHER TI REFLECT IN PRIGRITY CLNCERNS FIR DISCUSSION AND DEBATE. THIS REPLRT IS INTENDED TO SERVE AS A TILL FIR FUTURE COLPERATION AND FOLLOW-UP.

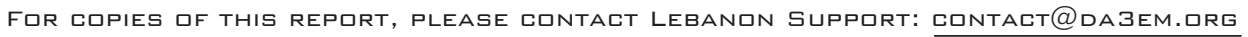

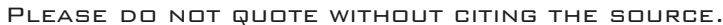




\section{Foreword}

In 1948, one hundred thousand Palestinians fled to Lebanon from Palestine, mainly from Haifa, Acre and the Galilee. In Lebanon "temporary" camps were established to provide shelter to the refugees. Today, most of the refugees live in camps that are still precarious settlements even if they have become more like permanent neighborhoods, or they live in clusters of Palestinian homes outside the camps, in the so-called "gatherings". They are reported to face the worst living conditions among the Palestinian refugees in the host countries in the Middle East. In a situation characterized as one of physical misery, fear and insecurity, most refugees face very limited employment opportunities and possess scant economic resources.

In May 2007, clashes between the Lebanese army and Fath el Islam in Nahr El-Bared Camp, led to the destruction of the camp, the displacement of entire families and the aggravation of the already vulnerable conditions of the community. Although the situation in Nahr El-Bared has stabilized, it remains fragile and thousands of families still rely on Aid to cope with the necessities of daily life.

The Nahr El-Bared Statistical Report is based on the data gathered through the IDP \& Returnee Database, one of the main components of Lebanon Support's Emergency and Recovery Information System (ERIS). It responds to an information gap on the situation of displaced, Returnees and Semi-Returnees as well as it provides the humanitarian, recovery and development actors with relevant data to better address the needs of the Palestinian refugee community in North Lebanon.

Lebanon Support is an NGO aiming at supporting and enhancing information sharing and coordination, in the goal of increasing efficiency and effectiveness of humanitarian, recovery and development response.

The Report was developed and authored by Lebanon Support, in collaboration with Handicap International (HI), United Nations Development Programme (UNDP), United Nations Resident Coordinator Office (UNRCO), United Nations Relief and Works Agency (UNRWA) and supported by the European Union Humanitarian Aid Office (ECHO).

This long awaited report is ready for use and is indented to serve as a tool for UN agencies, NGOs, professionals, donor organizations, journalists and academics in developing a comprehensive overview of the current issues of concern regarding the well being and recovery of the Nahr El-Bared community. It constitutes a base for further research, investigation and reflexion and aims at highlighting the most prevalent characteristics and current trends regarding recovery of the Nahr El-Bared camp. Comments, additions and suggestions are welcome and can be sent to: info@da3em.org

Lebanon Support would like to thank the team in the field and in the main office for their commitment and work, the local organisations and more specifically those in the Nahr El-Bared and Beddawi area, for their trust and support. We would also like to thank Handicap International (HI), the United Nations Development Programme (UNDP), the United Nations Resident Coordinator Office (UNRCO), the United Nations Relief and Works Agency (UNRWA) as well as the European Union Humanitarian Aid Office (ECHO) for their financial support.

Finally Lebanon Support hopes that this report can be of support to NGOs, international organizations, policymakers, UN agencies and the donor community in developing strategies and policies that can enhance the quality of life and the dignity of the Palestinian community in Nahr El-Bared Camp and in Lebanon as a whole. 


\section{Background}

\section{Lebanon Support's Organization Profile}

Lebanon Support is an Emergency, Recovery and Development information center and portal (http:// www.lebanon-support.org) launched during the 2006 July war, through a partnership initiative between Handicap International, Mada Association and Lebanon’s Ministry of Social Affairs.

Lebanon Support was registered as a National Non-Governmental Organization in November 2008, after being a hosted project by the above-mentioned partnership.

The organization started work as an information-sharing platform to coordinate relief and recovery efforts during and in aftermath of, the 2006 July war. Its activities covered Beirut and South Lebanon and emphasized on hosting humanitarian, recovery and civil society news, projects, information and publications, under the financial support of ECHO.

In May 2007, Lebanon Support dispatched the Direct Response Unit (DRU) in response to the Nahr el Bared crisis, and set-up an emergency information system in Beddawi camp. (The project was under the support of Handicap International and ECHO and in partnership with UNDP/RC.)

Since 2007, Lebanon Support has since been supporting and enhancing information sharing and coordination mechanisms in the aim of increasing efficiency and effectiveness of humanitarian response.

By the beginning of 2008, Lebanon Support launched the first "Lebanon Civil Society Directory" listing profiles of more than 450 NGOs and International Organizations working in Lebanon.

By March 2010, the Ministry of Social Affairs in partnership with Lebanon Support will release the second version of the directory containing the profiles of about 1,200 Organizations.

While on the field, Lebanon Support had expanded its operations in Beddawi Camp to cover early recovery activities, and was designated by the Humanitarian and recovery community as the Information focal point for the Nahr el Bared Crisis.

On the 1st of March 2009, Lebanon-Support launched the Emergency \& Recovery Information System's (ERIS) website: http://www.lebanon-support.org/nbc. The project was supported by UNDP/ $\mathrm{RC}$, Handicap International and under with the financial support of ECHO.

Lebanon Support has also developed, implemented and is still implementing several other projects on a national level, among these projects:

- Lebanon's civil society portal in partnership with the Ministry of Social Affairs has the profiles of more than 1200 NGOs, hosts a library of more than 2,600 resources, and has a considerable visitor base (approximately 20,000 visitors per month), which makes it one of the top destinations for civil society organizations and development actors in Lebanon. (continuous)

- Lebanon Support's National Mapping of Vulnerabilities (2007-2008)

- Lebanon Support Security and Mobility Tracker (May 2008)

- Palestinian civil society directory with Save the Children, Sweden (2009)

- The Nahr el Bared Reconstruction Conference in Partnership with Oxfam GB and Transparency International (February 2008)

- Mental and Reproductive Health Survey in Nahr el Bared and Beddawi Camps in partnership with Welfare Association (2009-2010)

- Municipal Elections Referral System with Catholic Relief Services (2010)

Lebanon Support's main operational framework is focused on information management, production and delivery, aiming at enhancing the knowledge base of civil society actors and development, recovery and emergency actors, to best respond to the emerging needs of the vulnerable communities in Lebanon. As it is within Lebanon Support beliefs, that an informed development and recovery and emergency community, renders it more efficient and more effective, thus enabling it to reduce the existing vulnerabilities within the country. 
This report is a statistical output of Lebanon Support's Emergency and Recovery Information System (ERIS) for Nahr El-Bared.

ERIS was put in place to facilitate and support existing coordination mechanisms between the humanitarian and recovery community working with the Nahr El-Bared community.

ERIS is composed of three main components:

- IDP \& Returnee Monitor: Monitors the activity and mobility of the affected population in terms of Displacement and Return

- Needs Assessment System: Monitors and records the situation and conditions of the affected population

- Aid Monitoring System: Monitors and records aid delivery through the various existing coordination mechanisms and provides information about existing gaps and possible duplication

These three components provide the humanitarian and recovery community with a comprehensive and a clear view on the situation and conditions of the affected population, their current location, their needs, and how they are being supported, thus providing tools to measure effectiveness and impact of aid. These tools provide the platform for effective aid coordination.

\section{Rationale behind ERIS}

- The $3 \mathrm{Ws}$

In any crisis or displacement situation, there are several factors that restrict and impact the situation: the location of the affected population and their movement; the conditions and the situation of the affected population; and at last but not least is how they are being supported and what are they being supported with.

These factors are commonly known as the three "W": Who? What? Where?

These factors provide the grounds for any actor to be able to programme, design and deliver aid. The existence of such information is essential to guarantee that what is being delivered is coherent with the needs of the population, and that aid is being delivered to where the population is currently residing and that what is being delivered has not been delivered yet.

Yet adopting the rationale of aid coordination is not enough to obtain effective coordination, as most actors conduct specific surveys and assessments for their planning purposes, rendering usability specific to certain types of interventions;

- Information Management

Thus, to guarantee coordination effectiveness, there is a necessity to develop a system that plays the role of an information focal point, that acts as the consolidator of available information, but also determines existing information gaps and works on filling these gaps with the relevant information products in the aim of enhancing the efficiency of Aid delivery and fortifying existing coordination mechanisms.

The ongoing process of consolidating information, disseminating them, and collecting new information, provides the humanitarian and recovery community with the tools and the framework to plan before-hand, to anticipate developments, and to understand the impact of their actions on the affected population and most importantly to have the ability to respond more effectively.

Yet this process cannot be implemented as a "ready-to-use" solid structure within any crisis, it has to be molded and structured to best fit the existing information coordination mechanisms, i.e. it is necessary to contextualize the system to best fit the needs of the involved actors.

Hence, since its creation, ERIS was conceptualized and developed as a system that can adapt itself to the changing situation of the crisis. 
The statistics and figures available in the report are mainly based on the data collected through the IDP \& Returnee Database, which is a major component of the Needs Assessment System of Lebanon Support's Emergency and Recovery Information System (ERIS)

IDP \& Returnee Database

The Nahr El-Bared IDP \& Returnee Database mapped and assessed the conditions and the location of all families and individuals whose natural place of inhabitance was Nahr El-Bared camp (Official Camp and Adjacent Area). The database's aim was to provide the humanitarian and recovery community with the appropriate information tools and products to best plan, assess and monitor their interventions in Nahr El-Bared and Beddawi camps.

Data collection for the database was conducted through three main surveys:

- Shelter Survey: assessing shelter conditions of the displaced, semi-returnee and returnee population of NBC (All of Lebanon)

- Socio-Economic Survey: assessing social, economic, health, education and consumption and reliance on services of the displace, semi-returnee and returnee population of NBC (All of Lebanon)

- Buildings Survey: A mapping of residential and commercial buildings and units in all of the NBC Adjacent Area

The Database has information and data on 5467 families, counting around 27,000 people.

\section{Survey Design}

The survey used in the IDP \& Returnee Database was divided into two main tracks. One track assessed the condition of the household as a whole, mainly focusing on the location, contact information, shelter and services; where as the second track focused on a individual

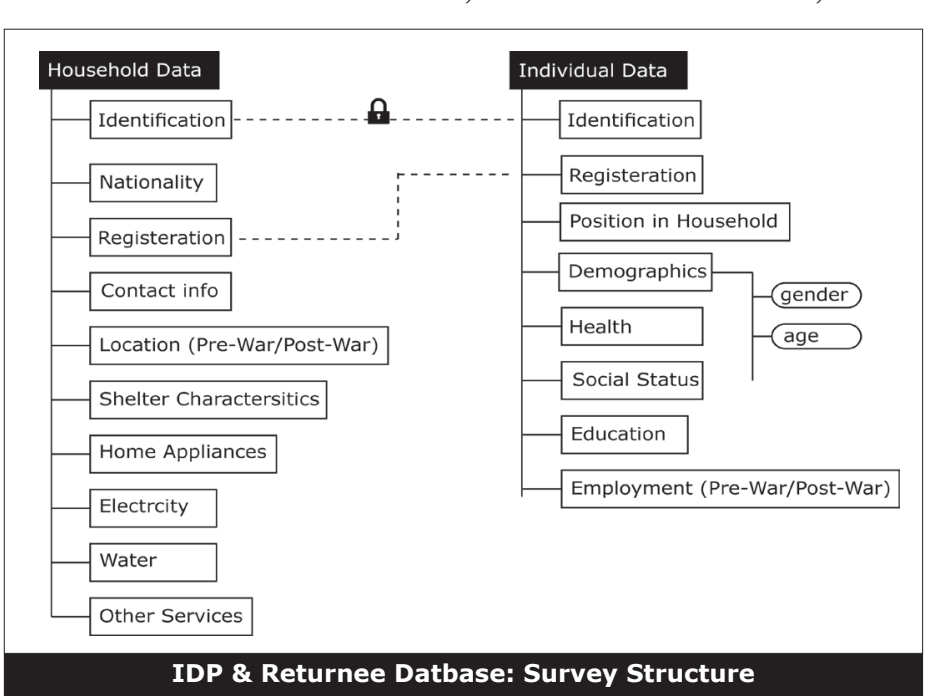
information, such as demographics, health condition, social situation, education and employment.

This method allowed Lebanon Support to assess both the conditions of households and the conditions of population segments based on their social and economic conditions.

The same rationale was used in all areas, with locality specific differences, e.g. in Nahr El-Bared adjacent area, additional indicators were used to assess damages to housing units, safety conditions and general environmental conditions, among other issues.

The process of localizing the survey indicators while keeping key indicators the same, allowed Lebanon Support to indicate the differences in the situation and the conditions between regions, and at the same time to compare between the shared conditions.

This method proved to be useful in providing a good overview of the situation and the differences between regions, which are highly probable due to several factors: 1) Urban fabric of the assessed regions; 2) Proximity from service providers, 3) Presence of damage; 4) Presence of humanitarian and recovery projects; among other factors.

\section{Data Collection}

To be able to map the totality of the Nahr El-Bared population, data collection was based on areas of displacement and identified 5 Main areas of displacement: North Lebanon, Bekaa, Beirut, Saida and Tyr

North Lebanon being the host of the majority of IDPs and returnees was divided into three 
main areas: Beddawi Camp, Jabal El-Beddawi and Tripoli Suburbs and the third area being Nahr El-Bared Adjacent Area and surroundings.

These areas have been mapped house to house over the course of 12 months, starting in areas of displacement and finishing in the NBC Adjacent Area, this method allowed us not to miss any of the NBC families, and to reduce the risks of information gaps.

Lebanon Support developed a logistical plan for the data collection, sectioning each region into different sectors based on their urban composition (buildings, houses, huts, etc...), and data collection teams were dispatched to tour all houses, buildings, schools, shops and other structures, identifying existing families and inteviewing them. A family is validated to be from Nahr El-Bared either through the UNRWA ID card or through the file number given to the non-ID Palestinians.

\section{Data Validation and Audit}

Data validation for the survey consisted of three main steps:

1) Identification of possible duplication: Checking if the interviewed family has been interviewed twice, in that case if both surveys are consistent, then latest is preserved, while the other is dropped, if they are no consistent, then the family is re-interviewed.

2) Identification of information gaps: In some cases, the surveyor might miss some questions in the survey, or the family did not answer to specific questions, if these questions are integral to the survey, the family is interviewed again, if not the data is then preserved.

3) Checking inconsistencies in supplied information: this process validates that the information supplied by the family is consistent throughout the survey, (e.g. Family size, as some families mention their married children as members of the family, while in the official UNRWA registration card they are not mentioned, since they would have their own separate card) in such cases the family si re-interviewed.

Data Audit is a separate process conducted after one area is completed, based on the area and the number of families, a random sample of $10 \%$ to $15 \%$ of completed surveys are selected, and then the families are tracked back based on the information present in the survey. If the audit results show an error margin larger than 5\%, then a larger sample of $25 \%$ to $30 \%$ is selected and tracked back, if the error margin is increasing, then the surveying process is restarted in that specific area, if the error margin disappears in the larger audit sample, then the errorous surveys are re-done and the other surveys are approved and preserved.

Multiple Marriage: In case of multiple marriage, two options are considered: a) if the women who are married to the same man are all living in the same house, then only one survey is conducted for the household; b) if each woman is living separately form the other, then each household is interviewed separately;

\section{Sample for the Statistical Analysis}

Factors related to sample selection:

1. The data collection was undertaken over a period of one year, which meant that the number of households and individuals have changed between the time of the data collection and the time of analysis and production of this report.

2. Many families who were assessed in Beddawi Camp or in Jabal Beddawi, where assessed a second time, since they have moved to NBC Adjacent Area, when the assessment reached NBC Adjacent Area; these families were identified and only their latest information were kept in the database.

3. Mobility is higher for IDPs moving out of Jabal El-Beddawi towards NBC Adjacent Area, where as Beddawi camp shows a lesser degree of mobility (Beddawi to NBC Adjacent Area).

4. Many families are still moving to North Lebanon, more specifically to Beddawi camp and 
surrounding areas, waiting for their turn to get back to NBC.

5. Several families in Jabal El-Beddawi have witnessed an increase in rent prices and consequently have left towards Beddawi Camp seeking cheaper rent.

Based on these factors, Lebanon Support increased the sample from Beddawi camp to reflect the mobility towards it, and lessened the sample size from Jabal El-Beddawi, while leaving the sample size in NBC the same.

\begin{tabular}{|l|c|c|c|c|}
\hline & $\begin{array}{l}\text { Beddawi } \\
\text { Camp }\end{array}$ & $\begin{array}{l}\text { Jabal EI- } \\
\text { Beddawi }\end{array}$ & $\begin{array}{l}\text { NBC Adjacent } \\
\text { Area }\end{array}$ & $\begin{array}{l}\text { Total Number of } \\
\text { Families }\end{array}$ \\
\hline Sample Size (\%) & $30.51 \%$ & $19.15 \%$ & $50.32 \%$ & 3,424 Families \\
\hline $\begin{array}{l}\text { \% of Families living in selected areas per } \\
\text { Total Population (June 2009) }\end{array}$ & $27.35 \%$ & $21.84 \%$ & $50.8 \%$ & 4,084 Families \\
\hline \multicolumn{2}{|r|}{} & \multicolumn{2}{|c|}{ Total Sample Rate } & $83.8 \%$ \\
\hline Geographic Distribution of Analytical Sample & \multicolumn{5}{|l}{} \\
\hline
\end{tabular}

The total sample represents about $84 \%$ of the actual number of population in the assigned areas. The number represents the percentage of the population that have the most consistent data over time (i.e. their situation have not changed considerably between the time of the survey and the time of analysis)

Moreover the representation of the sample within each area is also sufficient to provide a solid overview of their situation, where the sample size compared to the current actual population number of each area is higher than $70 \%$.

\begin{tabular}{|l|l|l|l|}
\hline Area & $\begin{array}{l}\text { Actual Number of } \\
\text { Families at the date of the } \\
\text { survey }\end{array}$ & Sample Size & $\begin{array}{l}\text { \% of Sample per } \\
\text { actual number of } \\
\text { families }\end{array}$ \\
\hline Beddawi Camp & 1117 Families (Oct 08) & 1045 Families & $93.5 \%$ \\
\hline Jabal El-Beddawi & 892 Families (Dec 08) & 656 Families & $73.5 \%$ \\
\hline NBC Adjacent Area & 2075 Families (Mar 09) & 1723 Families & $83.0 \%$ \\
\hline \multicolumn{4}{|l|}{ Sample Size per actual number of families in each of the selected areas } \\
\hline
\end{tabular}




\section{I- Executive Summary}

This report aims to provide statistical and analytical tools for the recovery community working in North Lebanon, specifically those working with the Nahr El-Bared displaced and returnee population. the information will allow for better assessment of current needs and gaps, which will eventually support the development of appropriate strategies of intervention on both the short and long term.

The report highlights persistent vulnerabilities, which are not a direct cause of the Nahr ElBared crisis, but have contributed considerably to the general trend of slow recovery. Knowing that Nahr el Bared's community is still in the recovery phase since autonomy and economic self sufficiency haven't been achieved.

The situation of ongoing displacement and the prevalence of temporary rather than permanent residence. Add to that minimal economic activity, and restricted business exchange levels within the Nahr El-Bared Adjacent Area, indicate that the situation, although seemingly stable, is still fragile and is yet to recover.

The stability of the situation is based on: 1) the continuation of emergency interventions (rent subsidy program, construction of temporary housing, food distribution); 2) the start-up of recovery activities in NBC Adjacent Area (Livelihood projects, re-establishing major services (water, electricity, etc...)); 3) and community solidarity;

The fragility of the situation is characterized by several factors, which can be grouped into two main categories:

A) Current factors: 1) emergency interventions, which are guaranteeing surface stability, can at any moment encounter funding shortages and consequent termination; 2) access to the NBC Adjacent Area is still limited; 3) economic activity indicators show prevalence of temporary or short-term jobs; 4) shortage in funding needed for reconstruction and economic rehabilitation which have delayed these two processes.

B) Pre-Existent factors: 1) lack of basic human and civil rights for the Palestinian community in Lebanon; 2) concentration of poverty and deprivation in North Lebanon area in general (including NBC and Beddawi Camps); 3) lack of rights to ownership/property and employment, are major determining factors to limited recovery performance; 4) recurrence of violence in North Lebanon, in a generally fragile political situation.

This delicate balance between stability and vulnerability requires from the recovery community and policy makers to intervene on different levels. Hence, interventions should be focused on guaranteeing stability, while at the same time working on reducing pre-existent vulnerabilities, which could considerably enhance recovery performance and provide the population with better coping capacities and mechanisms.

Within this framework, the Nahr El-Bared statistical report lists the major trends and findings that best describe the situation and the conditions of the Nahr El-Bared population after more than two years of the end of crisis. 


\section{Key Trends and Findings}

The report is divided into eight main sections, which are considered to be the most relevant to the recovery community in Nahr El-Bared, and are salient to development actors and policy makers.

\section{Displacement and Return:}

a. At the beginning of the crisis, most of the Nahr El-Bared families displaced to Beddawi Camp and its neighboring areas, this showed that community solidarity with the affected population was to a degree restricted to the Palestinian community, rather than being spread into both the Lebanese and Palestinian communities in the North of Lebanon.

b. The provision of temporary shelter by the various interveners, more specifically the UNRWA rent subsidy program managed to stabilize to a certain degree the mobility of the displaced population.

c. Moreover shelter provision has over time considerably reduced crowdedness, which was the main characteristic of shelter conditions in the early phase of displacement.

$\mathrm{d}$. The opening of the NBC Adjacent Area was a trigger for many families displaced outside the North, to return back, as it became a buffer zone for NBC families, while waiting to return to their homes in the camp.

e. The delay in the reconstruction process, has exacerbated the general feeling of insecurity and fear of the future. And it created a new category within the population those lingering between displacement and return, this group will be called in this report "Semi-Returnees". f. Limitations on access and mobility imposed on the Palestinian community, in and out of NBC are considerable contributers to the heightening of feelings of insecurity and instability among the population

\section{Demographic Composition of the Nahr El-Bared Population:}

a. The male to female ratio of the Nahr El-Bared population is approximately 1 to 1 for both displaced and returnees

b. The Nahr El-Bared community generally has a high birth rate and low mortality

c. The average NBC family size is 4.93 members

d. There is no data to indicate whether the prevalence of new 2 member families will lead in the near future to either an increase or a decrease in family size.

e. The whole population of NBC is almost entirely living within a nuclear family unit residence. There isn't a significant number of individuals leading an independent life outside this unit.

This could be related to the fact that services available to the Palestinian community are delivered on a family or household basis. Thus economic and social independence and access to services for youth is perceived to be guaranteed only through young marriages.

f. Early Marriage: there are no accurate figures of marriages of persons below 18 years before the crisis. But current figures show that $2.02 \%$ of recently married individuals are under 18 years of age. $95.8 \%$ of those individuals are girls while $4.16 \%$ are boys; showing a prevalence of early marriage for girls far larger than that of boys.

\section{Shelter Characteristics:}

a. The majority of the population is living in residences under or equal to the $10 \mathrm{~m} 2$ per person average (49.95\% in NBC Adjacent Area, 39.67\% in Jabal El-Beddawi and 58.09\% in Beddawi Camp)

b. Yet people who live in Jabal El-Beddawi and NBC Adjacent Area are relatively the most vulnerable in terms of crowdedness index (26.32\% in NBC Adjacent Area and $21.73 \%$ in 
Jabal El-Beddawi are living under the $5 \mathrm{~m} 2$ per person average).

c. Crowdedness over access to house facilities (bathrooms and kitchens) is highest in Beddawi camp and in Jabal El-Beddawi, which could be related to high occurrence of residence-sharing between displaced families compared to a lower level in semi-returned and returned families. (7.98 and 6.25 Persons per Bathroom, and, 9.59 and 8.47 persons per kitchen are the overall rates for families living in Jabal El-Beddawi and Beddawi Camp respectively)

$\mathrm{d}$. The type of residence is different between the areas: apartments, garages and shops are more frequent in Jabal El-Beddawi, while houses are more frequent in Beddawi camp with a smaller number of apartments. NBC Adjacent Area has a more balanced distribution between apartments, houses and UNRWA temporary units (PLOTs).

Yet it is important to mention that there is no clear differentiation between "House" and "Apartment", the only visible difference, is that "Houses", are smaller buildings with higher construction density and Apartments are buildings, which are present in a more visibly independent constructions. These definitions reflect a rather popular cultural and historical interpretation of the development and transformation of the camp construction fabric.

\section{Access and Costs of Services:}

a. State Electricity (EDL) coverage is different between regions, the majority of returnees and semi-returnees in NBC Adjacent Area receive between 10 and 14 hours a day of electricity coverage, while in Beddawi camp and Jabal El-Beddawi, the majority of displaced families receive between 14 and 18 hours a day.

b. State Electricity (EDL) costs per month also vary between areas, displaced families in Beddawi camp pay the least for electricity while displaced families in Jabal El-Beddawi, and, semi-returnees and returnees in NBC Adjacent Area pay a higher monthly bill.

c. $49 \%$ and $42 \%$ respectively of the displaced population in Jabal El-Beddawi and Beddawi Camp buy drinking water.

\section{Health Characteristics:}

a. The majority of PwDs in the NBC community have a mobility related disability.

b. PwDs form 5\% and 3.45\% of the total displaced population in Jabal El-Beddawi and Beddawi Camp respectively; while among the semi-returned and returned population they form $3.8 \%$ of the total population.

c. About $14.5 \%$ of the population suffers at least from one chronic disease, the most prevalent chronic diseases are hypertension and heart related diseases.

\section{Characteristics of Education}

a. School enrollment rate is at its lowest averages for people below the age of 4 and those above the age of 25, while it is highest for people between the ages of 4 and 25; although about a third of those between the ages of 4 and 25 are not enrolled in any type of educational facility.

b. $11.52 \%$ of the population is illiterate,

c. $78 \%$ of those who attend intermediate education do not attend secondary education.

d. Female enrollment is lower than male enrollment in primary and university education, while it is higher in intermediate and secondary education

e. Female illiteracy is $2.6 \%$ higher than male illiteracy. 


\section{Work and Employment}

a. The working population among the displaced in Beddawi Camp, has dropped by $30 \%$ as a result of the war.

b. Owners of businesses were the most affected in the war, as they have recorded the highest decrease in their numbers after the war, while daily labor has considerably increased as a result of the war.

c. The majority of the working population is paid less than the National Minimum Wage, and as a result of the war, the number of those who fall within the extremely low-income category has considerably increased.

$\mathrm{d}$. The bulk of female labour is in unpaid-labor "house work".

e. Female labor participation is very low and stands at $5.62 \%$, income disparities between men and women is quite high. The majority of working women before the war got paid less than 300,000 LBP while the majority of men got paid above 300,000 LBP.

f. Income levels dropped considerably for those who have finished primary and secondary education levels, while it dropped slightly for those who have university degrees.

\section{The situation of small and medium businesses in NBC Adjacent Area}

a. Almost the totality of owners of businesses are men, and most of them are between 25 and 60 years of age.

b. Most businesses have zero employment level i.e. operated solely by their owners, and employment levels are considerably low, less than $11 \%$ of businesses employ 3 or more workers.

c. The majority of workers in these businesses get paid less than 450,000 LBP per month

d. Less than $20 \%$ of businesses surveyed mentioned that they have received grants.

e. The highest rated obstacles to business growth are security checkpoints and lack of capital and supplies.

f. Due to the limitation on mobility, businesses have relocated and are more concentrated in the camps surrounding areas rather than within NBC which was the case before June 2007. This requires a re-assessment of livelihood strategies and developing a rather comprehensive and balanced strategy for recovery between the camp businesses and the businesses in the surrounding Lebanese areas. 


\section{Conclusion and Recommendations}

\section{Need to achieve basic human and civil rights}

The reports findings show that the war has severely and negatively impacted the lives of Nahr el Bared's residents in addition to emphasizing their vulnerabilities. Yet it revealed more rooted vulnerabilities related to the status of Palestinian refugees in Lebanon and the volatile socio-economic conditions they live.

Thus it is highly important for the recovery community in NBC to adopt strategies that would seek remedies for the direct impacts of the war, but also aim to reduce the existing vulnerability factors, acting more specifically on achieving basic human rights and civil rights for Palestinian refugees in Lebanon.

\section{Need to achieve better economic rehabilitation}

Army checkpoints and mobility limitations are having a considerable role in limiting recovery performance, and are contributing to the migration of the economic activity to the outside of the camp. This could create unbalanced economic competition between Lebanese and Palestinian run-businesses, hence affect negatively efforts aiming at reducing communal tensions between the two communities.

The outburst in daily labor and the drop in sustainable income generating activities are having a negative effect on the recovery potential of sections of the NBC community.

The limited research and analysis conducted on market needs and potentials in Nahr El-Bared and North Lebanon as a whole is limiting the growth of businesses, a large proportions of businesses is concentrated in the retail sector, and does not generate employment, which could have a stagnating effect on economic activity and limits economic growth.

One of the most important issues that the recovery community needs to resolve is to boost the levels of employment, thus enabling a healthier business cycle, and allows a better flow of income within the NBC community.

A faster reconstruction process could be a significant incentive for faster recovery among the NBC population and could widely contribute to reduce current insecurities, which are widely present among the community.

\section{Need to enhance access and quality of education}

Education seemingly suffers from major obstacles, as drop out rates are very high in secondary and higher education, and there is a high lack of accessibility to pre-school education.

The reasons behind the high drop out rates is related to several factors, the most prevalent are education quality and access to jobs; the latter can be observed in the type of jobs offered by the market and through labor participation levels; while the first needs to be studied more thoroughly since assessments on the quality of education in UNRWA schools are not available to really be able to identify the problems and the possible solutions that could implemented to remedy such deficiencies.

\section{Need for better focus on women status and issues}

Women status, vulnerabilities and issues should be targeted and adressed, since the gap between men and women on different levels is significantly high, and women are suffering from highly restricted access to social and economic independence. 


\section{II- Palestinian Refugees in Lebanon}

\section{Historical Overview}

In 1948, one hundred thousand Palestinians fled from Palestine to Lebanon, where "temporary" camps were established to provide them shelter. More than half a century later, around 450,000 Palestinians refugees are still living in Lebanon. "Though insecurity is an outstanding feature of Palestinian life in most places where they live (...), yet their situation in Lebanon is unique in degree of political, economic and social exclusion" ${ }^{\prime}$. Today, most of the refugees live in camps that are still precarious settlements even if they have become more like permanent neighborhoods, or live in clusters of Palestinian homes outside the camps, in what is called "gatherings".

An unpublished survey done by the Norwegian research institute FAFO in 1999, showed that the rate of unemployment in the camps is around 17\%; Rosemary Sayigh ${ }^{2}$ noticed that "most from the generation that came to maturity after 1982 have never done work for which they were trained", the same point was made by Ziad, an engineer living in Burj El-Barajneh Camp: «My father had no education, and he was able to feed the family well, even to provide me and my brothers with higher education. As an engineer, I cannot even afford to live in a proper place, or to marry»3 .

Another main characteristic of employment in Palestinian camps is that of casual labor ${ }^{4}$. Lebanon Support through an assessment done on the Nahr el Bared community (IDP Database, 2008-2009), noticed that $31.6 \%$ of people who have declared working, occupy casual jobs, mainly daily jobs; while on the National Lebanese level, the same category occupies a $13.0 \%$ of the total working Lebanese. The situation in other camps is not very different, and one common sentence repeated by many community figures describes the situation as follows: "Unemployment is the norm in Palestinian camps, while employment is the exception to the rule"

"Adding to the plight of Palestinians are Lebanon immigration policies, which classify all Palestinians as foreigners and not citizens (...); The Lebanese Government does not provide health services to Palestinian refugees, who rely on the UNRWA and UNRWA-contracted hospitals." ${ }^{5}$ In 2001 the Lebanese Parliament enacted a law that prohibited Palestinian refugees from owning property in the country. Under the new legislation, Palestinians may not purchase property and those who already own property will not be allowed to pass it on to their children.

After more than sixty years of forced migration, the Palestinian population in Lebanon still suffers from harsh social, economic and legislative exclusion, and camps and gatherings have become pockets of extreme poverty dubbed with high distress and fear of the future.

1) No Work, No Space, No Future: Palestinian Refugees in Lebanon, Rosemary Sayigh,, Middle East International, August 2001

2) Rosemary Sayigh is the author of Too Many Enemies: Palestinians in Lebanon (London: Zed Books, 1994)

3) Quoted by Bendik Sorvig in "Exile Without Refuge", MPhil thesis, University of Oslo, 2001, p 66.

4) Casual labor is a common term used in the employer community to describe workers performing a variety of services, usually on a temporary or part-time basis

5) Assessment for Palestinians in Lebanon, University of Maryland, Minorities at Risk Project, December 2006 


\section{Camps and Gatherings}

\section{i. Who is a Palestinian refugee?}

Under UNRWA's operational definition, Palestine refugees are persons whose normal place of residence was Palestine between June 1946 and May 1948 and who lost both their homes and means of livelihood as a result of the 1948 Arab-Israeli conflict. UNRWA's services are available to all those living within its area of operations and who meet this definition, who are registered with the Agency and who need assistance. The descendants of the original Palestine Refugees are also eligible for registration. When the agency became operational in 1950, it was responding to the needs of about 750,000 Palestine refugees. Today, 4.6 million Palestine refugees are eligible for UNRWA services.

ii. The Palestinian refugees living in Lebanon are typically divided into three groups ${ }^{6}$ :

1) Registered refugees: This group consists of refugees registered by both UNRWA and the Lebanese authorities. According to UNRWA statistics of March 2005 this group constitute 100,000 households with a total of 400,000 people. $53 \%(224,000)$ of these live in the 12 UNRWA camps while the remaining $(176,000)$ live in gatherings or are scattered in the Lebanese community. One should however be aware that a large number of Palestinian refugees remain registered with UNRWA in spite of living permanently abroad - this often in order not to loose their legal rights as internationally recognised refugees. Some estimates therefore go as low as 250,000 Palestinian refugees actually present in Lebanon.

2) Non- registered refugees: Refugees who fall under this group are not registered by UNRWA because they left Palestine after 1948, took refugee outside UNRWA areas of operation or were not in need. Originally, UNRWA was only providing services to registered refugees, but has since 2004, extended the service to non- registered refugees also. This group is estimated to 35,000 people.

3) Non-identified or non-ID refugees: This group of refugees is not registered by any authority in Lebanon and do not possess any valid documents acknowledging their legal existence. Thus they are not entitled to any services provided by UNRWA or Lebanese authorities. Organizations like Palestinian Red Crescent Society also provide some services. The nonID refugees cannot leave the gatherings and camps due to potential legal persecution. The number of non- ID refugees is estimated to 3,000 (DRC, 2005). In official camps UNRWA is providing education, health care, and infrastructure, including shelter, water and sanitation.

UNRWA also provides health and educational services to refugees living in gatherings. Due to the legal aspect of land ownership, UNRWA, however, cannot always provide infrastructure such as shelter and water and sanitation assistance outside the camps.

\section{iii. Distribution of Palestinian Camps and Gatherings in Lebanon}

\begin{tabular}{|c|c|c|c|c|}
\hline Camp & $\begin{array}{l}\text { Number } \\
\text { of Refugees }\end{array}$ & Camp & $\begin{array}{l}\text { Number } \\
\text { of Refugees }\end{array}$ & $\begin{array}{l}\text { There are currently } \\
12 \text { official }\end{array}$ \\
\hline Mar Elias & 616 & Burjel-Shemali & 19,074 & Palestinian camps ${ }^{7}$ \\
\hline Dbayeh & 4,025 & Beddawi & 15,947 & \\
\hline Shatila & 8,370 & Wavel & 7,668 & \\
\hline El-Buss & 9,508 & Total & 215,890 & \\
\hline Rashidieh & 29,361 & & & \\
\hline
\end{tabular}

6) Danish Refugee Council, «Needs Assessment of Palestinian Refugees in Gatherings in Lebanon», 2005

7) United Nations Relief and Works Agency for Palestine Refugees in the Near East, http://www.unrwa.org 
In addition to camps, a considerable number of the palestinian population is distrbuted in 39 Gatherings $^{8}$ all over Lebanon

\begin{tabular}{l|l|l|l} 
& NUMBER & & \\
AREA & OF GATHERINGS & POPULATION & \\
\hdashline Bekaa & 4 & 8,335 & \\
North Lebanon & 8 & 14,700 & \\
Mount Lebanon & 4 & 3,925 & \\
Saida & 12 & 19,203 & \\
Tyre & 11 & 12,462 & \\
\hdashline Total & $\mathbf{3 9}$ & $\mathbf{5 8 , 6 2 5}$ &
\end{tabular}

It is important to mention that the numbers of Palestinian refugees in Lebanon as a whole or in individual camps or gatherings are not completely accurate and differ between sources; this is mainly due to the lack of efficient refugee registration systems, thus the reader will encounter several discrepancies as most of these numbers are still considered as estimates, and the above listed tables are not exhaustive.

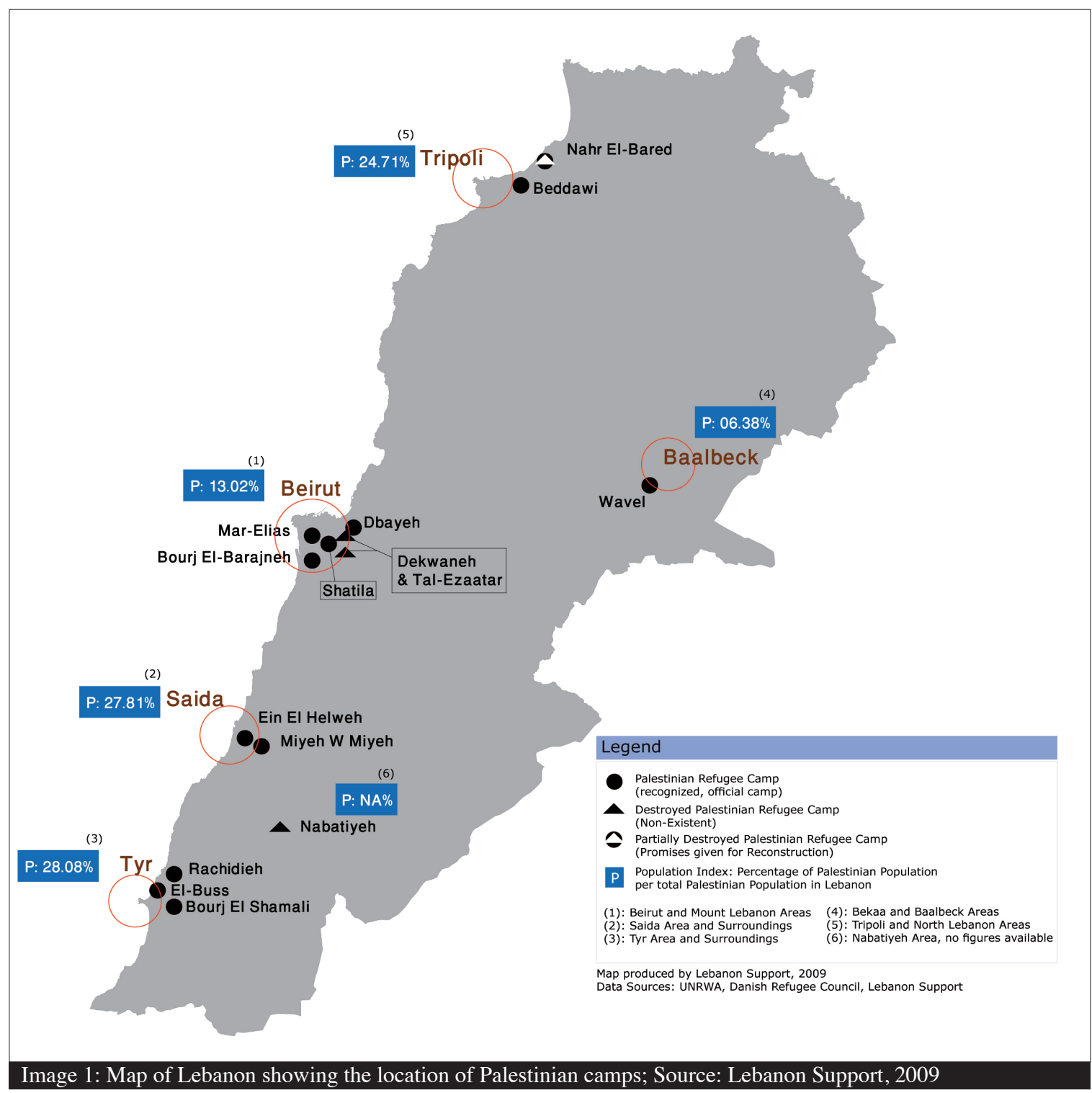

8) Needs Assessment on Palestinian Refugees in Gatherings in Lebanon, Danish Refugee Council, 2005 


\section{III- Nabr El-Bared Crisis}

The Nahr el Bared Camp was established in 1948 by the ICRC, as a result of the forced deportation of Palestinians from historical Palestine. With time the camp has extended from its original area to what is commonly known as the "new camp", this extension came as a response to the natural growth of the Palestinian community of Nahr el Bared. Thus it is important to mention that the Old Camp and the New Camp are an extension of the same social fabric and structure.

Nahr el Bared Camp had a major economic significance to North Lebanon; it is situated between Tripoli, the second largest city in Lebanon, the agricultural plains of Akkar, and is also situated along the highway leading towards the Lebanese-Syrian Borders of Abdeh.

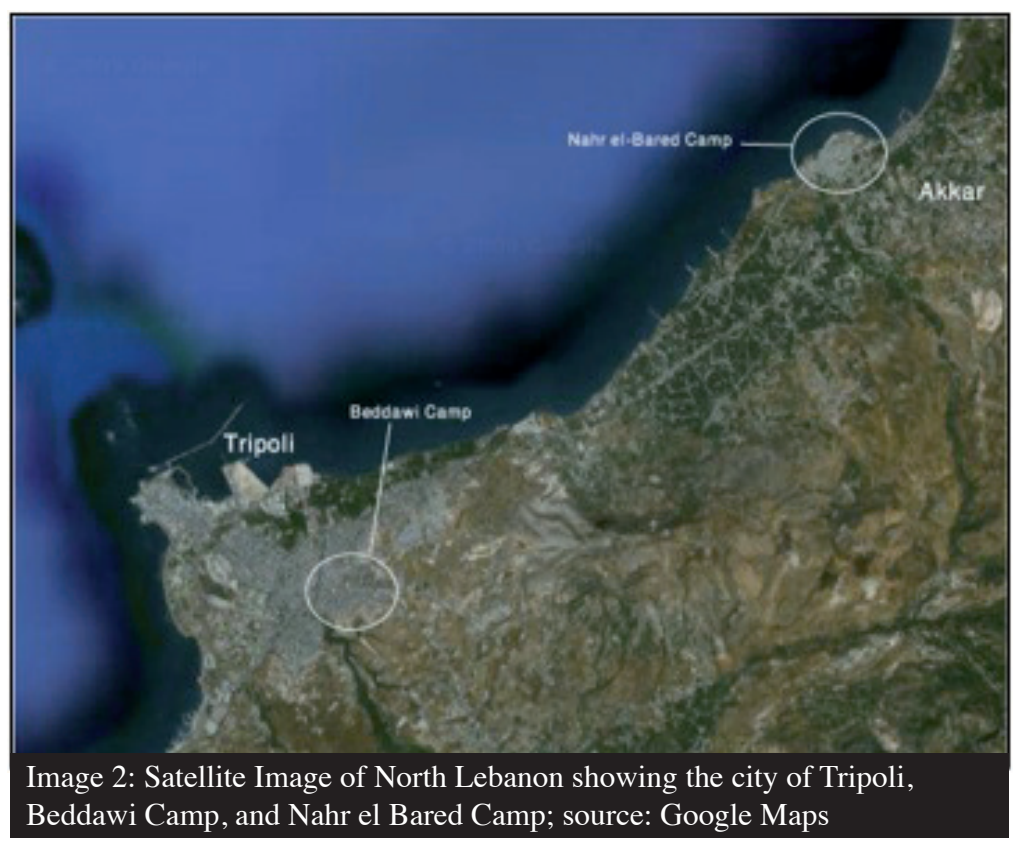

Nahr el Bared Camp had a major economic significance to North Lebanon; it is situated between Tripoli, the second largest city in Lebanon, the agricultural plains of Akkar, and is also situated along the highway leading towards the Lebanese-Syrian Borders of Abdeh.

The camp is a major provider of Labour force, in construction, and agriculture, for the surrounding Lebanese areas. Also the camp developed, through time, as a major market and hosted several manufacturing industries especially furniture manufacturing. In summary Nahr el Bared Camp was one of the main commercial hubs of the Akkar area.

On the 20th of May, 2007 clashes started between the Lebanese Army and Fateh el Islam, which lasted about 105 days and ended by September 2007, the clashes claimed the lives of at least 340 people, at least 48 of them are civilians, 163 militaries and 222 fighters ${ }^{1}$.

The clashes has affected directly about 36,000 people, $\left(27,000^{2}\right.$ Palestinian refuges inside the camp and about 9,000 Lebanese nationals from the areas adjacent to the Nahr el Bared Camp (Mouhammara, Bebnine))

1) AFP, September 6th, 2009

2) Based on the Lebanon Support IDP database and in collaboration with UNRWA, the figure 27,000 seems to be the most accurate number of the currently resident Nahr El-Bared population 


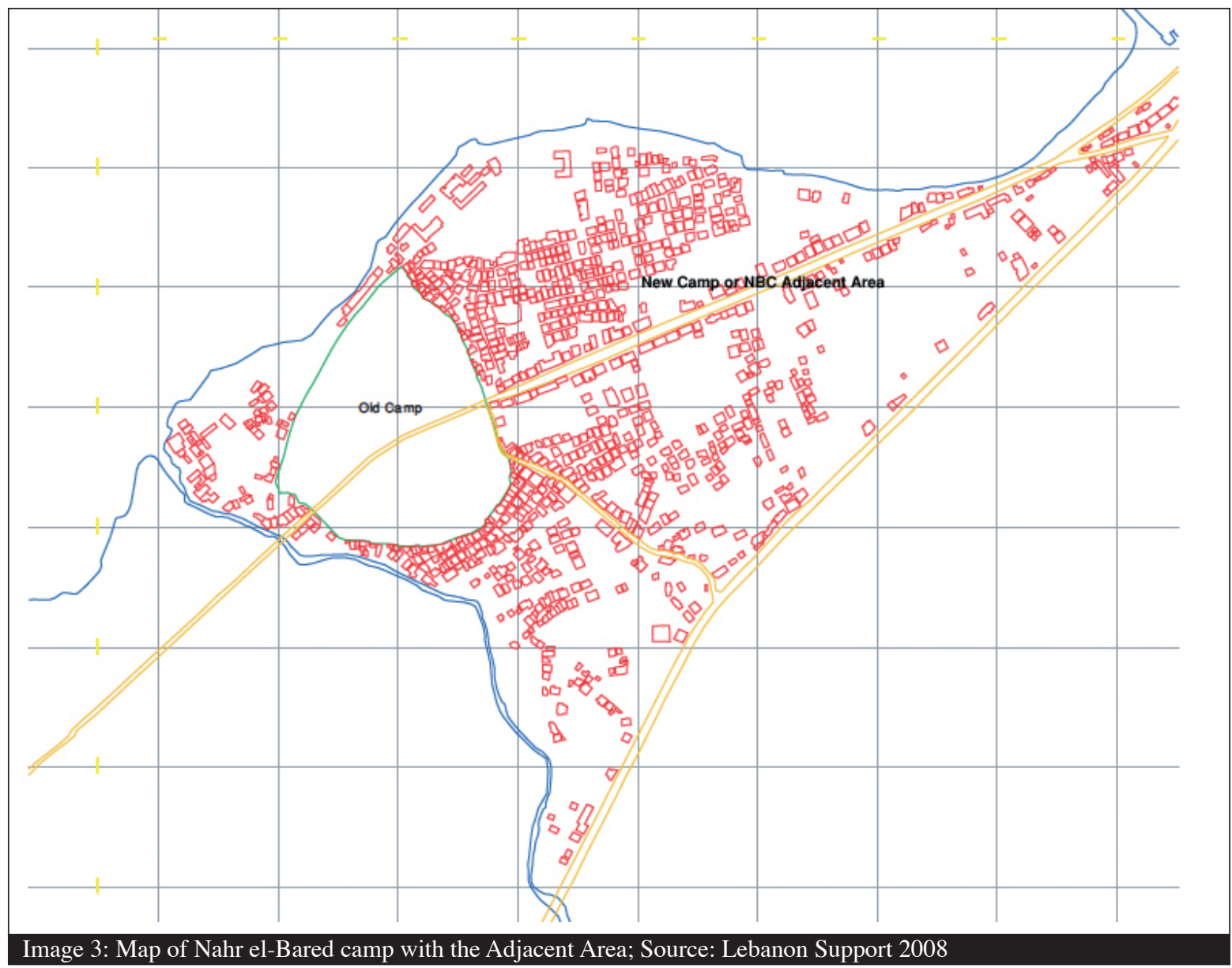

The general effects of the clashes in NBC are drastically and tragically enormous, the Old Camp was completely destroyed and levelled to the ground by heavy bombardment.

"Nearly 6,000 residential and commercial units were damaged or destroyed. Even for building which have not been fully demolished, their structural integrity is at risk. (...) Also at least 433 small enterprises-especially single-family artisans, shopkeepers-were also totally or partially destroyed by the heavy bombing and rocket explosions. (...) 3 hospitals and 4 clinics requiring either reconstruction or extensive repair, and over 15 schools, mainly, kindergarten, destroyed or damaged." 3

All the residents of the Nahr el Bared camp were forcefully displaced, the majority of them went to Beddawi Camp and its surrounding areas, while others sought refuge with their extended families in other camps in Lebanon. It was not until October and November 2007 that families started to return to Nahr el Bared,

By February 2008, only $20 \%$ of families have returned to the Adjacent Area (the New Camp) and by June 2009, around 56\% of families have returned to the Adjacent Area, while the old camp has been levelled to the ground and reconstruction is still in its very early phases. ${ }^{4}$

3) Nahr El-Bared Crisis Appeal, Background Paper, Presidency of the Council of Ministers, September 10th, 2007

4) Lebanon Support IDP \& Returnee Monitor: http://lebanon-support.org/nbc 


\section{IV-Displacement and Return}

In June 2007, almost the totality of the Nahr el Bared population have fled the camp to seek refuge and safety. In this section of the report we will delineate the main trends of displacement and return. These trends are necessary when considering contingency planning within the context of Palestinian camps in Lebanon.

Due to the context of the Palestinian refugees in Lebanon, and more particularly the context of Nahr el Bared camp, it appears that we could not consider families who have returned to Nahr el Bared Camp Adjacent Area (New Camp) as returnees, unless they have returned to their actual homes; since the Adjacent Area is being used as a buffer zone, a waiting station, where the families would be provided temporary shelter units until their homes are reconstructed. Thus in this section and throughout the whole report we will be using an additional term of Semi-Returnee in addition to Internally Displaced Persons (IDP) and Returnee.

UNDP defines Internally Displaced Persons (IDPs) as: "persons or groups of persons who have been forced or obliged to flee or to leave their homes or places of habitual residence, in particular as a result of or in order to avoid the effects of armed conflict, situations of generalized violence, violations of human rights or natural or human-made disasters, and who have not crossed an internationally recognized State border." Nahr el Bared context would lead us to consider anyone who are still displaced outside the Nahr el Bared Camp (whether old camp or adjacent area) as an IDP.

As for Returnees the commonly used definition is: "persons who have returned to their home or habitual place of residence, esp. after a prolonged absence" thus this term can be used for families who have returned back to their actual homes in Nahr el Bared Camp and Adjacent Area.

Semi-Returnees: "persons or families who have moved back to the Nahr el Bared Camp and Adjacent Area but have not returned to their own homes yet, meaning they are hosted in temporary shelters in Nahr el Bared adjacent area."2

In addition to this, it is also important to compare displacement trends with the types of shelter IDPs used, since in most cases the priority regarding return was linked to the shelter type of the displaced families (e.g. people occupying schools and NGO centers were considered as priority when the return process started to the Adjacent Area); moreover the type of shelter people occupy in the Adjacent Area is central in determining their status, as mentioned in the above listed definitions.

1) UNDP, Crisis Prevention and Recovery, "Rehabilitiation: Crisis \& Post-Crisis development Initiatives". June 3, 2002.

2) Shelter Working Group validated definition 


\section{Patterns of displacement and return}

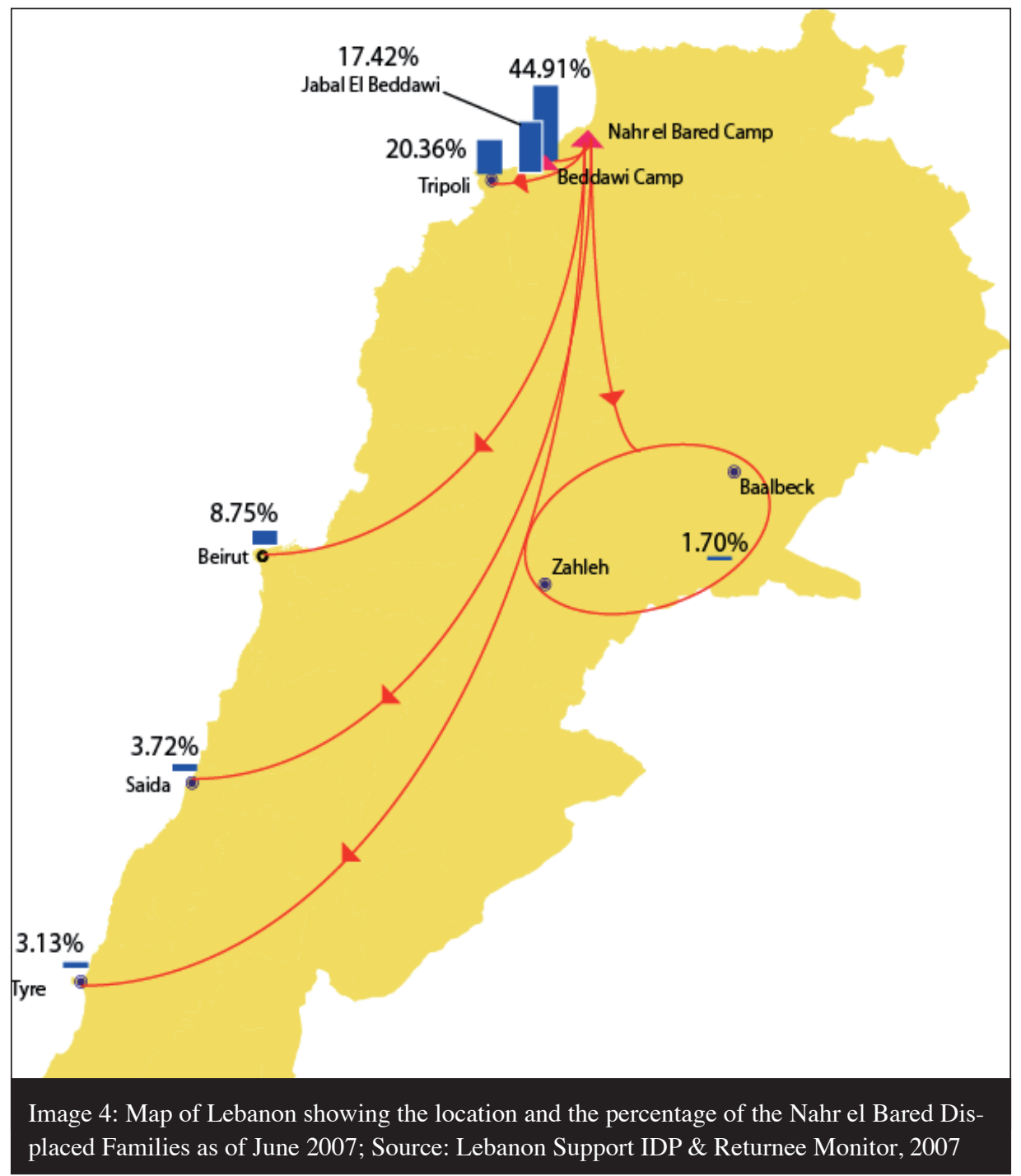

By June 2007, almost the totality of the Nahr el Bared residents had left the camp, and a clear majority of them took refuge in North Lebanon (82.68\% of displaced families) mainly distributed between Beddawi Camp (44.9\%), Jabal El Beddawi (17.42\%), and Tripoli $(20.36 \%)$; while the rest of the country (Beirut, South Lebanon and Bekaa) hosted $17.32 \%$ of displaced families.

$80.72 \%$ of the total displaced population was received in host-homes , and $19.28 \%$ were living in collective centers, UNRWA and Lebanese schools. The latter category became the priority population to be moved back to the Adjacent Area when it was opened to the public in October 2007.

Families who went back to the Nahr el Bared Adjacent Area, were either hosted in their own homes, or within specifically constructed temporary shelter units (e.g. UNRWA Plots), or within collective centers (e.g. El-Akki Buildings) which were rented by UNRWA for this purpose, or to apartments rented by the families and covered by the UNRWA rent subsidy program. 


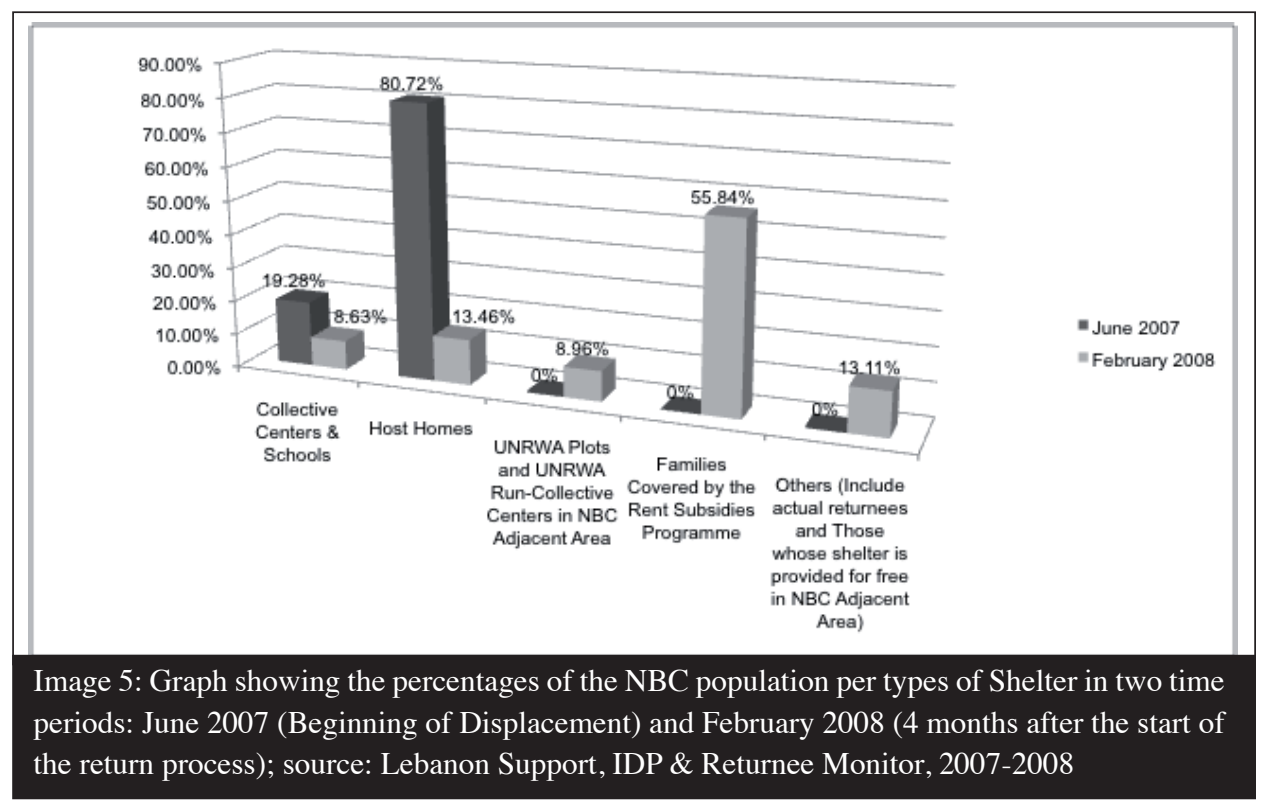

By February 2008, the rent subsidy program covered the rent for about $52.84 \%$ (inside and outside of the Nahr el Bared Adjacent Area) of displaced families, while UNRWA collective centers and the UNRWA plots in the Adjacent Area hosted about 8.96\% of families; while UNRWA schools in Beddawi hosted $6.53 \%$ of families and families who were still being hosted by host-homes constituted $13.46 \%$.

Going back to the global picture, the figures showed by February 2008, that some 1,264 families had returned to the Nahr el Bared Adjacent Area (constituting 23.12\% of the total population) while Beddawi Camp continued to host about $34.66 \%$ and Jabal El-Beddawi hosted $16.32 \%$, Tripoli $18.77 \%$ and the rest of the country hosted $7.13 \%$ of the total number of families.

Comparing between June 2007 and February 2008, we notice a considerable drop (67.24\%) in the number of families living in host-homes and a drop of $14.27 \%$ in the number of families living in Schools and Collective centers.

These changes in shelter conditions/or types are mainly related to the launching of the rent subsidy program which had a quick effect in shaping shelter conditions for a substantial number of displaced families, in addition to the temporary units constructed by UNRWA in the NBC Adjacent Area. In practice the UNRWA plots primarily hosted IDPs that were living in Schools and Collective centers, while the rent subsidies program targeted those living in host homes and minimized the possible negative effects of long displacement on the host population of Beddawi camp by either providing cash to host families in the form of rent, or by allowing displaced families to rent their own separate apartment.

The opening of the Adjacent Areas, triggered the mobility towards North Lebanon as a buffer zone for displaced families before returning back to NBC, thus we notice that in February 2008, that Beirut, Saida, Tyre and Bekaa witnessed a drop in the number of Displaced families, as many families preferred to go back to North Lebanon as they wait for their turn to go back to NBC. 


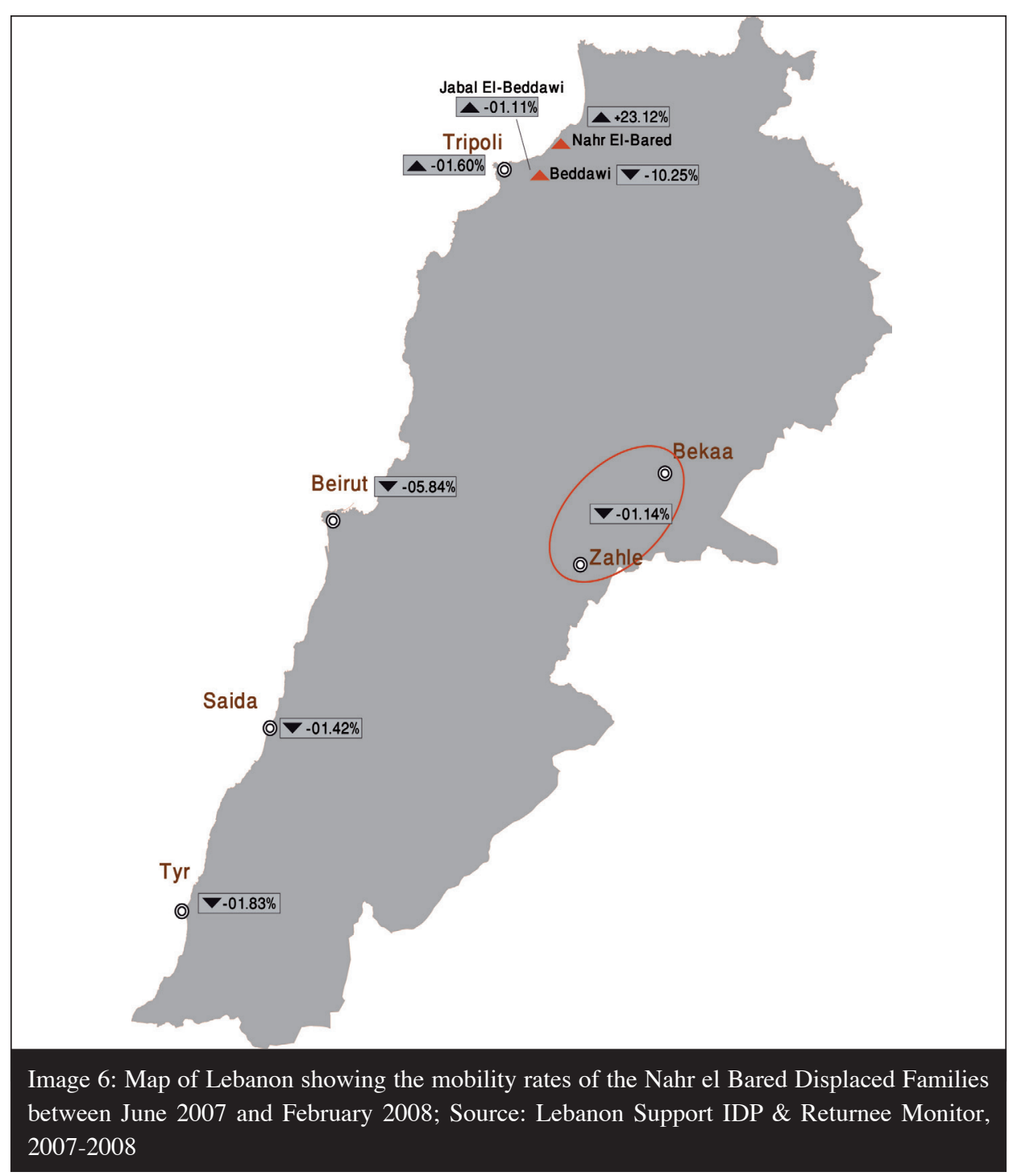

By February 2009, around 2075 families were hosted in the NBC Adjacent Area, a $64.16 \%$ increase compared to February 2008, while Beddawi Camp hosted 1032 families, a 45.54\% decrease compared to February 2008. Moreover we witnessed a decrease of the number of families in Beirut, Tyr and Bekaa, while we witnessed at the same time an increase of the number of families in Jabal el Beddawi and Tripoli, which proves the previous observation about North Lebanon becoming a buffer zone for the Nahr el Bared IDPs, waiting their turn to go back to NBC.

By the time of writing of the report (June 2009), the number of families in Nahr el Bared adjacent area has reached $3052(55.58 \%)$ families, and was continually increasing as more temporary shelters were being provided and as services are more and more being centralized in NBC. Beddawi camp at that same date hosted 1009 (18.45\%) families, while Jabal el Beddawi Camp has 964 (17.63\%) families, and Tripoli hosts 184 (3.36\%) families, and the rest of Lebanon host 258 (4.71\%) families.

Out of the 3052 families in NBC Adjacent Area, 28.80\% (879 families) are living in their own homes, i.e. they have gained the status of Actual Returnees. Thus the global rate of Actual Returnees is $16.07 \%$. 


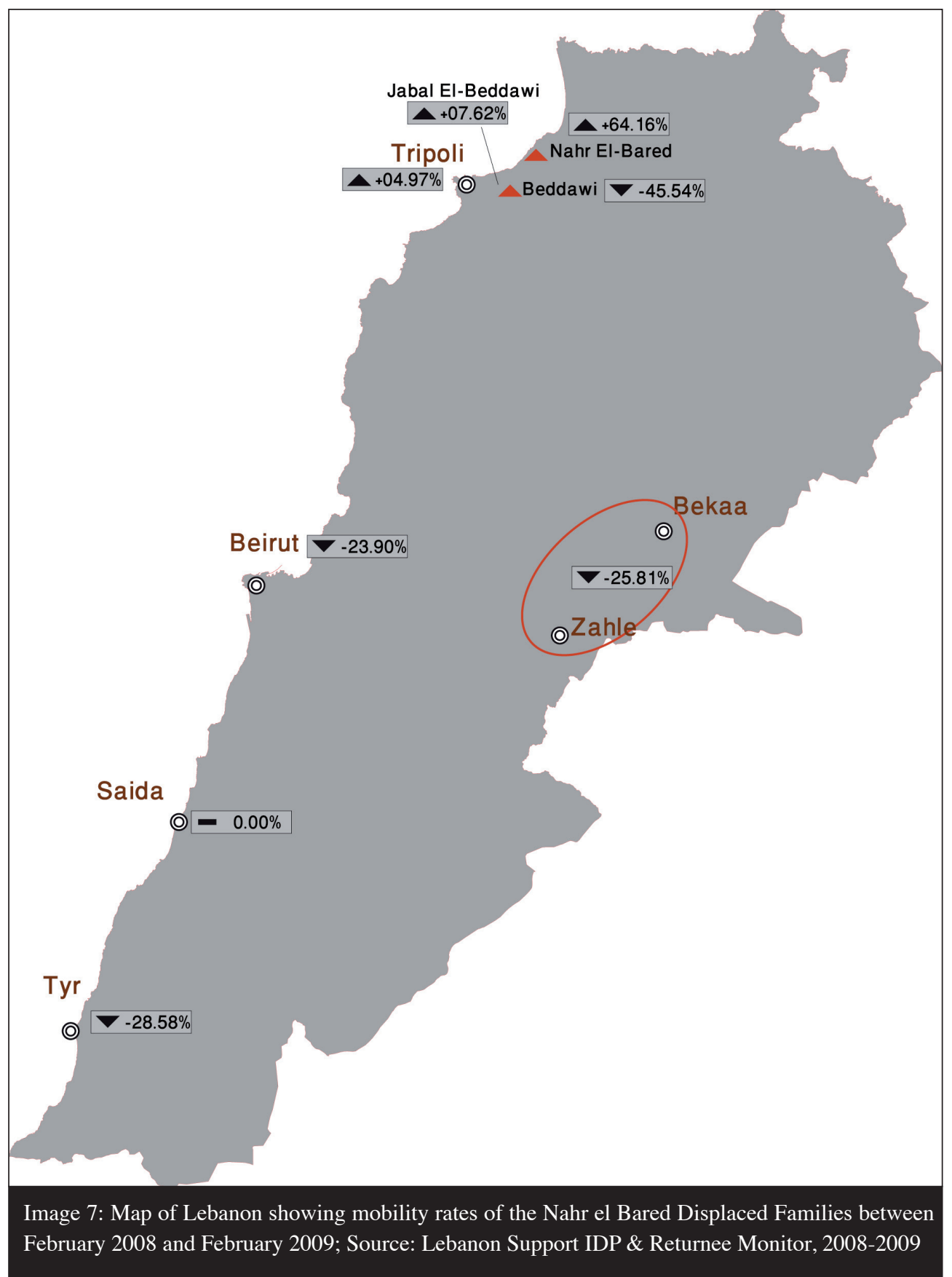

2173 have returned to the Nahr el Bared Adjacent Area but not to their actual homes, i.e. they are living in the UNRWA plots, rented apartments, collective centers and others.

Based on these conditions they are to be considered Semi-Returnees and they make $71.19 \%$ of the families currently living in NBC Adjacent Area, and globally they constitute $39.74 \%$ of the total number of NBC families. Lastly there are still 2415 families living outside NBC, thus they are considered displaced or IDPs, and they constitute globally $44.17 \%$ of the total number of NBC families. 


\section{V-Demographic Composition}

At the beginning of the crisis, the most common figure used as the number of Nahr ElBared residents was 31,000. Yet the results and findings of numerous surveys and mappings, especially that of the IDP and Returnee Database, proved that the actual number of residents of the Nahr El-Bared camp is actually about 27,000 people relative to 5,467 families . The discrepancy in figures is mostly related to the lack of effective mobility monitoring systems that can keep track of the population movement, as many families have left the camp in the past years, and are either living in other camps, or in Lebanese cities, or are currently living abroad.

Yet it is important to mention that many camp officials and key-community figures are still using the figure of 31,000 as the number of the Palestinian community of Nahr El Bared camp. The usage of this figure comes out of fear that the families who have left the country to live abroad be restricted entry to Lebanon, if they decide to return back to NBC or other Palestinian camps in Lebanon.

\section{Family Size:}

For the NBC IDPs living in Beddawi Camp, the mean family size is $4.76+/-2.61$ members, with the most frequent families being composed of two individuals $(19.33 \%)$.

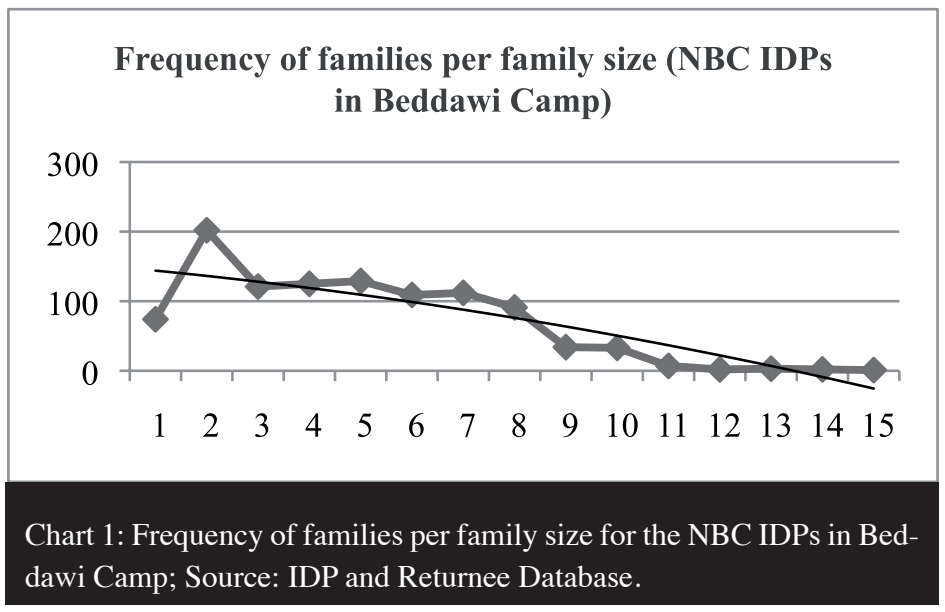

As for the NBC IDPs living in Jabal el Beddawi, The mean family size is $4.9+/-2.51$ members, with most frequent families being composed of two individuals $(16.46 \%)$.

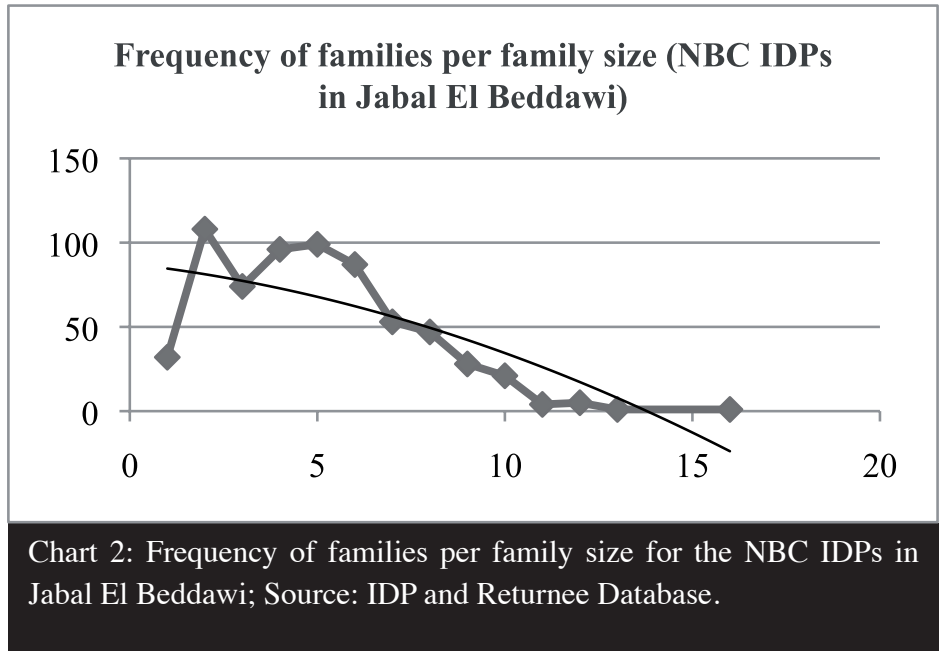


As for the semi-returnees and returnees in Nahr el Bared Adjacent Area, the mean family size is $4.95+/-2.69$ members, with most frequent families being composed of two individuals $(17.47 \%)$.

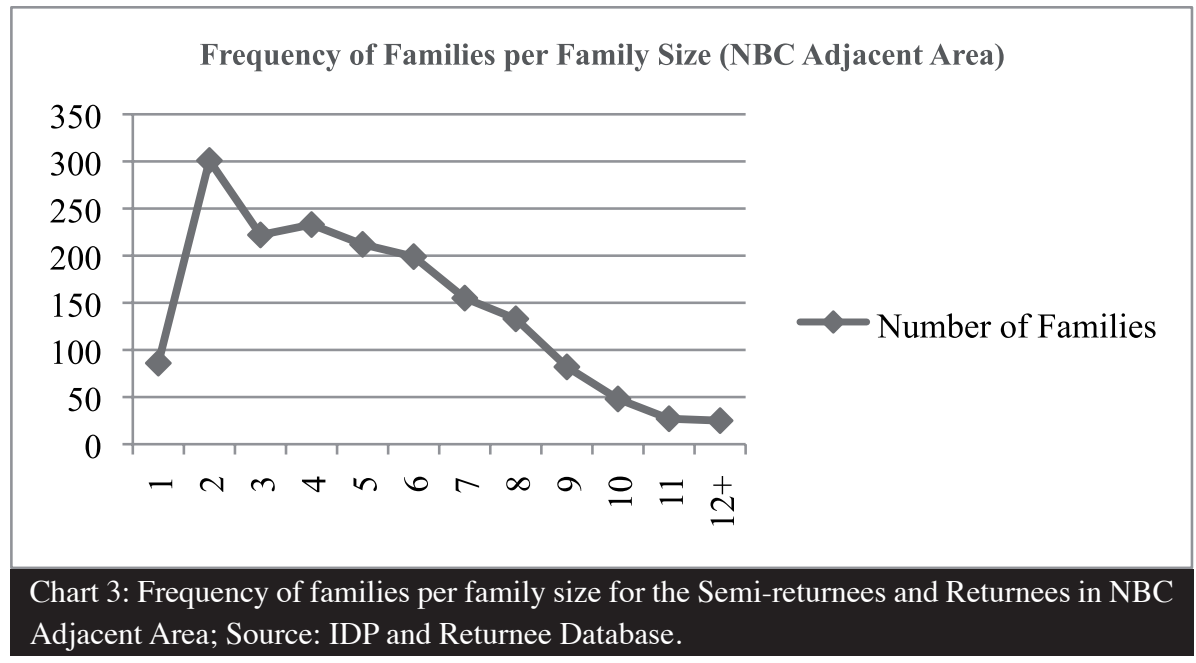

The above findings show that Nahr el Bared families share approximately the same frequency of family size in all the three assessed regions, which basically corroborates these findings. In general the average family size of NBC families is 4.93 members per family, with the most frequent family size being families composed of 2 members. Families with only 2 members may be considered as "newly wed couples", which suggests that these new families will soon bare children, thus it would be important to mention, that if these new families are excluded from the above listed graphs we can notice that the highest frequency is for families with 4 and 5 family members.

\section{Age and Sex Characteristics:}

As shown in the below graphic, the age distribution of the Nahr el Bared IDP population in Beddawi camp represent a population of a high birth rate, and low elderly mortality, and a sex ratio of almost 1 to 1 . (M: 50.04\%; F: $49.95 \%$ ).

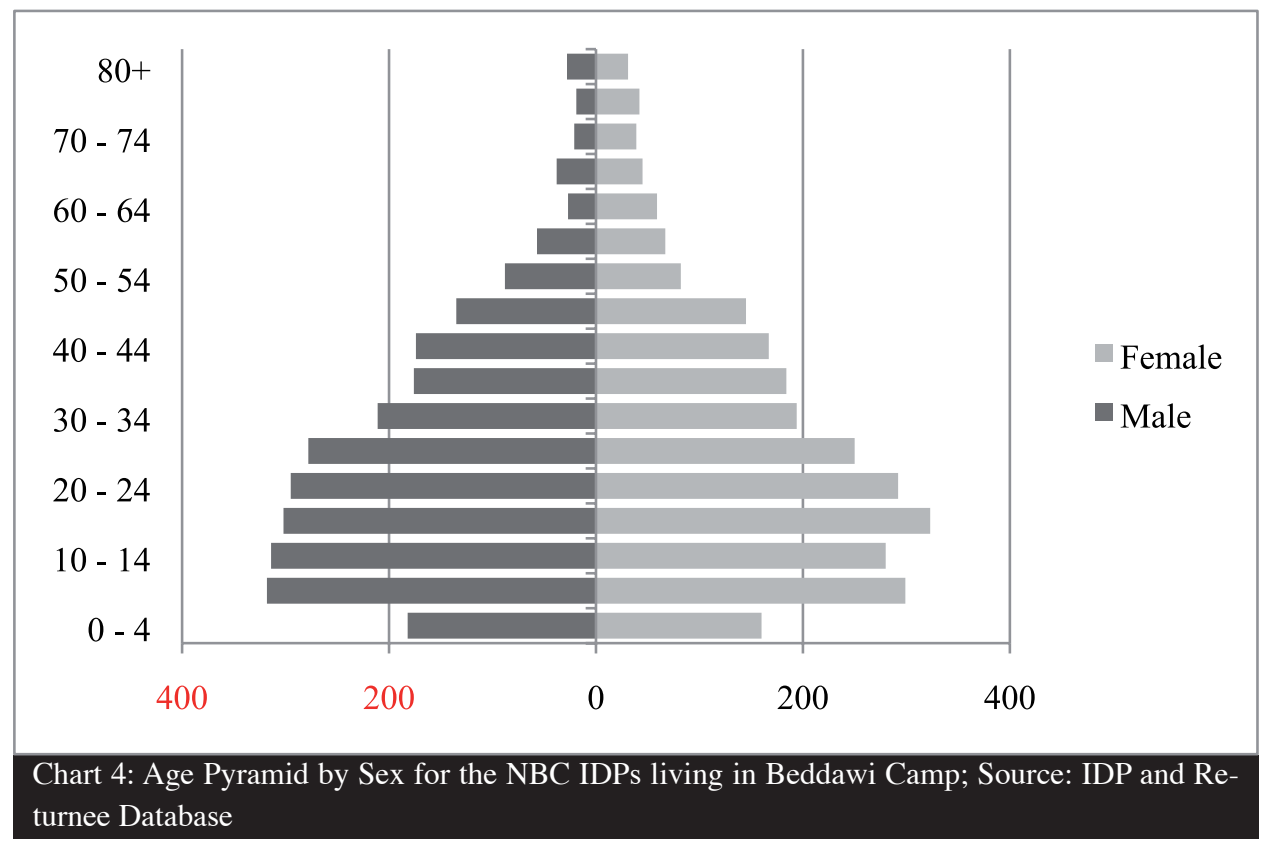


The average age of the Beddawi IDPs is 27.16 years with a Standard Deviation of 18.52 years and a difference between males and females ages $(M=26.20+/-17.79 ; F=28.13+/-19.18)$.

\begin{tabular}{l|l|l|l} 
Age characteristics & Male & Female & All \\
\hline Mean & 26.20 & 28.13 & 27.16 \\
\hline Median & 23 & 24 & 24 \\
\hline Std. Deviation & 17.79 & 19.18 & 18.52 \\
\hline Table 1: Age Characteristics for NBC IDPs in Beddawi Camp; Source: IDP \& \\
Returnee Database
\end{tabular}

As for IDPs living in Jabal el Beddawi, similarly to those living in Beddawi camp they represent a population with a high birth rate, and low elderly mortality, and a sex ratio showing an almost 1:1 equilibrium between both sexes (M: 49.44\%; F: 50.56\%).

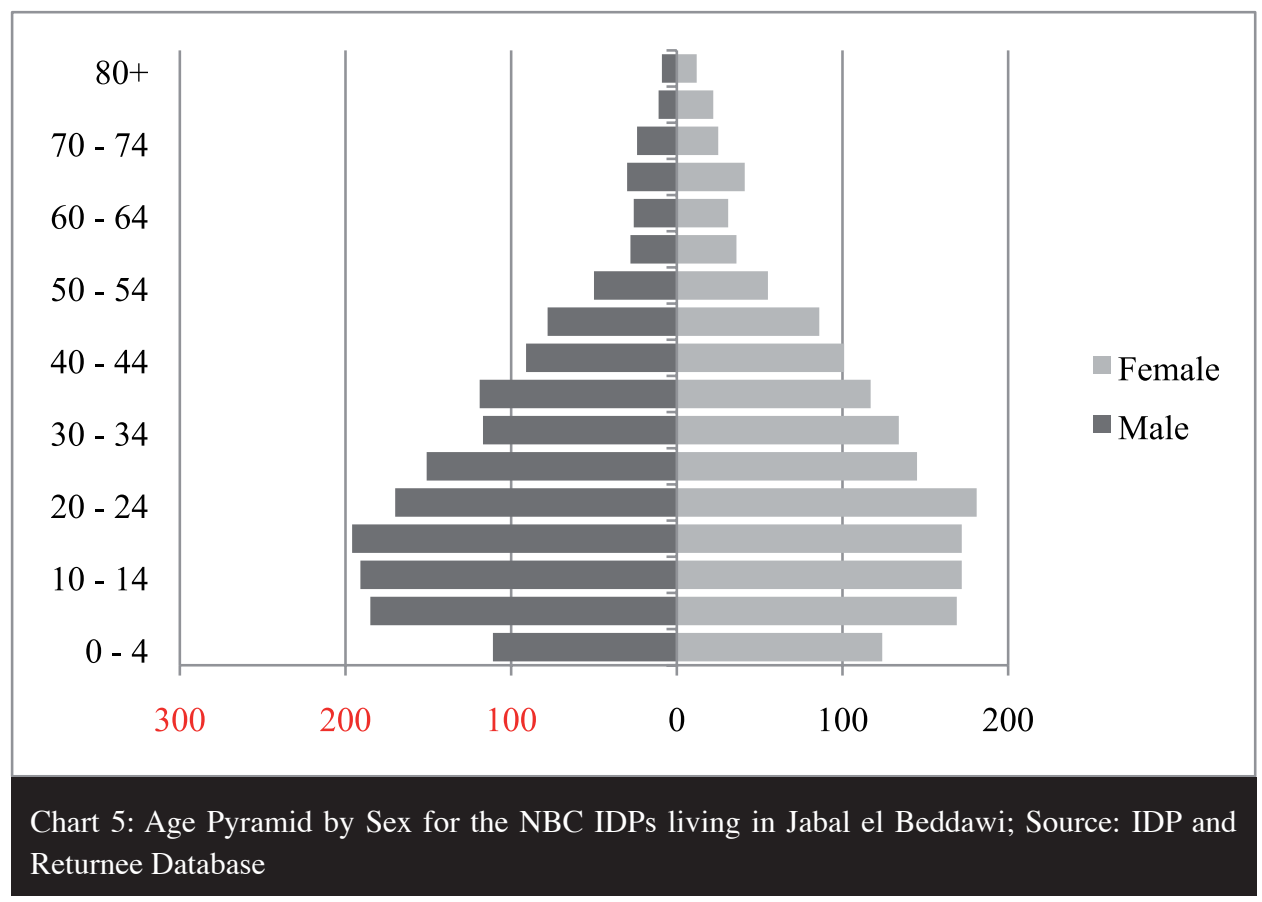

The average age of the Jabal el Beddawi IDPs is 27.14 years with a Standard Deviation of 18.56 years and no difference between males and females ages $(M=26.29+/-18.05 ; F=27.97$ +/- 19.01).

\begin{tabular}{l|l|l|l} 
Age characteristics & Male & Female & All \\
\hline Mean & 26.29 & 27.97 & 27.14 \\
\hline Median & 23 & 24 & 24 \\
\hline Std. Deviation & 18.05 & 19.01 & 18.56 \\
\hline
\end{tabular}

Table 2: Age Characteristics for NBC IDPs in Beddawi Camp; Source: IDP \& Returnee Database 
As for the returnees and semi-returnees in Nahr El Bared Adjacent Area, validates the previous age and sex composition showing a high birth rate and low elderly mortality, the sex ration being almost 1 to 1 . (M: 50.26\%; F: $49.74 \%$ ).

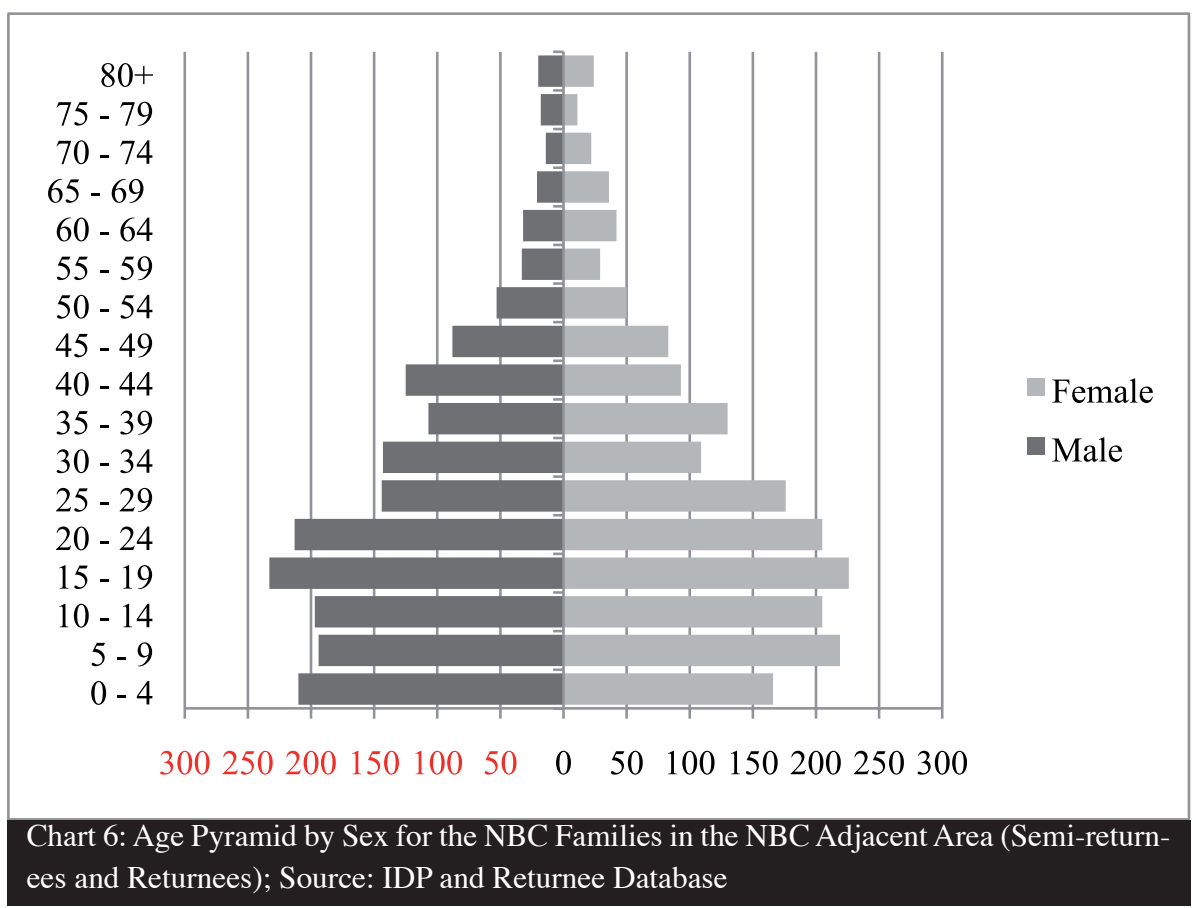

The average age of the NBC Returnees and Semi-Returnees is 25.93 years with a Standard Deviation of 19.51 years and no difference between males and females ages $(M=25.40+/-18.86$; $\mathrm{F}=25.98+/-19.23)$.

\begin{tabular}{l|l|l|l} 
Age characteristics & Male & Female & All \\
\hline Mean & 25.40 & 25.98 & 25.93 \\
\hline Median & 21 & 22 & 22 \\
\hline Std. Deviation & 18.86 & 19.23 & 19.51 \\
\hline
\end{tabular}

Table 3: Age Characteristics for NBC IDPs in Beddawi Camp; Source: IDP \& Returnee Database

\section{Early Marriage:}

A random sample of 1420 (25.9\% of Total Number of Families) families with 7197 individuals was selected out of all regions. Within this sample, there are 2375 individuals who declared themselves married, and 48 of them are under 18 years of age, i.e. we can consider that the rate of early marriage is that of $2.02 \%$. Yet it is important to differentiate between Male and Female early marriage, as out of the total number of early married individuals, 46 out 48 are girls, and only 2 out of 48 are boys. This means that early marriage for girls constitute $95.8 \%$ of early marriages, while for boys it is $4.16 \%$. 


\section{Civil Status:}

For the NBC IDPs living in Beddawi Camp, the majority of individuals are single $(61.20 \%)$. Married individuals constitute $35.24 \%$. while the widowed and divorced constitute $3.28 \%$ and $0.28 \%$ respectively. Moreover almost the totality of individuals $(97.41 \%)$ declared being living with family, while $1.92 \%$ are living abroad, and $0.55 \%$ are living alone.
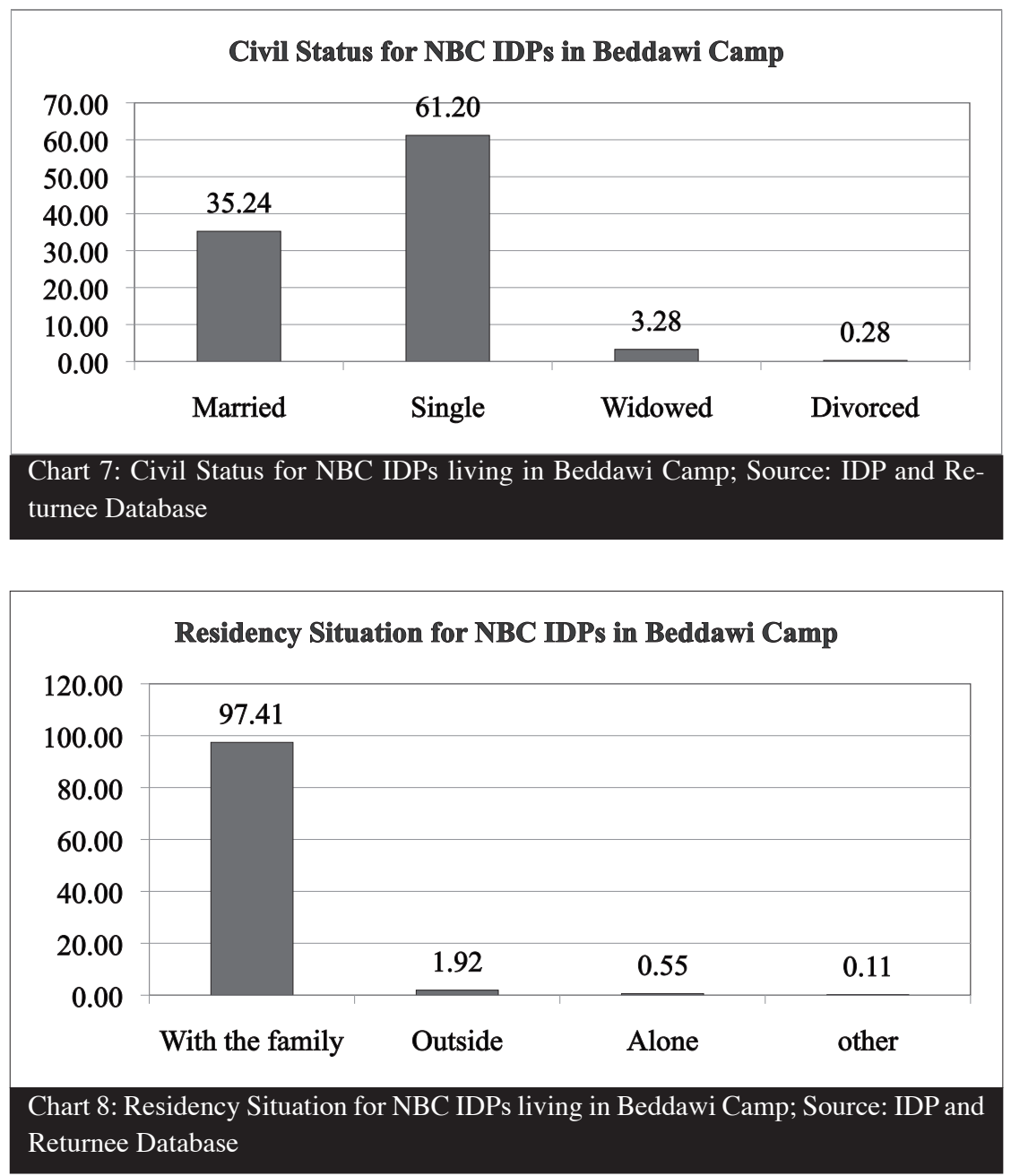

For the NBC IDPs living in Jabal El-Beddawi, the majority of individuals are single $(60.93 \%)$. Married individuals constitute $36.09 \%$, while the widowed and divorced constitute $2.82 \%$ and $0.16 \%$ respectively. Moreover almost the totality of individuals (97.04\%) declared living with family, while $2.40 \%$ are living abroad, and $0.40 \%$ are living alone.

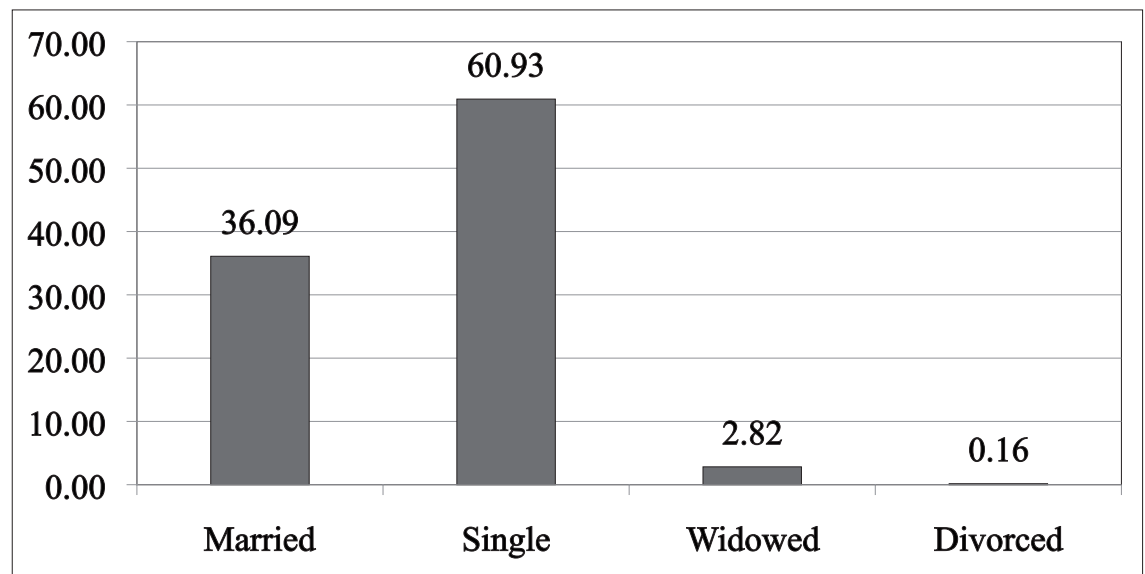

Chart 9: Civil Status for NBC IDPs living in Jabal El-Beddawi; Source: IDP and Returnee Database 


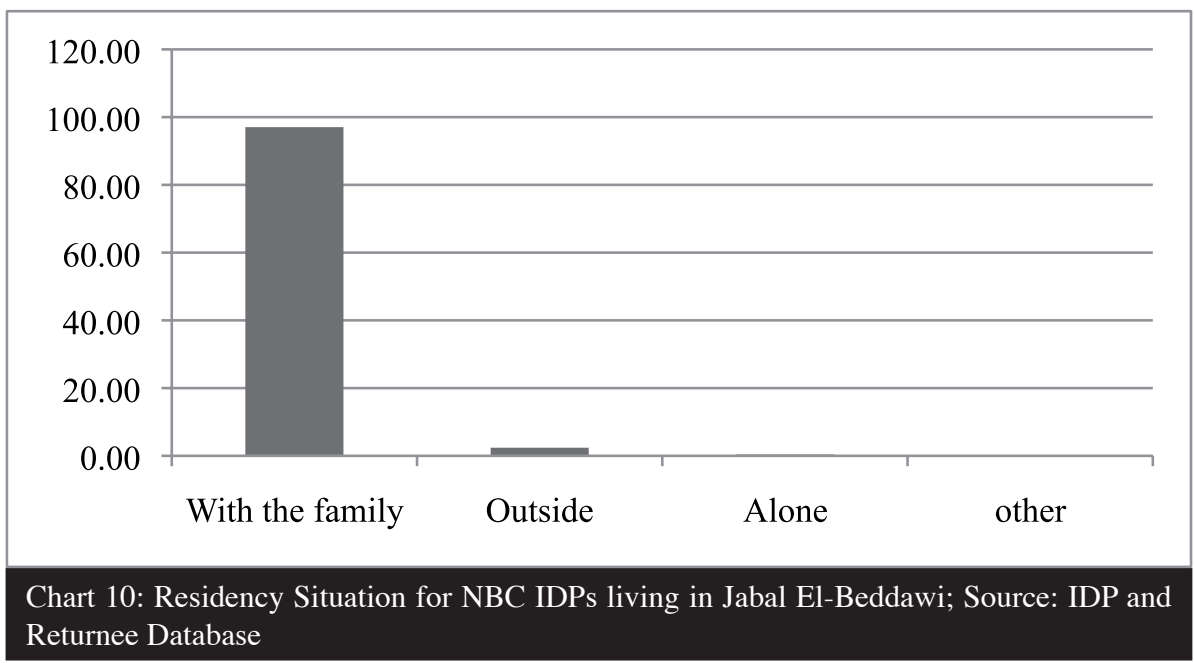

For the NBC population living in Nahr El-Bared Adjacent Area, the majority of individuals are single (62.29\%). Married individuals constitute $34.73 \%$, while the widowed and divorced constitute $2.52 \%$ and $0.46 \%$ respectively. Moreover almost the totality of individuals $(97.86 \%)$ declared being living with family, while $1.07 \%$ are living abroad, and $0.78 \%$ are living alone.

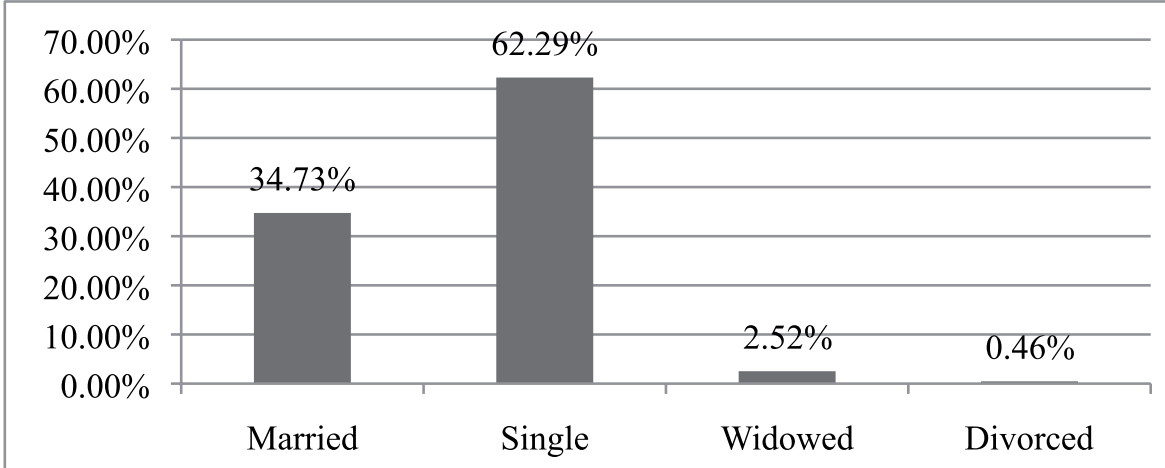

Chart 11: Civil Status for NBC population in Nahr El-Bared Adjacent Area; Source: IDP and Returnee Database

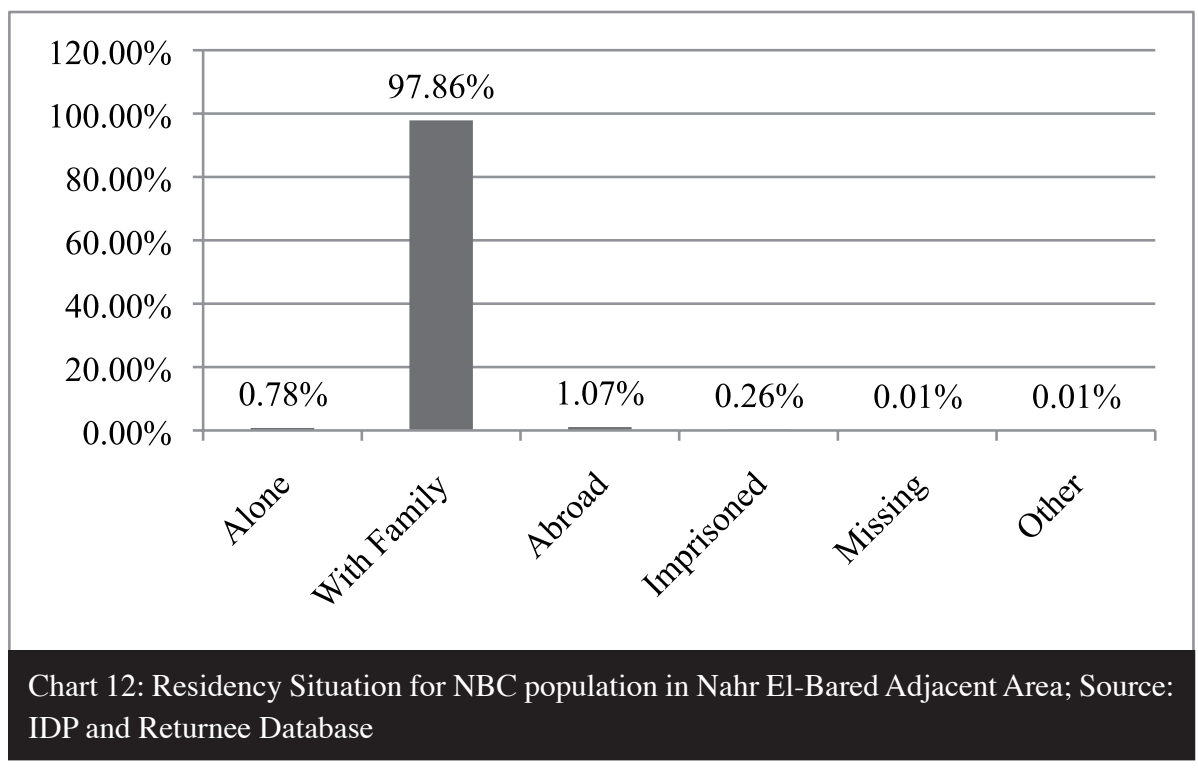




\section{VI- Shelter Characteristics}

\section{NBC IDPs in Beddawi Camp}

The majority $(89 \%)$ of the displaced population was a resident of the old camp while $11 \%$ was of the new camp.

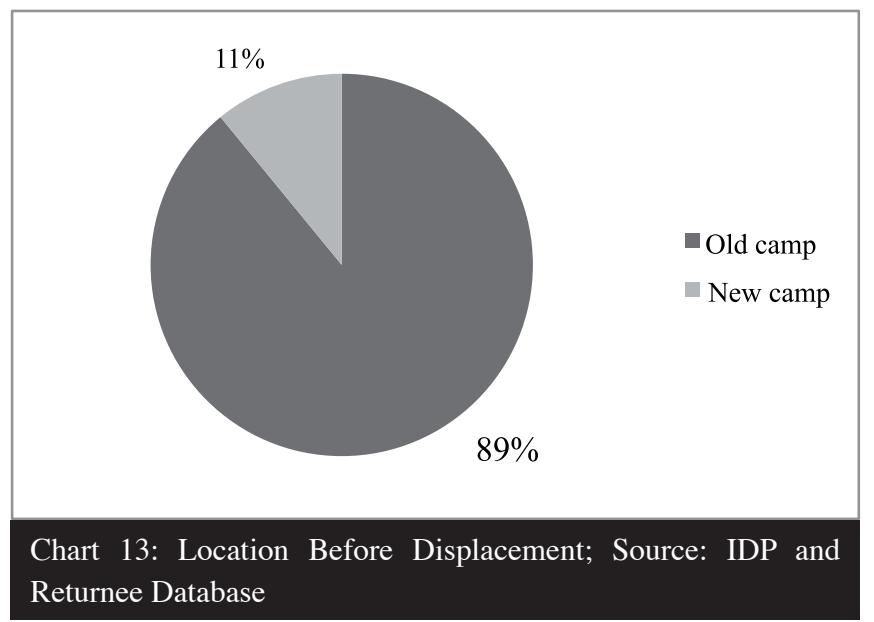

The majority of NBC IDPs in Beddawi Camp (61.12\%) are living in a house, $34.79 \%$ are living in an apartment, while a minority $(4.09 \%)$ is living in garages.

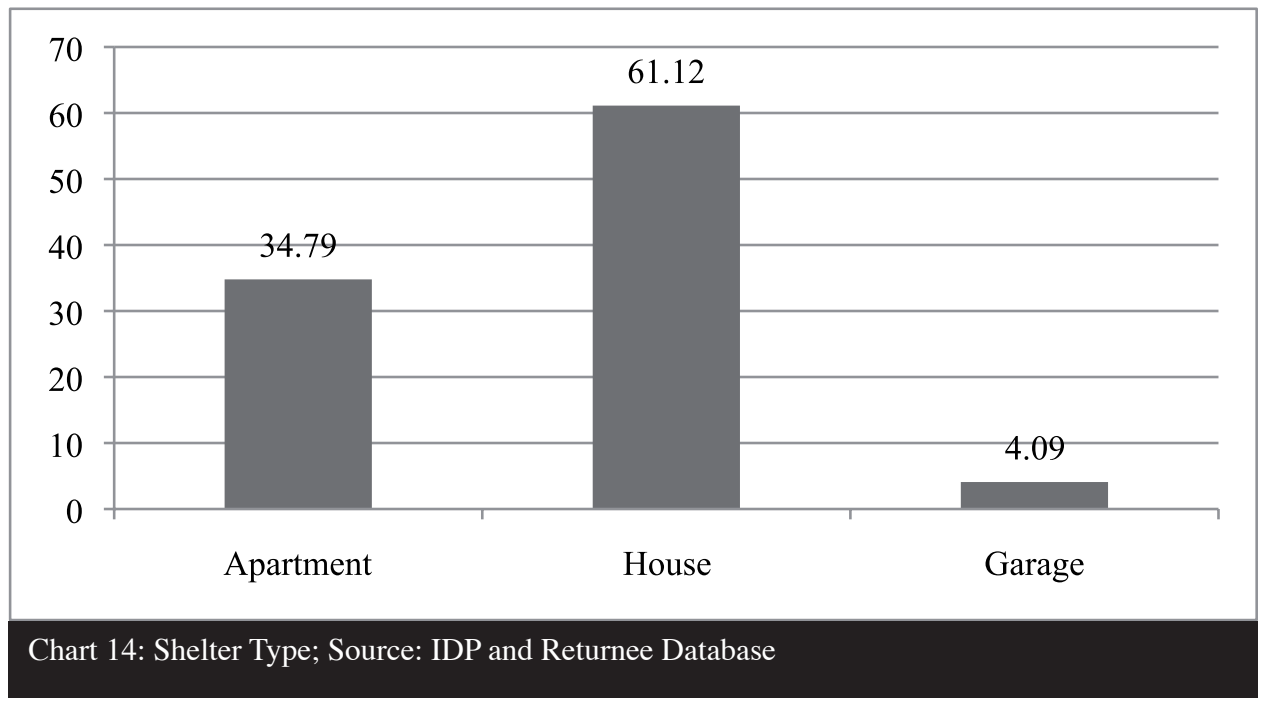

Almost the totality (98.9\%) of the surveyed population are living in rented accommodation while the rest $1 \%$ were living free of charge. But not all those who live in a rented apartment are receiving rent subsidies, as only $82 \%$ declared receiving rent subsidies. Yet it is important to mention that in the time of Beddawi Camp survey, rent subsidies had not yet reached all of the families who are currently receiving rent subsidies. 
Shelter space varied from $7 \mathrm{~m} 2$ to $200 \mathrm{~m} 2$, with the highest percentage of shelters' space $(37.53 \%)$ being between 51 and $80 \mathrm{~m} 2$.

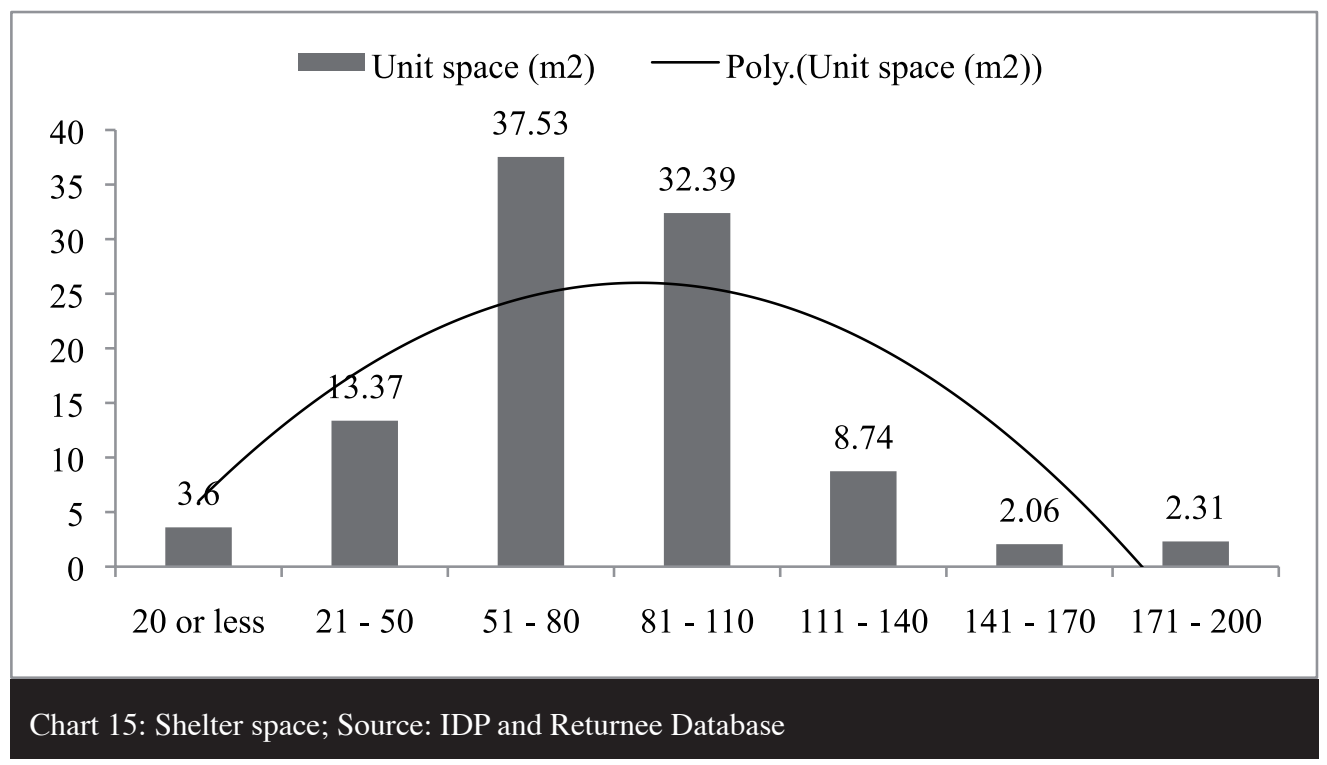

Around $41 \%$ of the shelters contained 5 to 8 persons, with a mean of $8.51+/-4.89$ persons per shelter. And as for the crowdedness, the results showed that the crowding index was at $10 \mathrm{~m} 2 /$ person or less for more than half of the surveyed population $(58.09 \%)$. In other terms, more than half of the displaced were living in a space $\leq 10 \mathrm{~m} 2 /$ person.

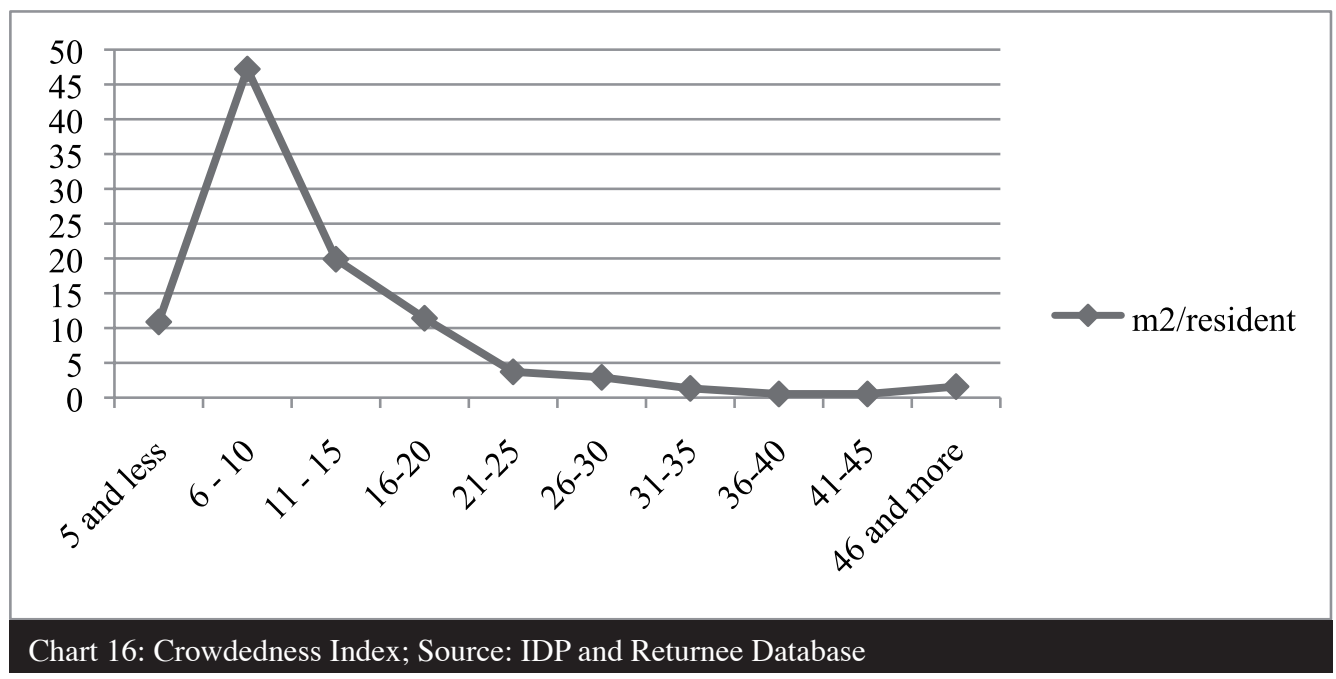

Half of the population (50.36\%) are living in a dwelling of one or two rooms, but the majority (39\%) are living in a dwelling of 2 rooms. The following table resumes some of the indicators related to the overcrowding, where we can see that in average: 7.98 persons are sharing one bathroom, 8.47 persons share one kitchen and 3.87 persons share one room.

\begin{tabular}{l|l|l|l} 
& Persons/bath & Persons/kitchen & Persons/room \\
\hline Mean & 7.98 & 8.47 & 3.87 \\
\hline Median & 7 & 8 & 3 \\
\hline Std. Deviation & 4.91 & 4.87 & 2.92 \\
\hline
\end{tabular}

Table 4: Shelter Facilities Index; Source: IDP \& Returnee Database 


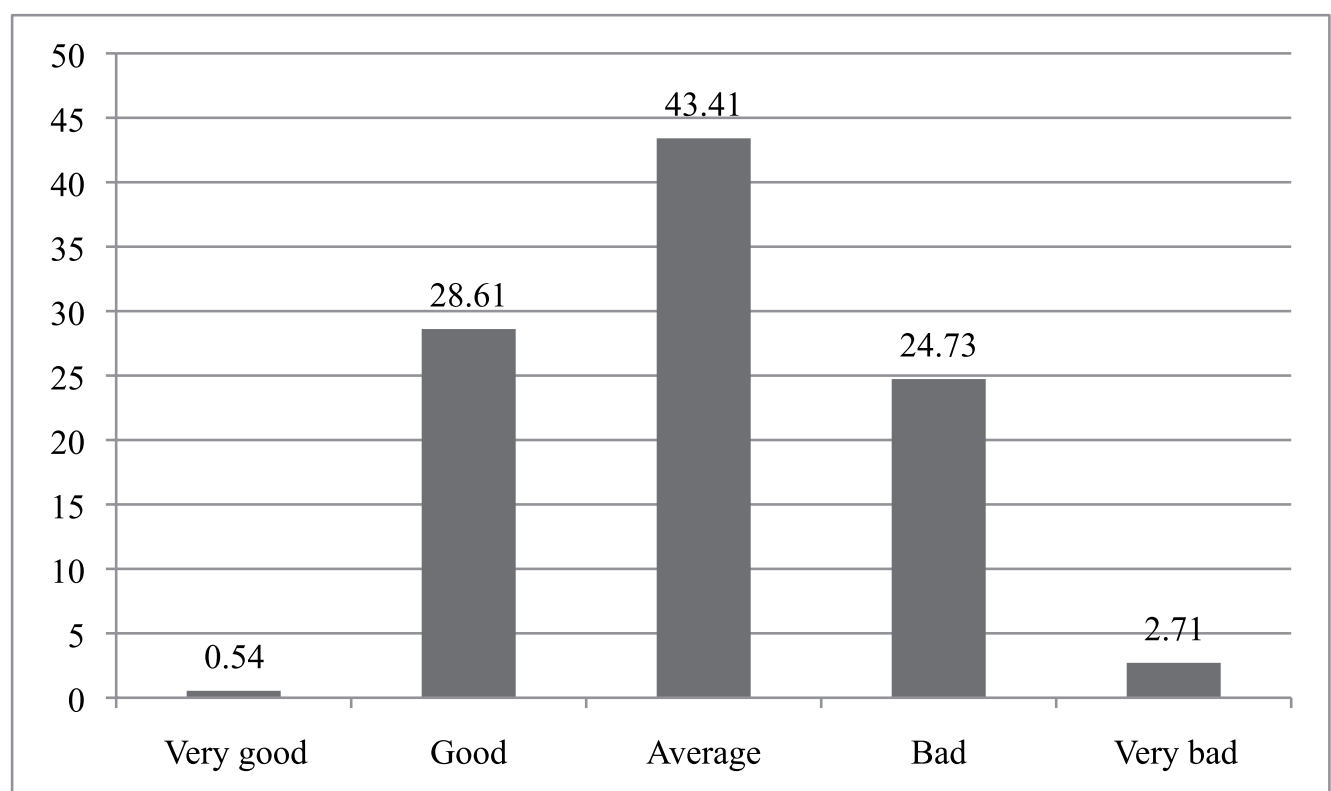

Chart 17: Shelter Conditions as assessed by the surveyed population; Source: IDP and Returnee Database

The majority $(43.41 \%)$ considered they were living in a dwelling with average conditions, while the minority $(0.54 \%)$ said they had very good conditions of shelter. 


\section{NBC IDPs in Jabal El-Beddawi}

The majority $(74.2 \%)$ of the displaced population was a resident of the old camp while $24.58 \%$ was from the new camp and a small minority (1.22\%) were residents of both camps.

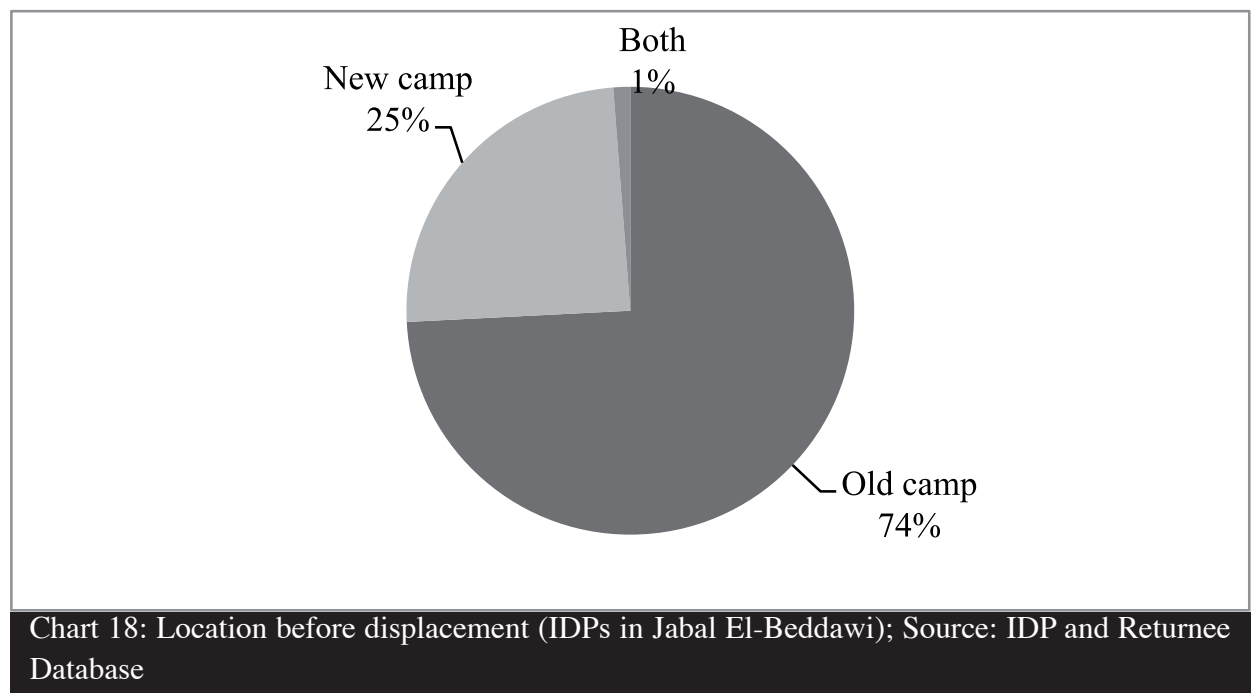

The majority of NBC IDPs in Jabal el Beddawi (70\%) are living in an apartment followed by $29.47 \%$ that are living in a garage.

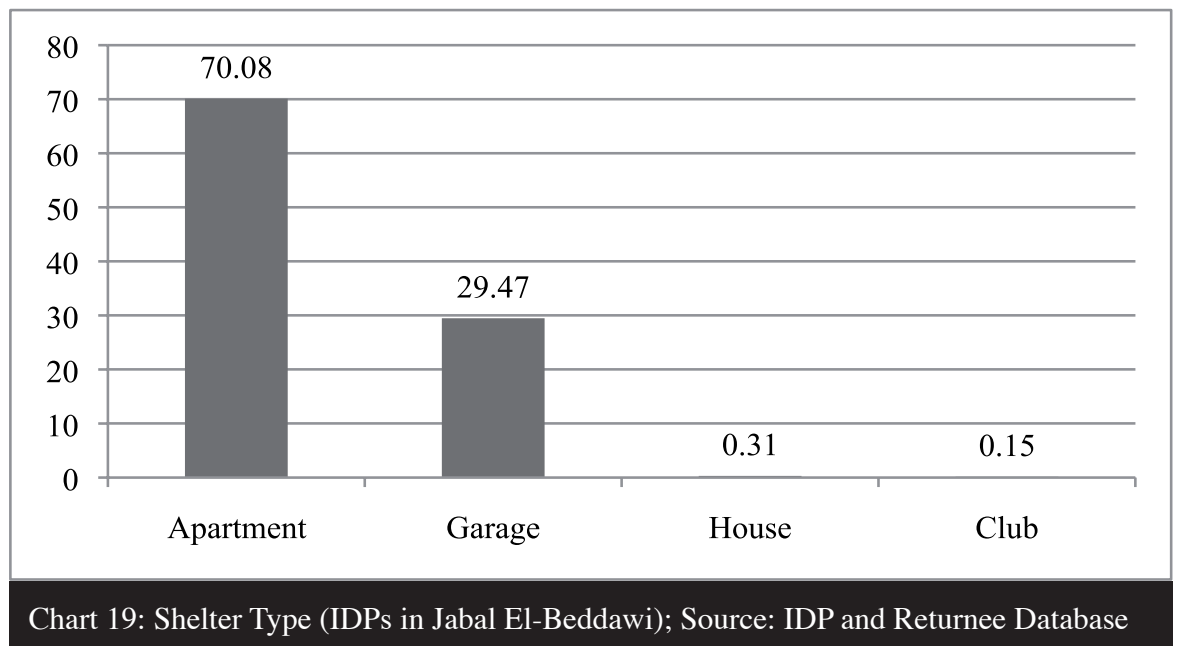

Also the majority $(95.42 \%)$ of the residents were living in a rented shelter, while only $2 \%$ owned theirs and another $2 \%$ had it for free. Almost $89 \%$ confirmed receiving rent subsidies.

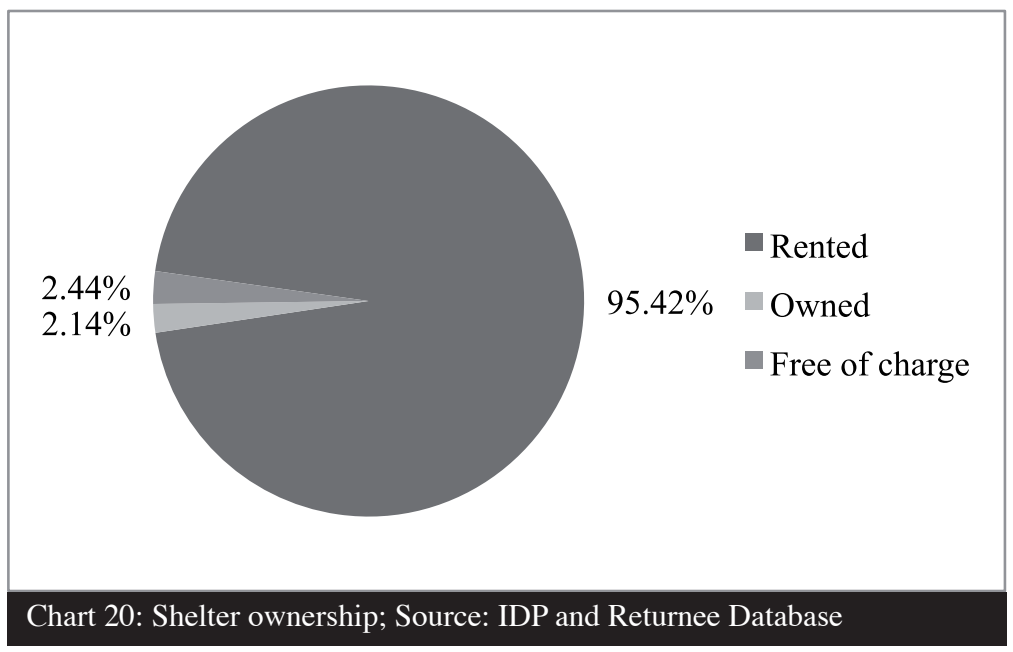


The space of the shelter varied from $6 \mathrm{~m} 2$ to $240 \mathrm{~m} 2$, with the highest percentage of shelters' space (37\%) being between $111 \mathrm{~m} 2$ and $140 \mathrm{~m} 2$.

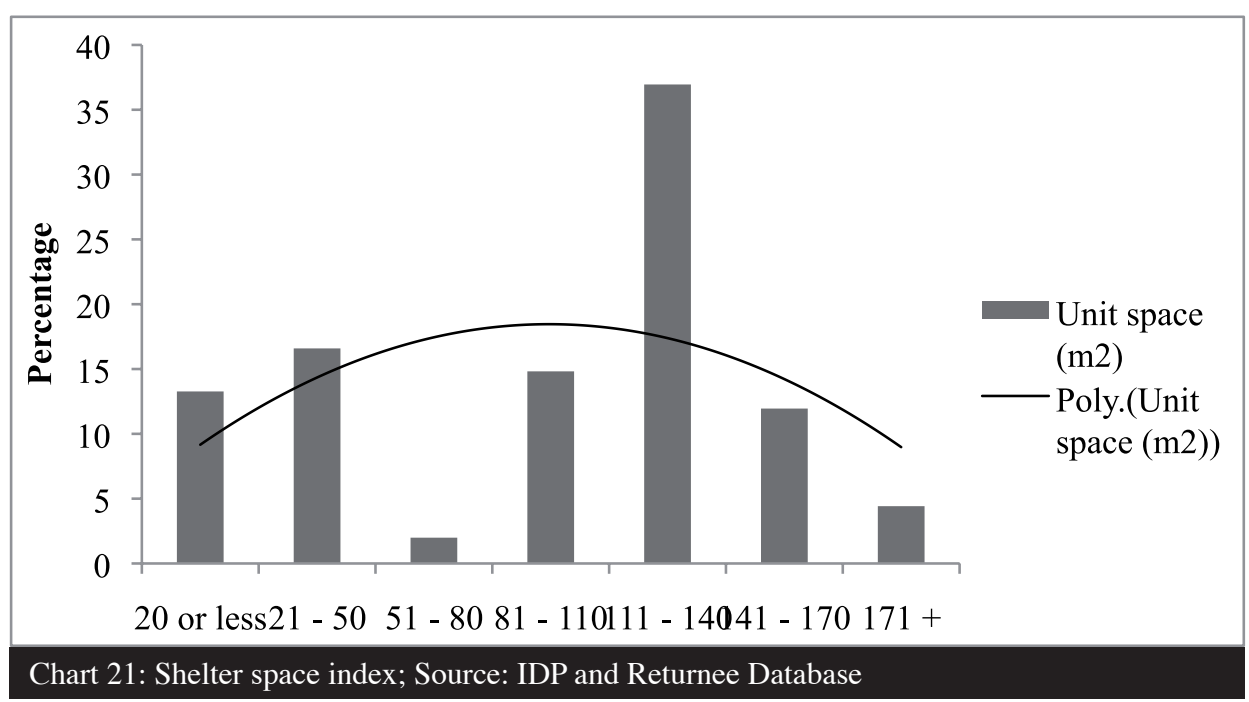

Around $43 \%$ of the shelters contained 5 to 9 persons, with a mean of $9.11+/-4.29$ persons per shelter. As for crowdedness, the results showed that the crowding index was at $10 \mathrm{~m} 2 /$ person or less for al-

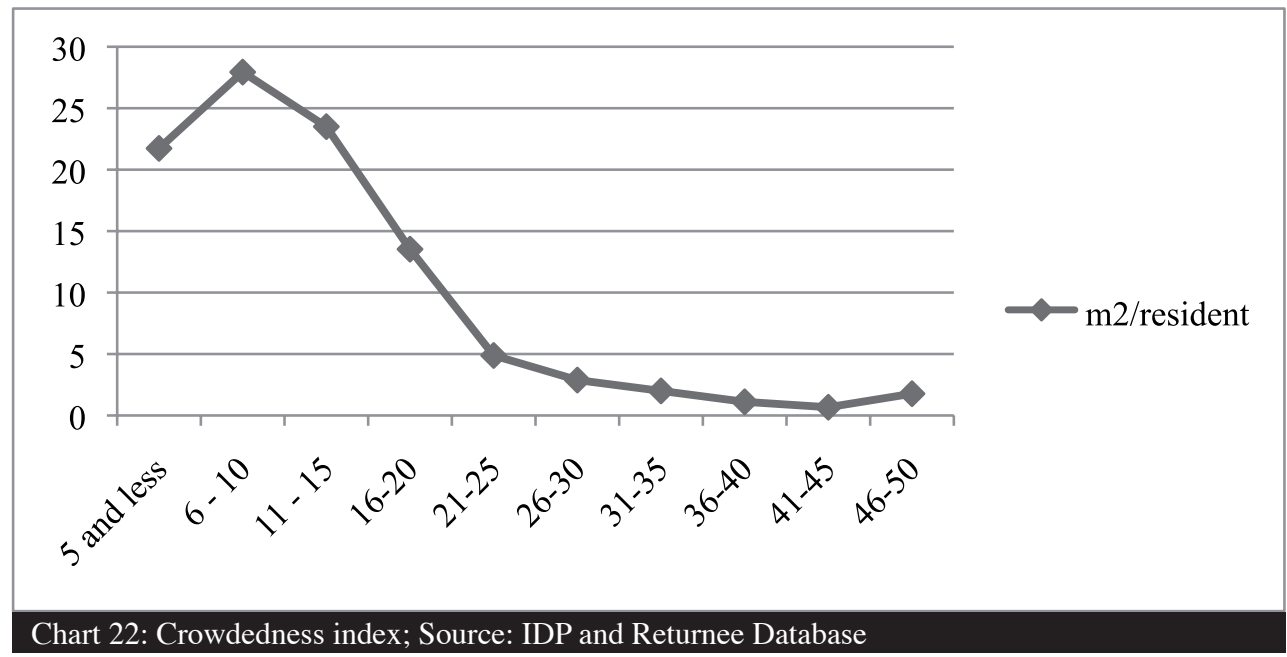

most half of the residents (49.67\%). In other terms, almost half of the displaced were living in a space $\leq 10 \mathrm{~m} 2 /$ person.

More than a third (34.4\%) of the population was living in a dwelling of one or two rooms, but the majority (39\%) was living in a dwelling of 4 rooms. The following table resumes some of the indicators related to the overcrowding, where we can see that in average: 6.25 persons are sharing a bath, 9.59 persons are sharing a kitchen and 3.96 persons are sharing one room.

\begin{tabular}{l|l|l|l} 
& Persons/bath & Persons/kitchen & Persons/room \\
\hline Mean & 6.25 & 9.59 & 3.96 \\
\hline Median & 5.5 & 9 & 3 \\
\hline Std. Deviation & 3.48 & 5.04 & 2.70 \\
\hline
\end{tabular}

Table 5: Shelter Facilities Index; Source: IDP \& Returnee Database 
The majority considered themselves living in a dwelling with "very good" or "good" conditions ( $2 \%$ and $37 \%$ respectively), while $19.75 \%$ and $9.49 \%$ considered themselves living in "bad" and "very bad" conditions respectively.

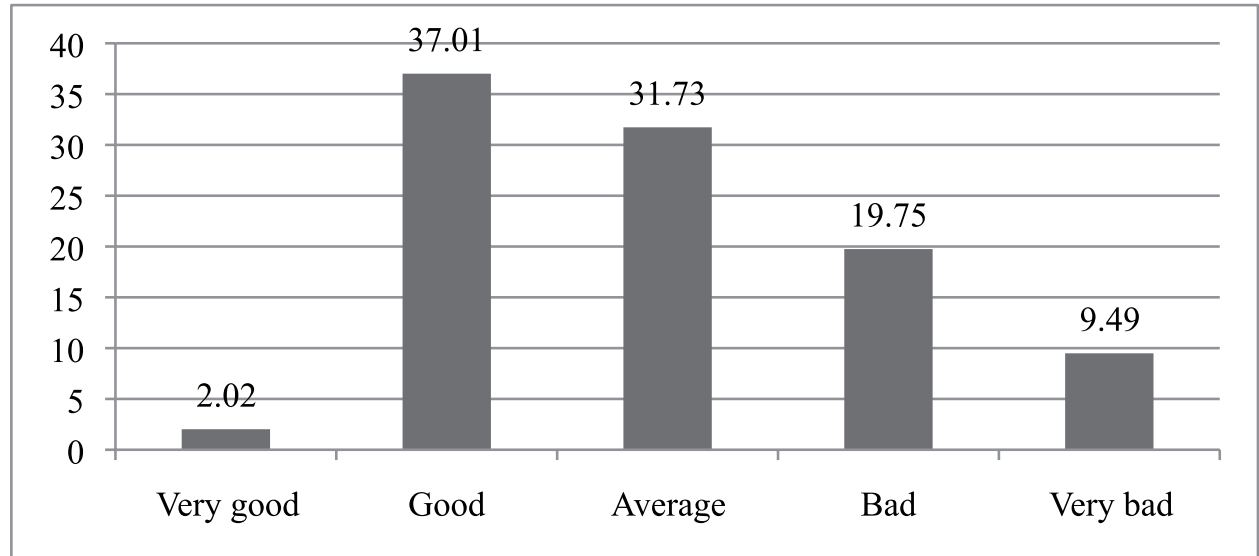

Chart 23: Shelter Conditions as assessed by the surveyed population; Source: IDP and Returnee Database 


\section{Returnees and Semi-Returnees in NBC Adjacent Area}

The majority (58\%) of the displaced population was a resident of the old camp while $42 \%$ was from the new camp.

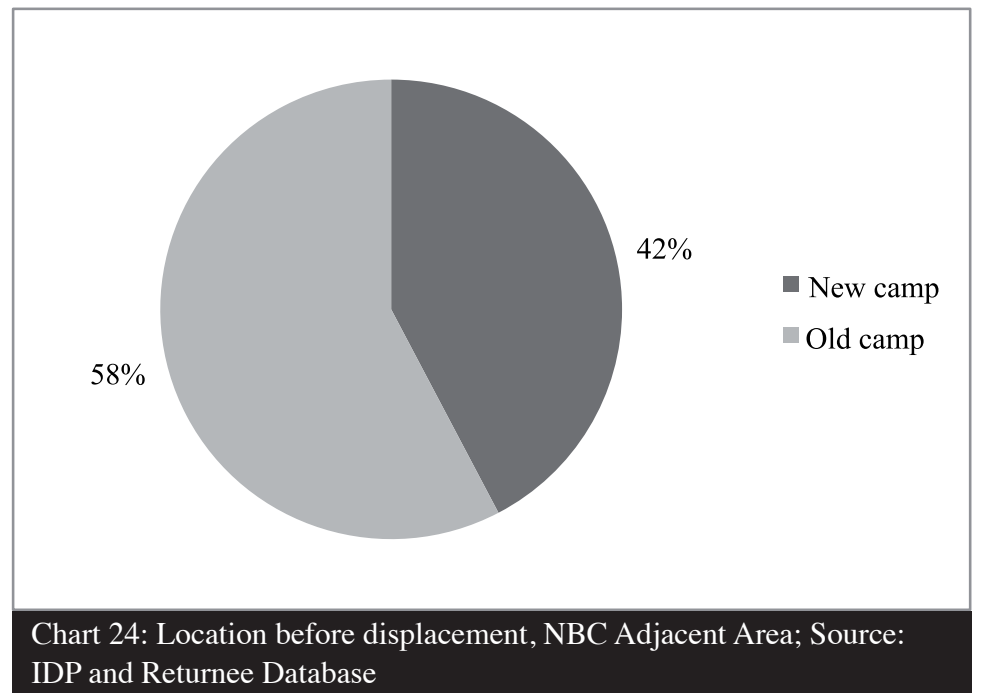

The majority of Nahr el Bared returnees and semi-returnees $(39.31 \%)$ are living in an apartment and a minority $(0.15 \%)$ was found to be living in a garage, while the "other" category (29.6\%) indicate people living in UNRWA plots, Collective Centers or public buildings such as mosques.

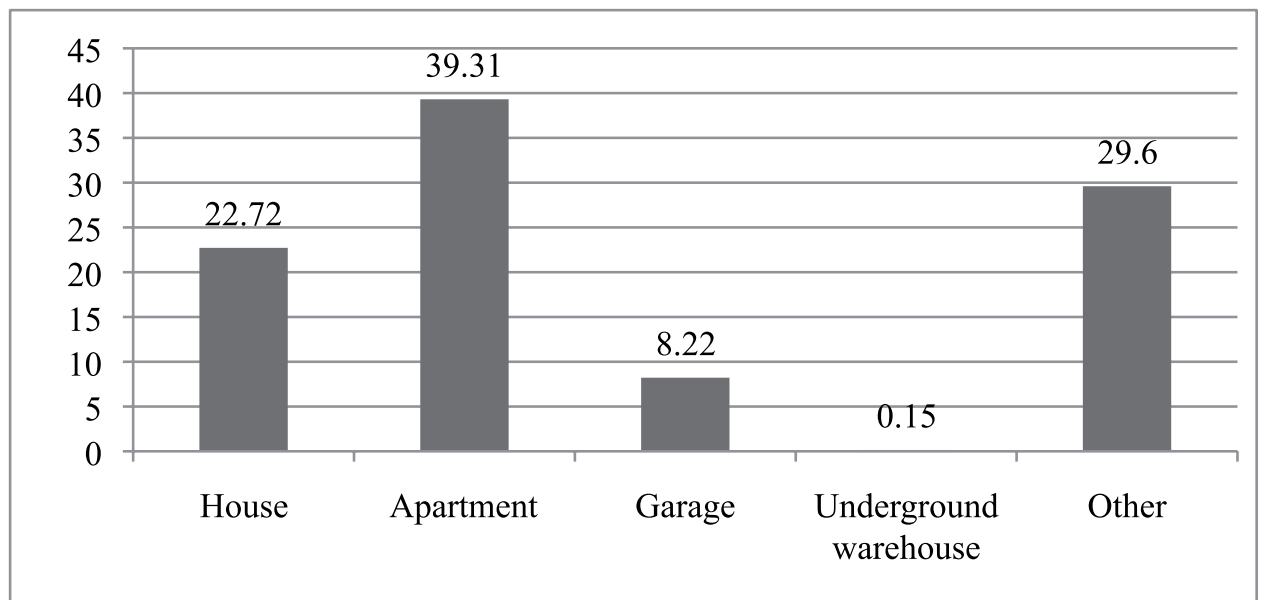

Chart 25: Shelter Type, NBC Adjacent Area; Source: IDP and Returnee Database

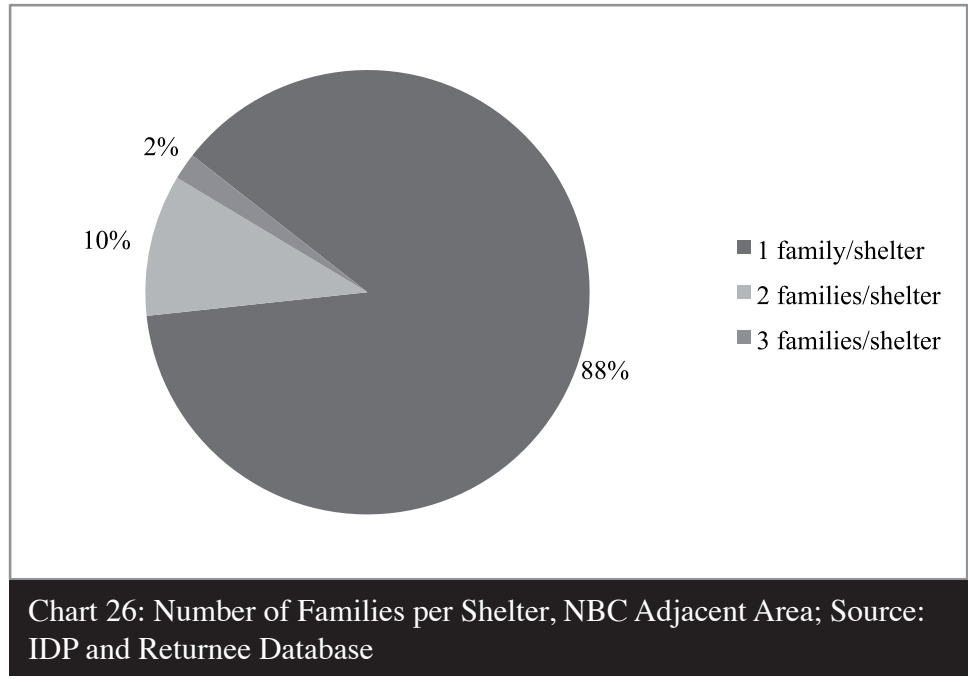


$12 \%$ of the accommodations were grouping more than one family: 2 or 3 families per shelter.

Houses seemed to have more number of people than the rest of shelters, where 6.25 persons were found to be sharing a house in average, while the general average independent of the shelter type is of 5.53 persons per shelter.

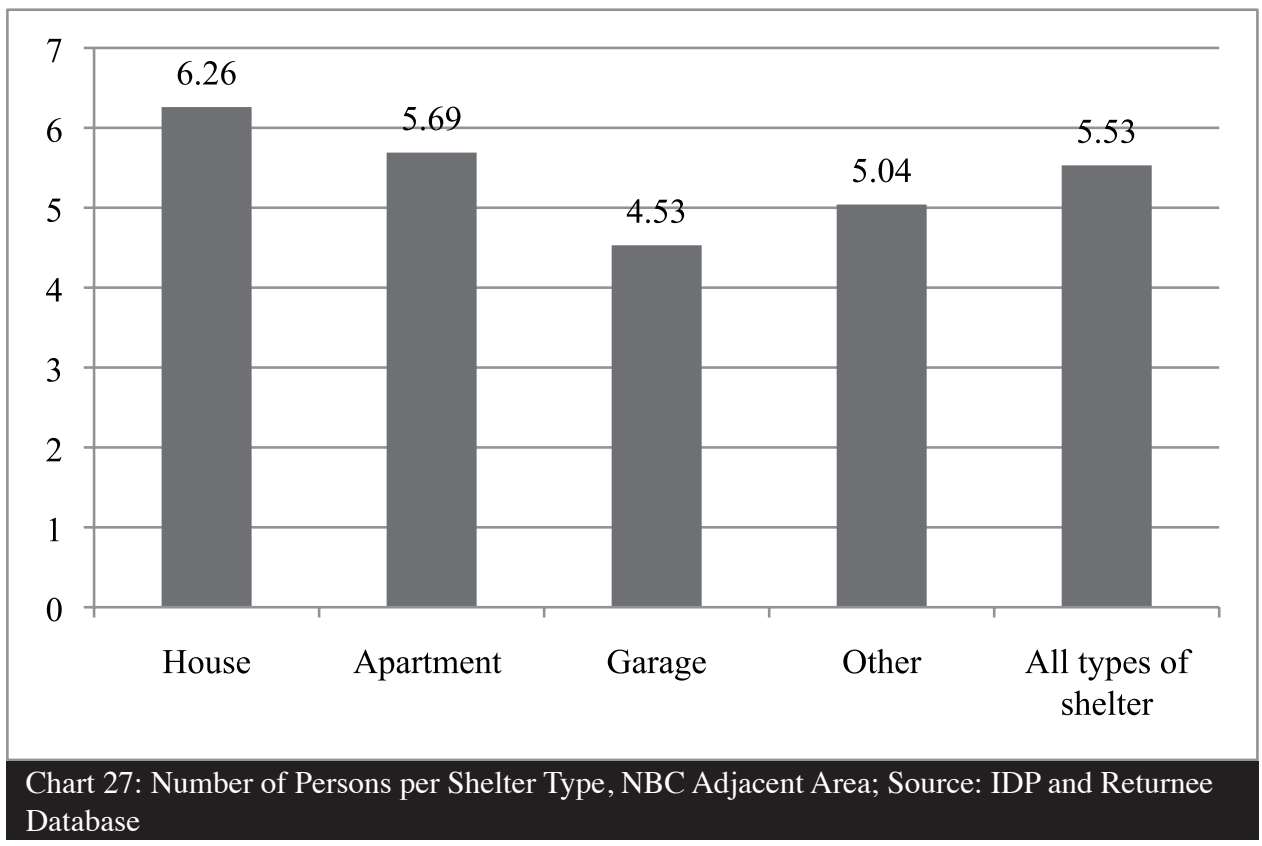

The majority $(72.62 \%)$ were living in a shelter where they didn't have any relationship with the other families sharing the same shelter and $26.79 \%$ were living with their relatives, while only $0.6 \%$ were at their neighbors or friends.

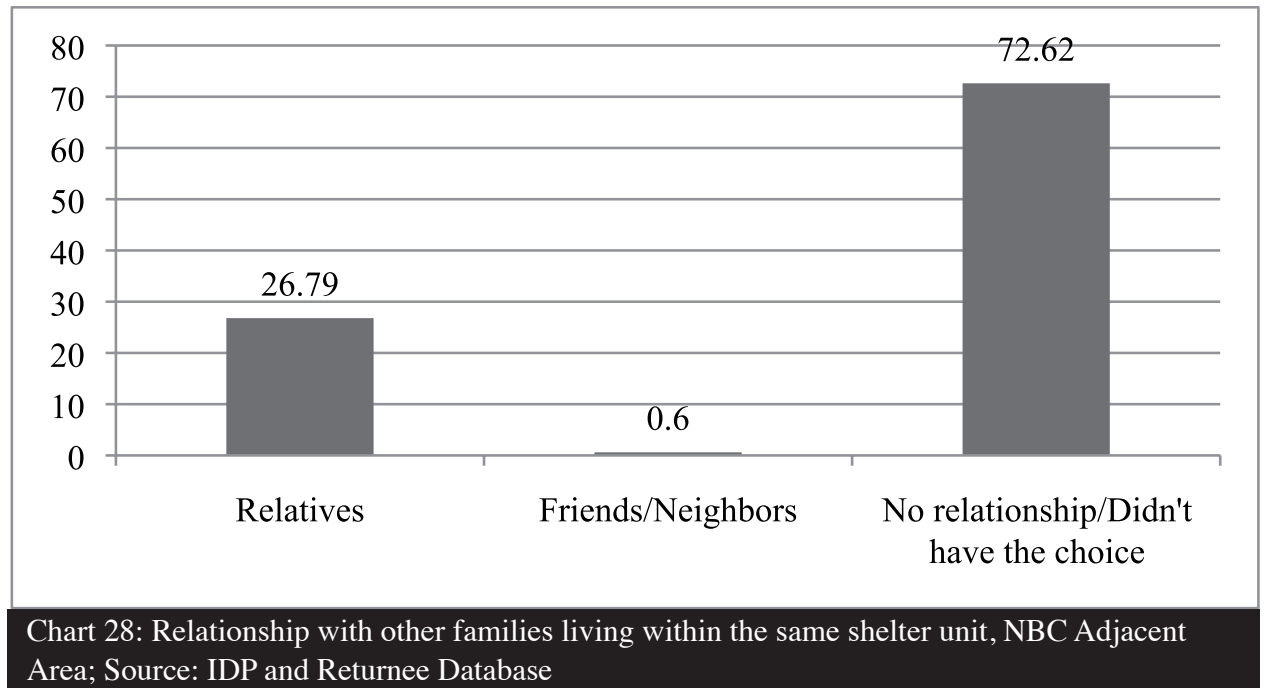

Only $(2.25 \%)$ of shelters had their structure done, and the rest $(97.75 \%)$ are shelters with uncompleted structure and are still under construction.

The space of the shelter varied from $9 \mathrm{~m} 2$ to more than $200 \mathrm{~m} 2$, with the highest percentage of shelters' space $(26.27 \%)$ being between for spaces of $20 \mathrm{~m} 2$ and less. 


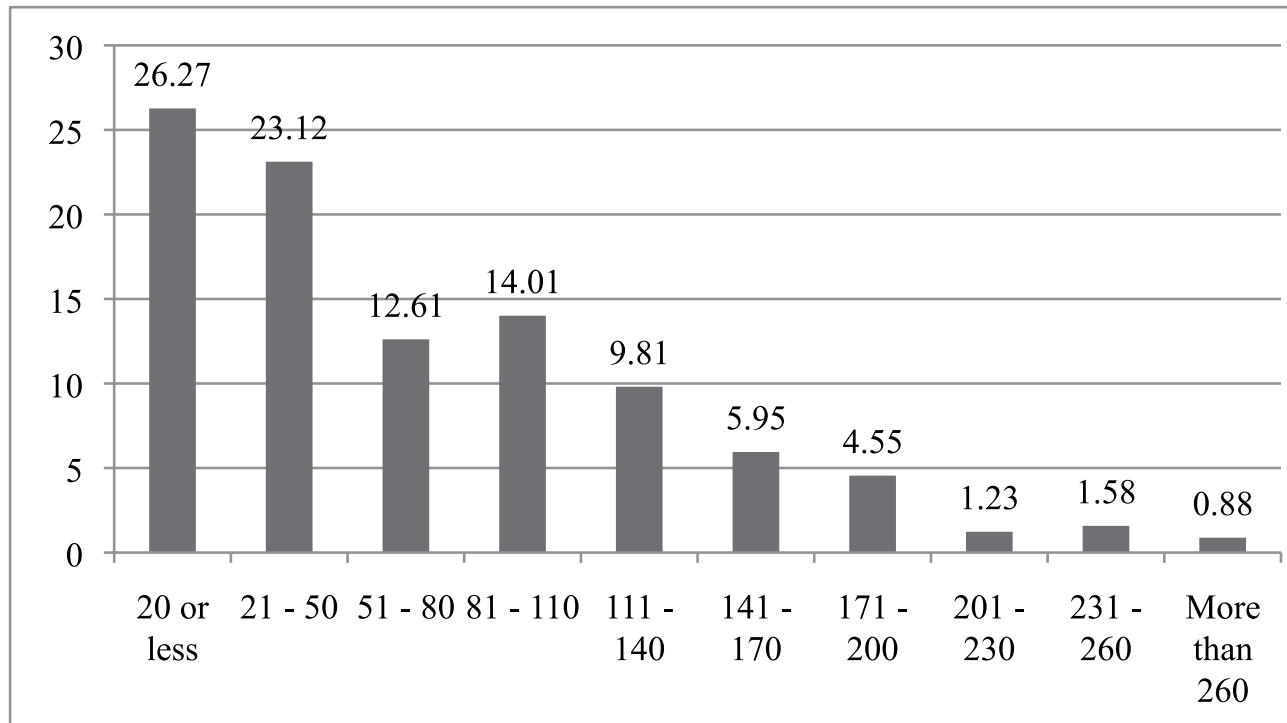

Chart 29: Shelter Space Index (X-Axis: Space in m2; Y-Axis: Percentage of Families), NBC Adjacent Area; Source: IDP and Returnee Database

Around $44 \%$ of the shelters contained 1 to 4 persons, with a mean of $5.53+/-3.07$ persons per shelter. As for crowdedness, the results showed that $26 \%$ of the residents are living in a space of $5 \mathrm{~m} 2 /$ person or less, and $19.6 \%$ live in a space between 6 to $10 \mathrm{~m} 2$ /person.

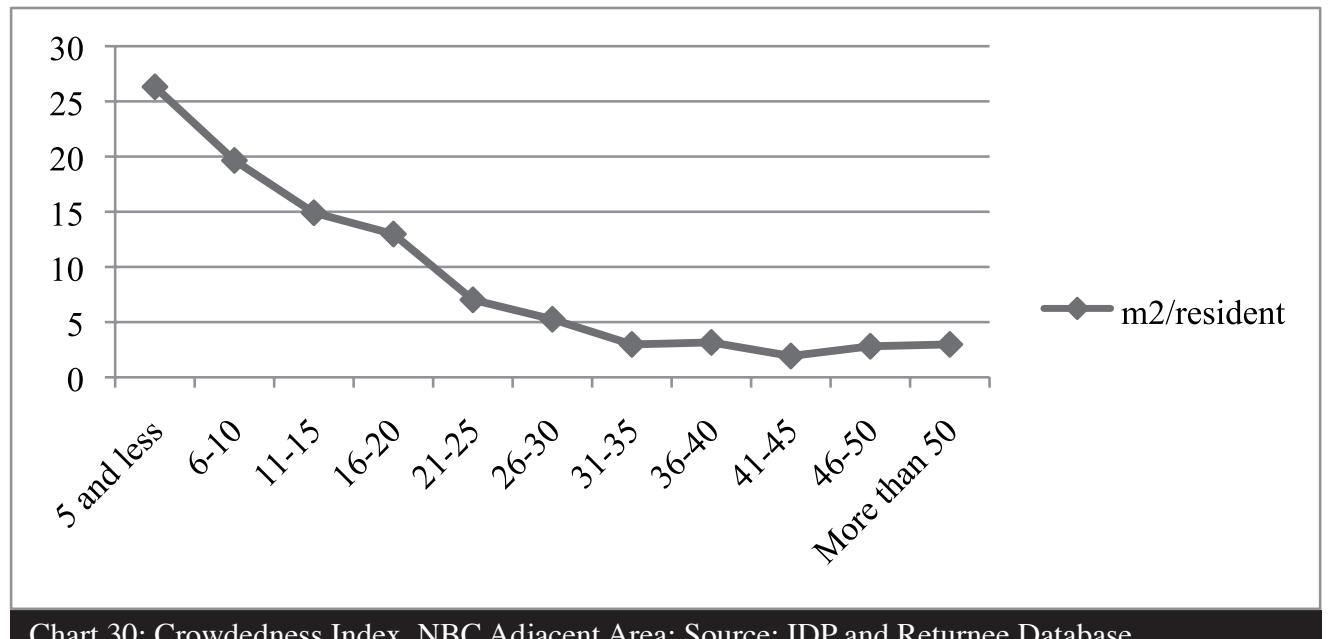

The following table resumes some of the indicators related to the overcrowding, where we can see that in average: 4.41 persons are sharing a bath, 5.38 persons are sharing a kitchen and 3.32 persons are sharing one bedroom.

\begin{tabular}{l|l|l|l} 
& Persons/bath & Persons/kitchen & Persons/bedroom \\
\hline Mean & 4.41 & 5.38 & 3.62 \\
\hline Median & 4 & 5 & 3.33 \\
\hline Std. Deviation & 2.42 & 3.00 & 1.95 \\
\hline
\end{tabular}

Table 6: Shelter Facilities Index, NBC Adjacent Area; Source: IDP \& Returnee Database 
The majority $(42.76 \%)$ considered they were living in a dwelling with average conditions (acceptable). $34.11 \%$ considered there shelter to be either of Bad or Very Bad condition, while a minority $(1.4 \%)$ considered there shelter to be of Very Good condition.

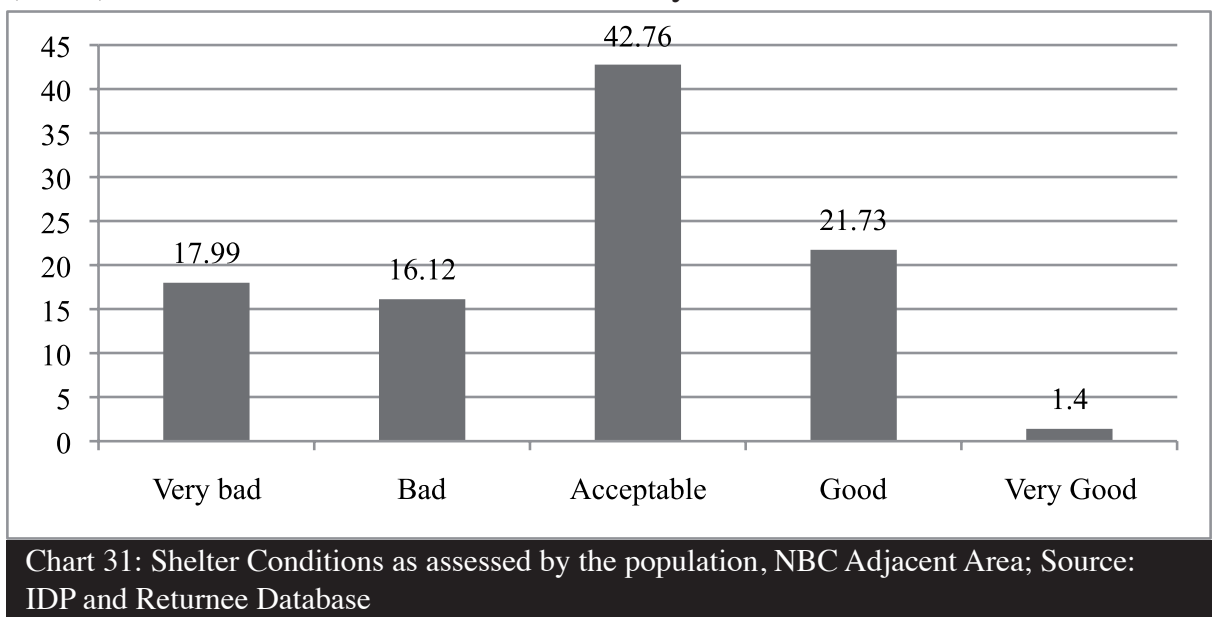

$84 \%$ of the surveyed population stated that they have received assistance in shelter repairs, while $16 \%$ stated that they did not receive any assistance. Also $54 \%$ of the surveyed population stated to have worked themselves on their own shelter.

The absence of some home furniture, necessary for daily life was remarkable at a significant percentage of the population; the most remarkable were: sitting room or salon furniture (60\%), beds $(71 \%)$ and refrigerators $(47 \%)$. While heaters were available in majority of the cases $(83 \%)$, and generally one piece was found per shelter. The majority works on gas consumption (95.5\% of cases).

Almost $80 \%$ didn't think they were living in a crowded shelter.

\section{Shelter Repairs}

The general inclination in shelter repairs done by NGOs is shown in the chart below and is mainly concentrated on windows and doors repairs; while self-assistance is mainly concentrated in fixing holes in walls and in roofs, as well as paint, power supply and sanitary infrastructure. Yet it is important to

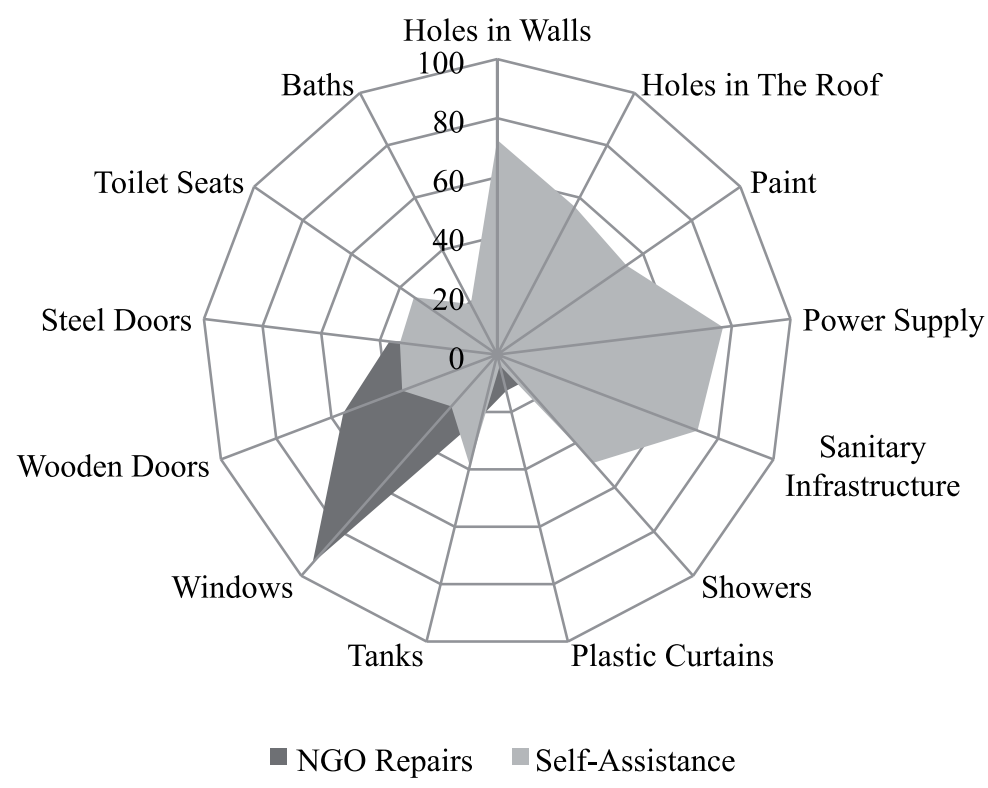

Chart 32: Shelter repairs inclination between NGOs and Self-Assistance, NBC Adjacent Area; Source: IDP and Returnee Database

mention that the chart below does not mention the volume and the size of these repairs, but constitutes an attempt to distinguish the repairs undertaken by NGOs and those undertaken by the families themselves. 


\section{Comparison of results between the three areas}

Considering the $\mathrm{m} 2$ /person index in all three major regions, we notice that crowdedness, varies between regions, in NBC adjacent area, the highest frequency of families being at $5 \mathrm{~m} 2$ and less per person $(26.32 \%)$, where as in other locations, the highest frequency is at 6 to $10 \mathrm{~m} 2$ per person $(27.94 \%$ for Jabal El-Beddawi and an obvious majority of $47.21 \%$ for Beddawi Camp). Thus clearly shows that the most crowded shelters are located in NBC (26.32\%), second is Jabal El-Beddawi at $21.73 \%$, and Beddawi Camp has the least crowdedness in comparison with only $10.88 \%$ of the population at less than $5 \mathrm{~m} 2$ per person.

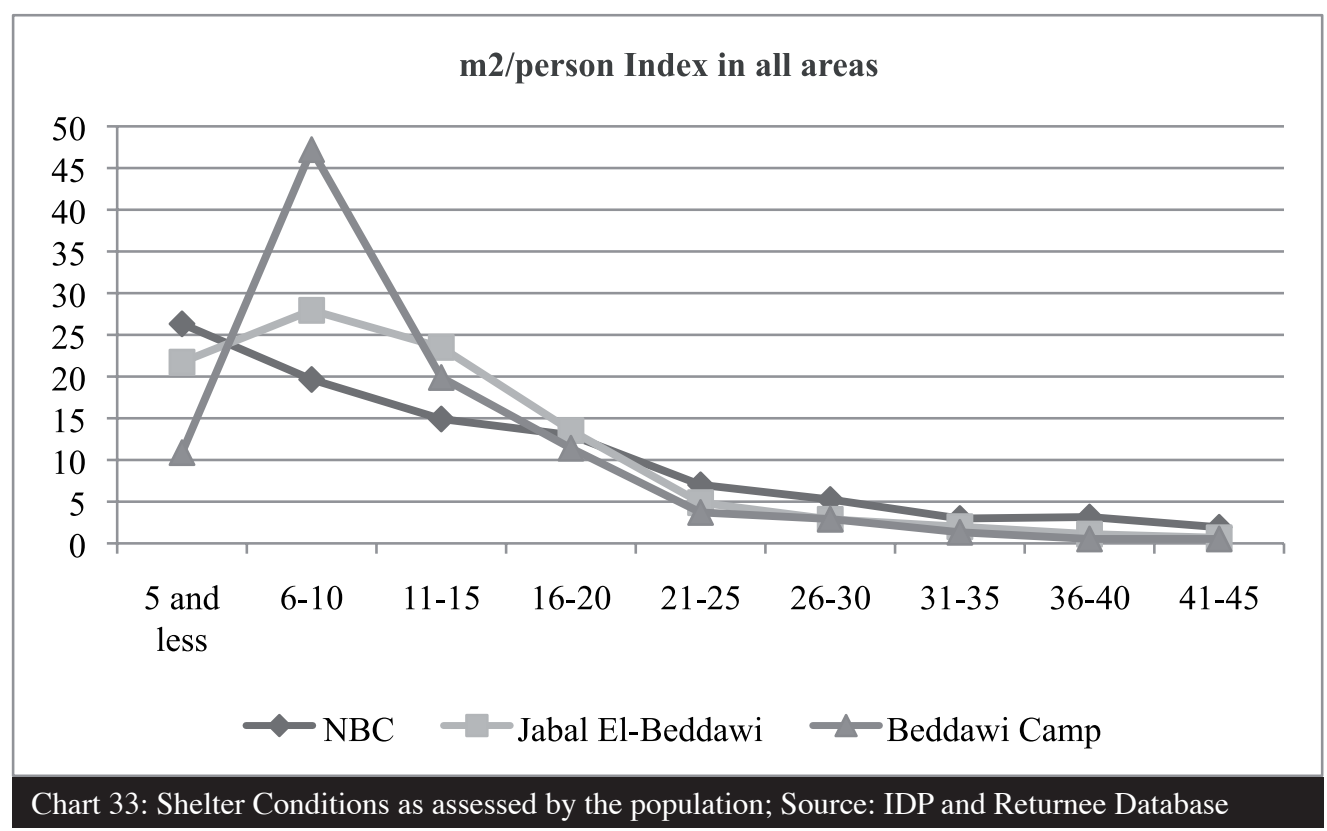

It is important to mention that in all regions fall below or equal to $10 \mathrm{~m} 2$ per person, $45.95 \%$ in NBC Adjacent Area, 49.67\% in Jabal El-Beddawi and 58.09\% at Beddawi Camp.

\begin{tabular}{|l|l|l|l|}
\hline m2/person & NBC & Jabal El-Beddawi & Beddawi Camp \\
\hline 5 and less & 26.32 & 21.73 & 10.88 \\
\hline $6-10$ & 19.65 & 27.94 & 47.21 \\
\hline $11-15$ & 14.91 & 23.5 & 19.89 \\
\hline $16-20$ & 12.98 & 13.53 & 11.41 \\
\hline $21-25$ & 7.02 & 4.88 & 3.71 \\
\hline $26-30$ & 5.26 & 2.88 & 2.92 \\
\hline $31-35$ & 2.98 & 2 & 1.33 \\
\hline $36-40$ & 3.16 & 1.11 & 0.53 \\
\hline $41-45$ & 1.93 & 0.67 & 0.53 \\
\hline Table 7: Crowdedness Index in all regions; Source: IDP \& Returnee Database & \\
\hline
\end{tabular}

Comparing between the mean values of the persons per room, persons per bathroom and persons per kitchen indicators in all regions, it appears that the biggest discrepancy falls mainly within the persons per kitchen indicator. Where as in NBC Adjacent Area, the rate is 5.38 persons per kitchen, while in Jabal El-Beddawi and Beddawi Camp it reaches 9.59 and 8.47 persons per kitchen respectively. 
The persons per bathroom indicator shows the second largest discrepancy, with the rate in NBC Adjacent area being 4.41 persons per bathroom, while in Jabal El-Beddawi it reaches 7.98 persons per Bathroom and 6.25 persons per bathroom in Beddawi Camp.

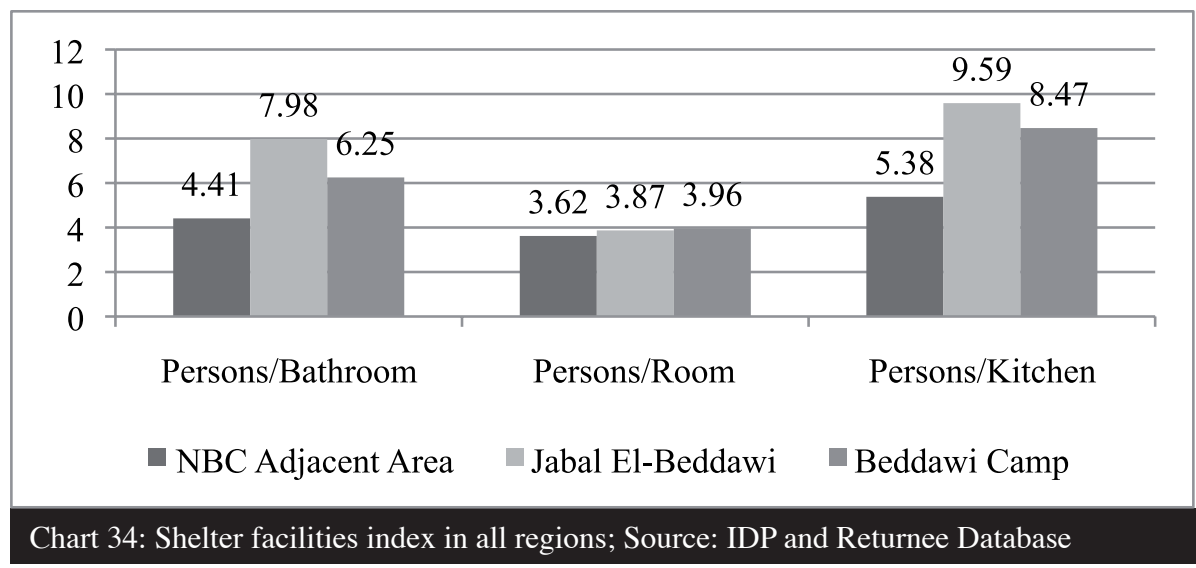

The persons per room indicator seems stable across regions, 3.62 persons per room in NBC Adjacent Area, with a 3.87 and 3.96 persons per bathroom in Jabal El-Beddawi and Beddawi Camp respectively. By comparing the type of shelter people have occupied in all regions, we can have an overall view of the urban structure of these areas, noticing that Houses are more frequent in Beddawi camp $(61,12 \%)$ where as in NBC Adjacent Area, are less frequent (22.72\%) and almost inexistent in Jabal El-Beddawi $(0.31 \%)$. Apartments are most frequent in Jabal El-Beddawi at $70.08 \%$, second in NBC Adjacent Area at $39.31 \%$ and at $34.79 \%$ in Beddawi Camp.

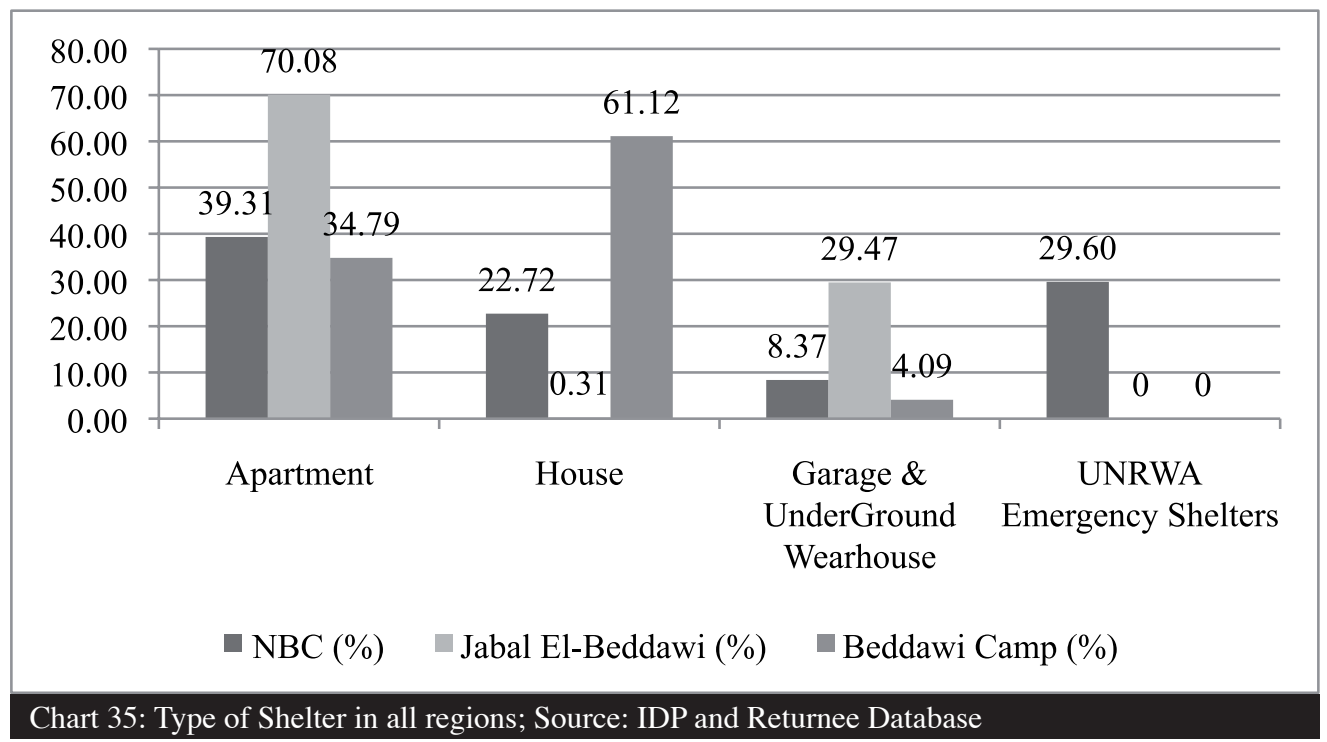

The use of garages and underground warehouses as shelters is mostly common in Jabal El-Beddawi as $29.47 \%$ of NBC IDPs occupy garages and underground warehouses, compared to $8.37 \%$ in NBC Adjacent Area and $4.09 \%$ in Beddawi Camp. 


\section{VII- State of Services}

\section{NBC IDPs in Beddawi Camp}

\section{Electricity:}
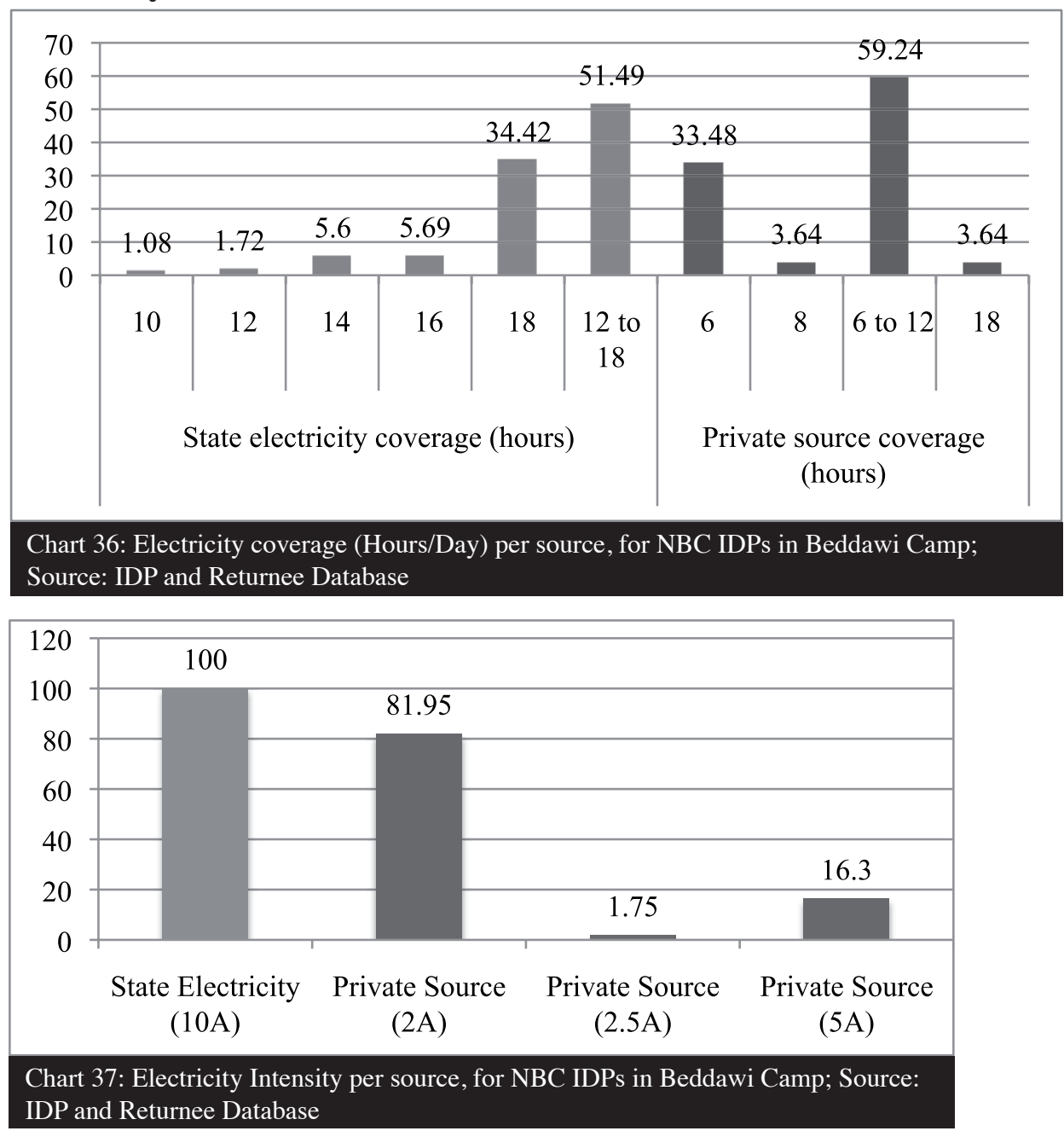

State electricity coverage is between 12 to 18 hours a day for $51.49 \%$ of the cases, which means for these cases, that electricity is cut-off round 6 to 12 hours a day, and in line with these trends, the private source coverage is 6 to 12 hours a day for $59.24 \%$ of the cases.

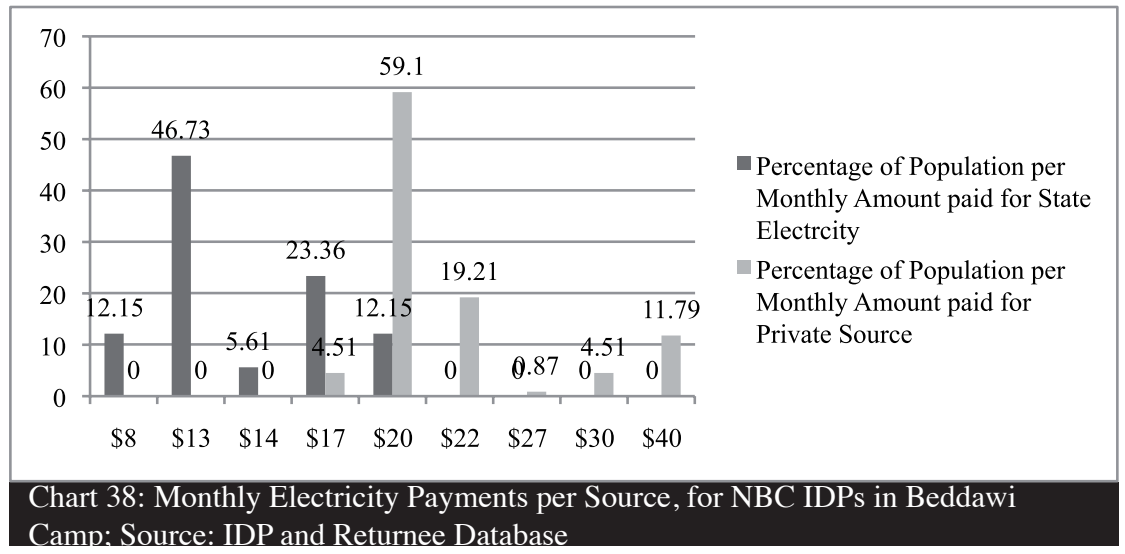

The totality $(100 \%)$ of the respondents said they are receiving 10A intensity from the state electricity, while in terms of private sources, the majority ( $82 \%$ ) benefit only from 2 A intensity. 
The amount paid for the state electricity varies from a minimum of $8 \$ /$ Month to a maximum of $20 \$$ per month while the amount paid for the private source electricity starts at $17 \$ /$ month with a majority (59\%) paying $20 \$ /$ month.

\section{Water:}

The results showed that water coverage is ensured for 6 hours per day for almost three quarter of cases $(73.62 \%)$, while $26.38 \%$ of cases have a 4 hour per day water coverage.

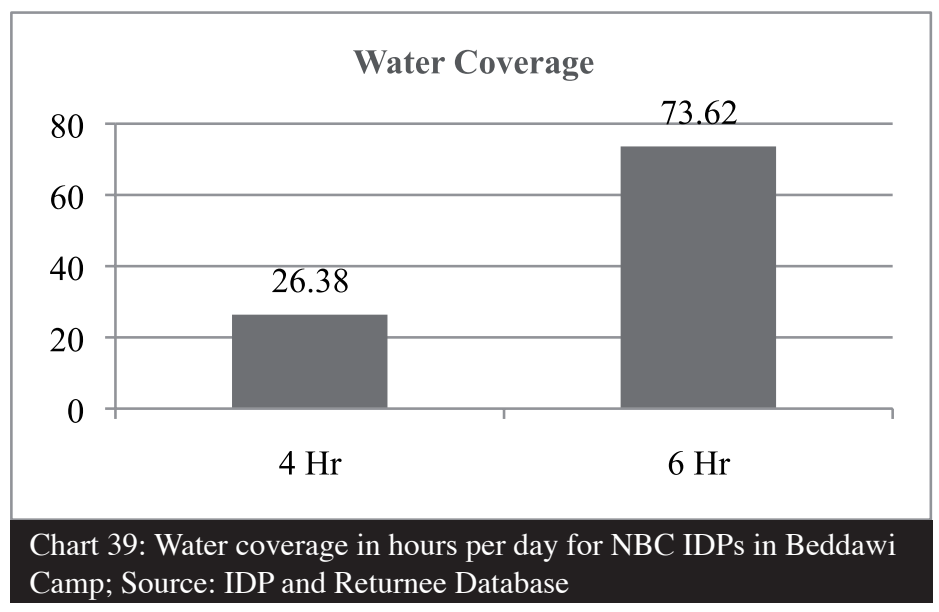

The capacity of water tanks varies from a minimum of 100 Liters to a maximum of 2000 Liters. Half of the respondent families stated that they are using tanks of more than 1000 Liters capacity.

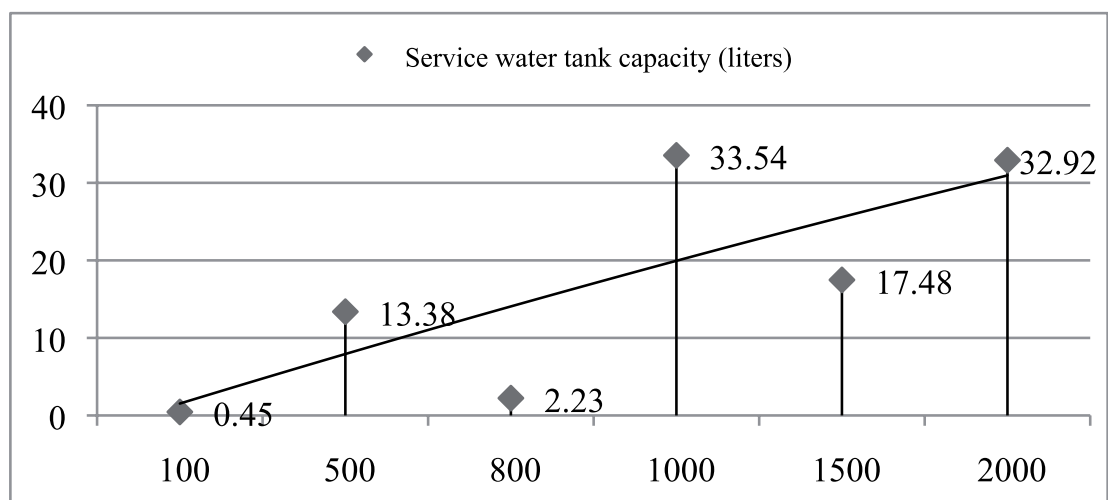

Chart 40: Water Tanks Capacity for NBC IDPs in Beddawi Camp; Source: IDP and Returnee Database 
Service water coonsumption varies from 300 to 2000 Liters per day and for the majority of families $(40.59 \%)$ it is at 1000 Liters per day.

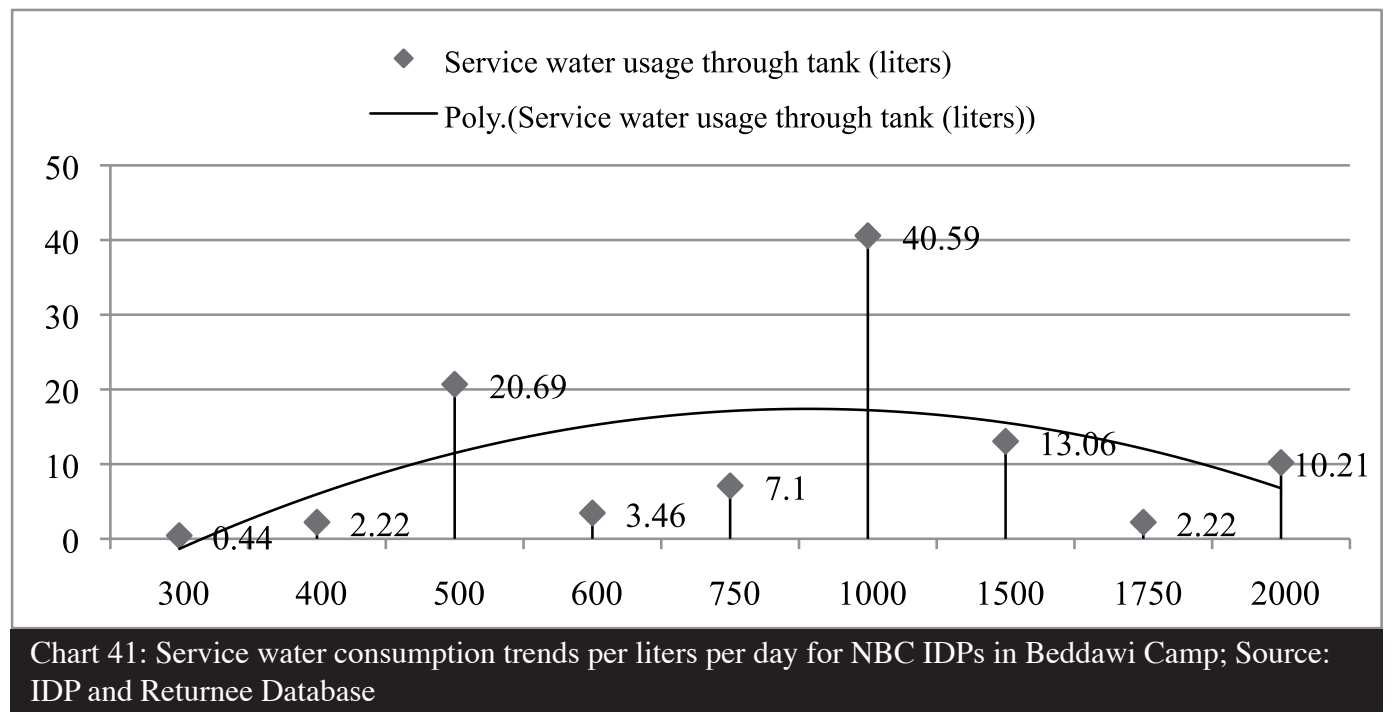

As the following chart clearly shows, drinking water is provided from only two sources that are equally represented. For $51 \%$ of the families, drinking water is provided through the UNRWA water network, while $49 \%$ buy their drinking water.

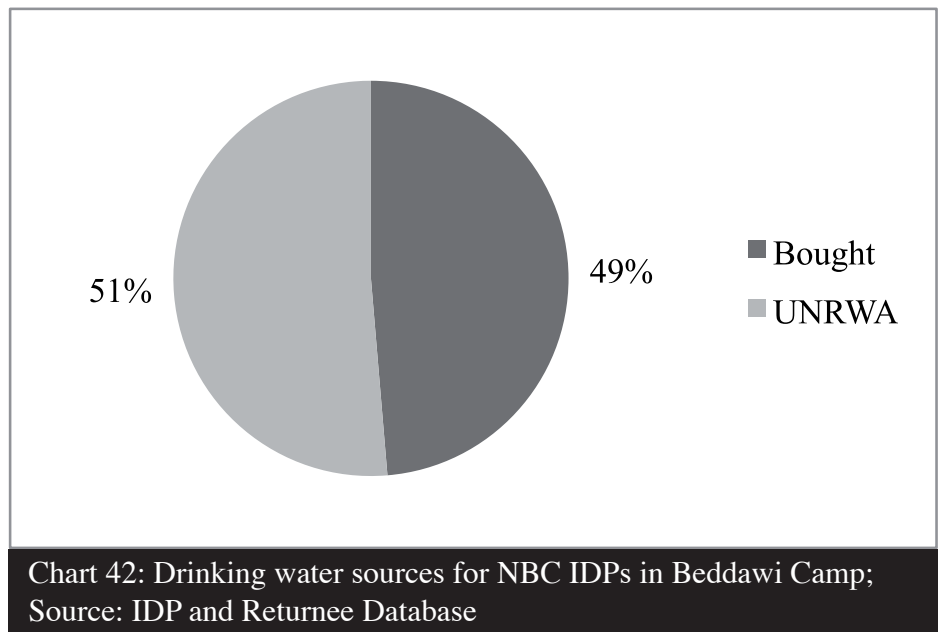

The majority (37.06\%) of families said they consume around 16 to 20 liters of drinking water per day, with an average consumption of 16.83 liters per day.

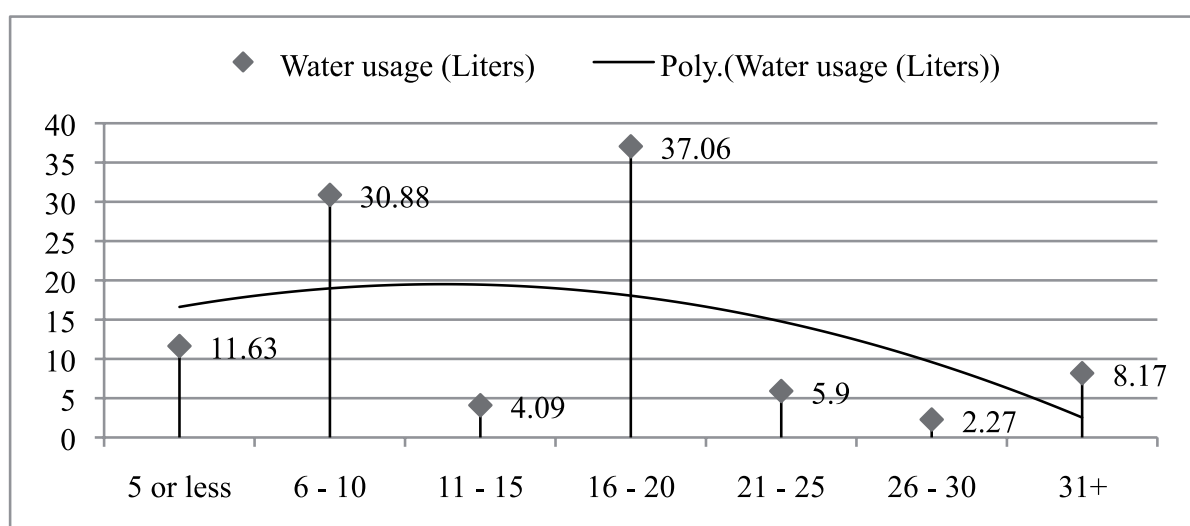




\section{NBC IDPs in Jabal El-Beddawi}

\section{Electricity:}

State electricity coverage for $50 \%$ of families is around 16 hours per day, which means that for these cases, the electricity is off for around 8 hours per day, while for three quarters of the families (73.4\%), the private electricity source covers around 6 hours per day and not 8 .

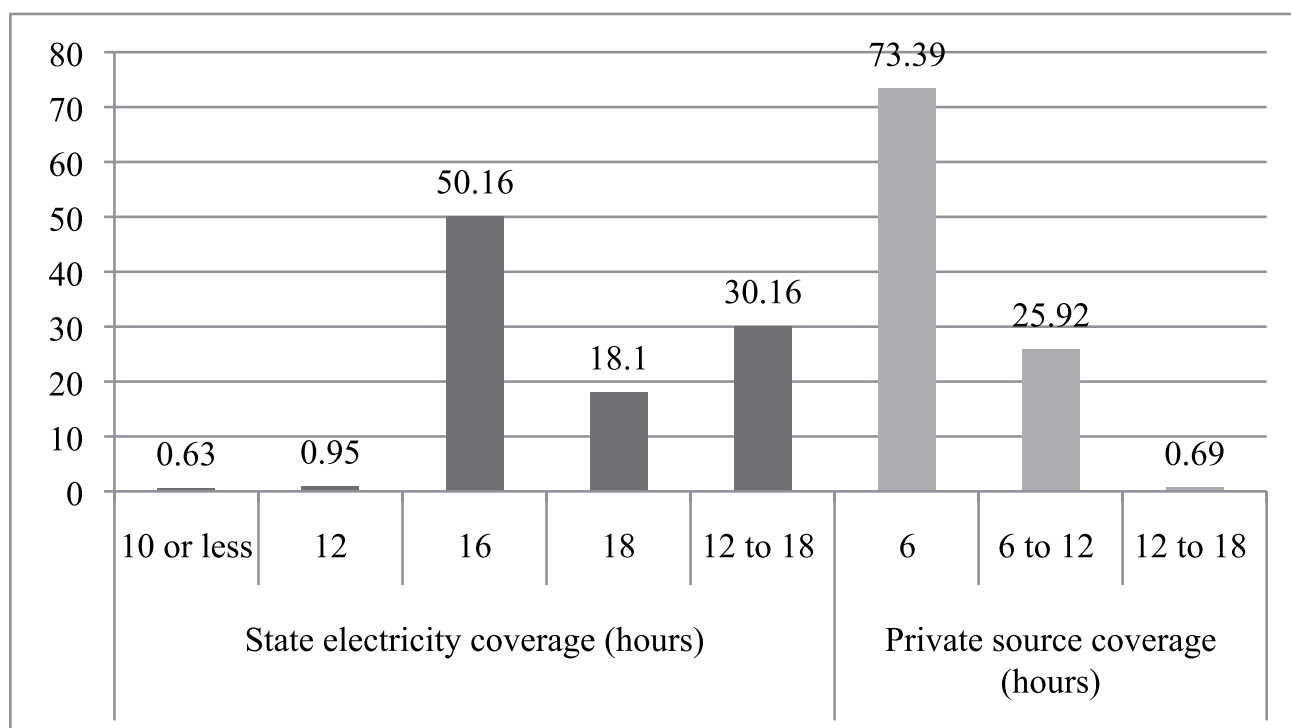

Chart 44: Electricity Coverage per day per source of electricity for NBC IDPs in Jabal El-Beddawi; Source: IDP and Returnee Database

The majority $(82.5 \%)$ is benefiting from $10 \mathrm{~A}$ intensity via state electricity, on the other hand, the majority $(68.5 \%)$ are benefiting from only 1 to $2 \mathrm{~A}$ via private electricity sources.

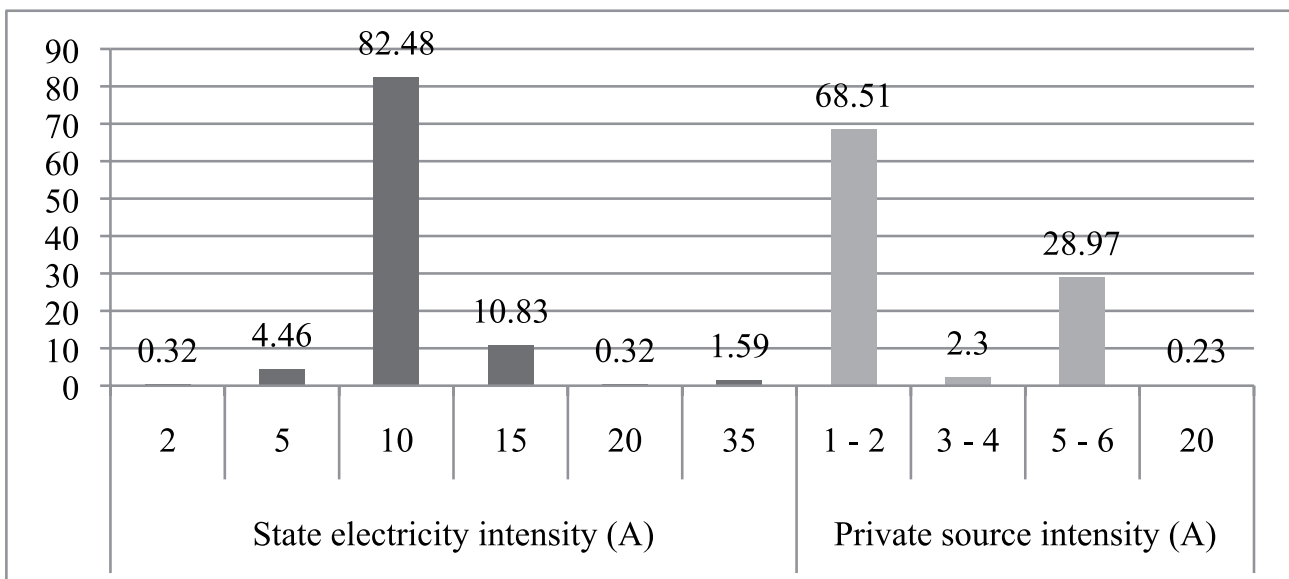

Chart 45: Electricity intensity per source of electricity for NBC IDPs in Jabal El-Beddawi; Source: IDP and Returnee Database

The amount paid for the state electricity seems to be higher than the one paid for the private electricity source, which can be explained due that the coverage in terms of hours and intensity of the state electricity are more advantageous than the private electricity source. The following figure summarizes the differences in amounts paid per month between the two sources. 


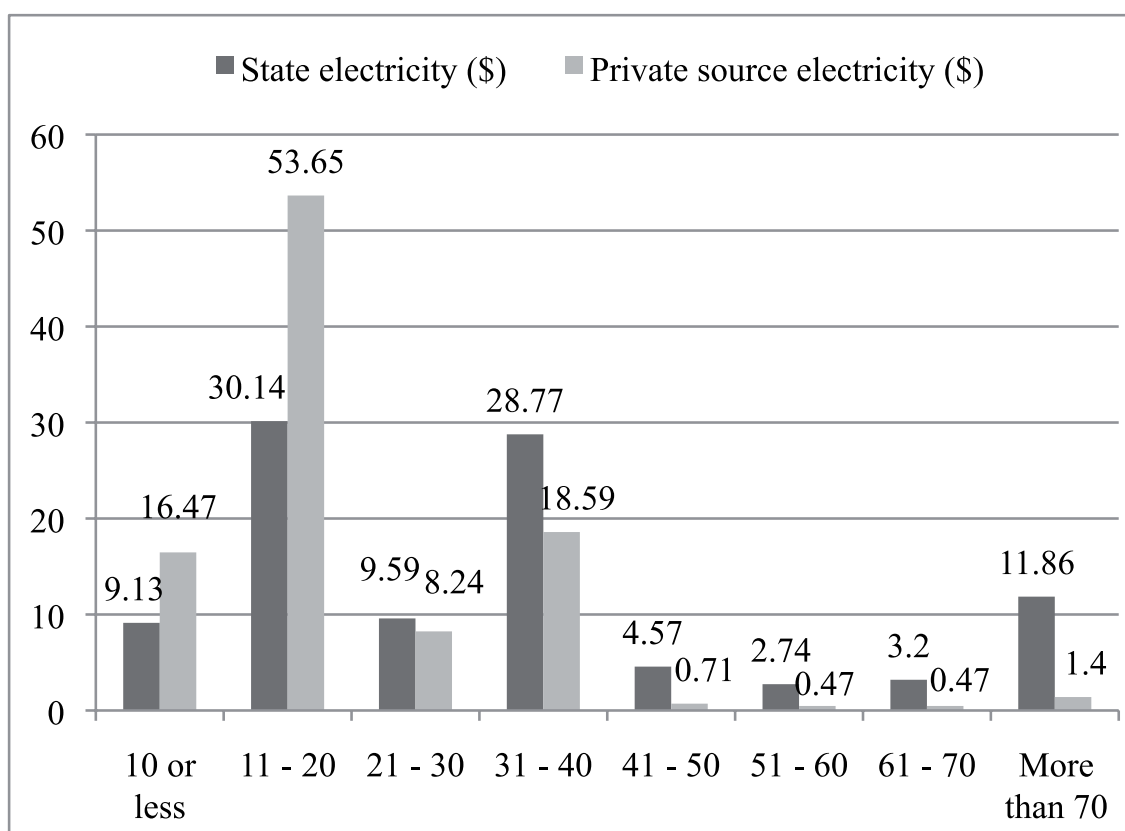

Chart 46: Monthly Electricity Payments per Source for NBC IDPs in Jabal El-Beddawi; Source: IDP and Returnee Database

\section{Water:}

Service water coverage for majority of the cases $(47.39 \%)$ is 2 to 6 hours per day, but half of the respondents were receiving water for more than 12 hours per day.

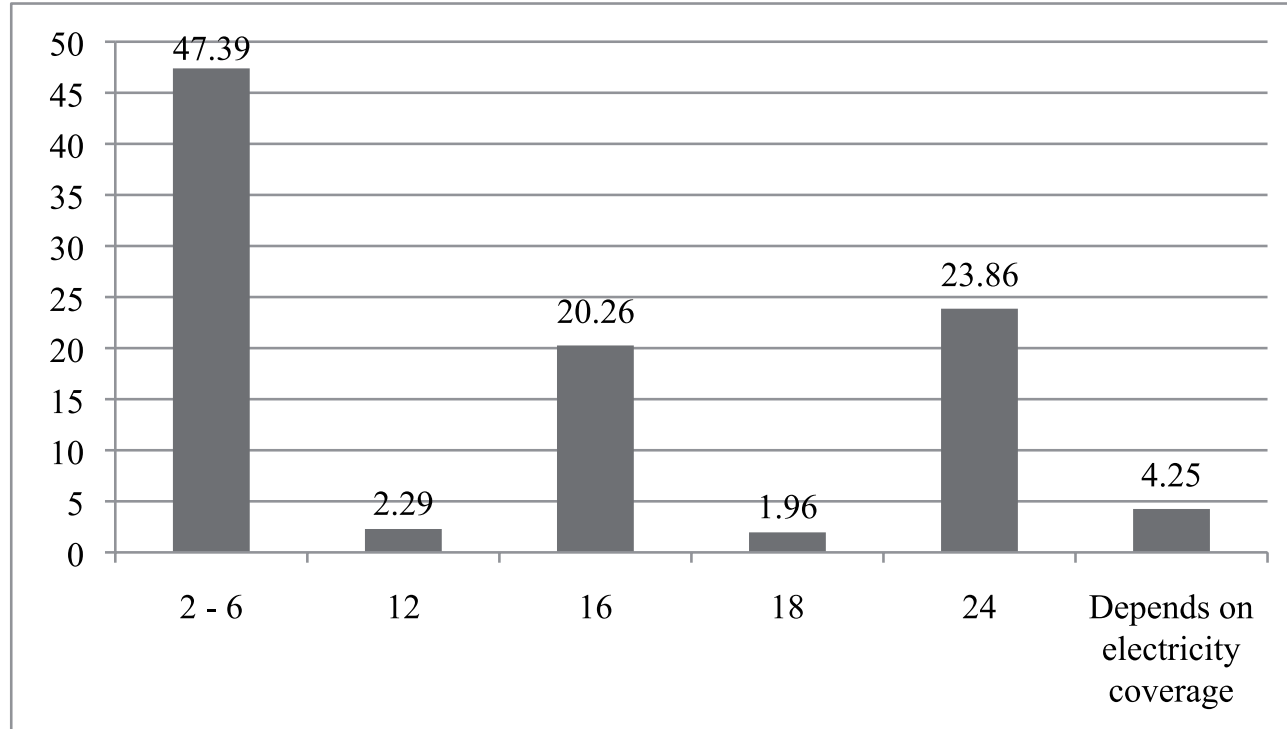

Chart 47: Water coverage in hours per day for NBC IDPs in Jabal El-Beddawi; Source: IDP and Returnee Database

The capacity of water tanks is of 3000 Liters for half of cases (49.34\%), while $33.4 \%$ have water tanks with a capacity less than 3000 Liters, and $17.26 \%$ have water tank with a capacity higher than 3000 Liters. 


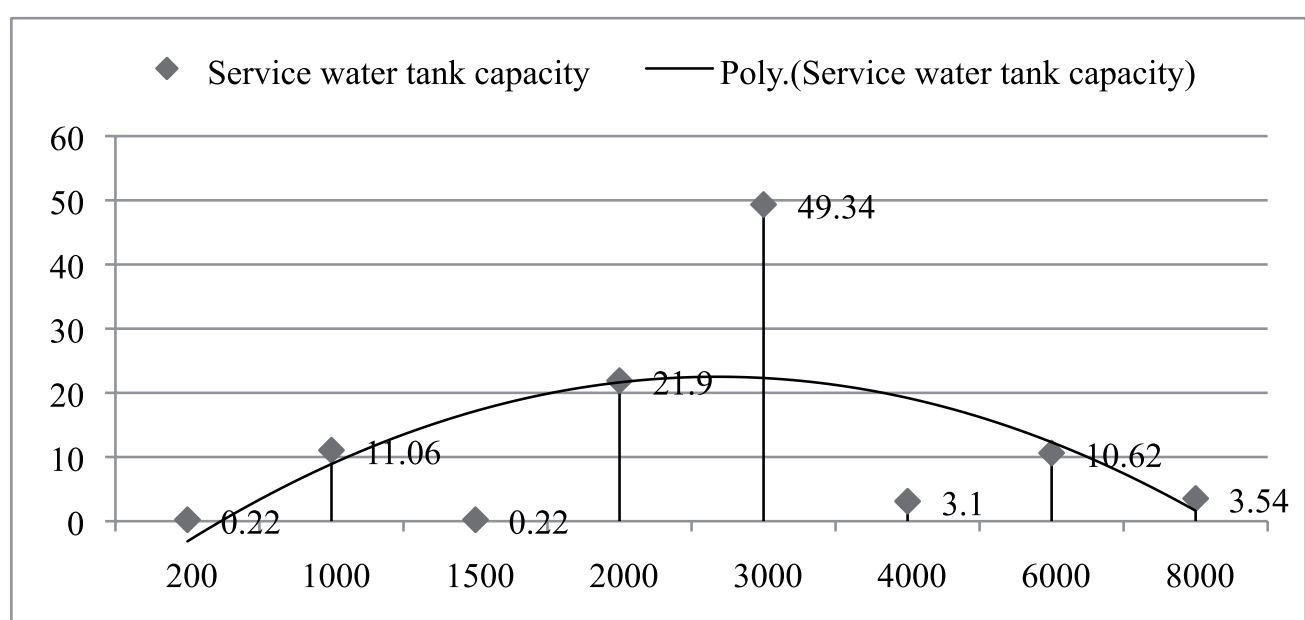

Chart 48: Service Water Tanks' Capacity for NBC IDPs in Jabal El-Beddawi; Source: IDP and

Returnee Database

Service water consumption is for the majority of families (38\%) at 201 to 500 Liters/day.

And around 39\% of the respondents said they consume more than 500 Liters/day.

Drinking water, as per the response of the majority (41.8\%) of the interviewed families, was

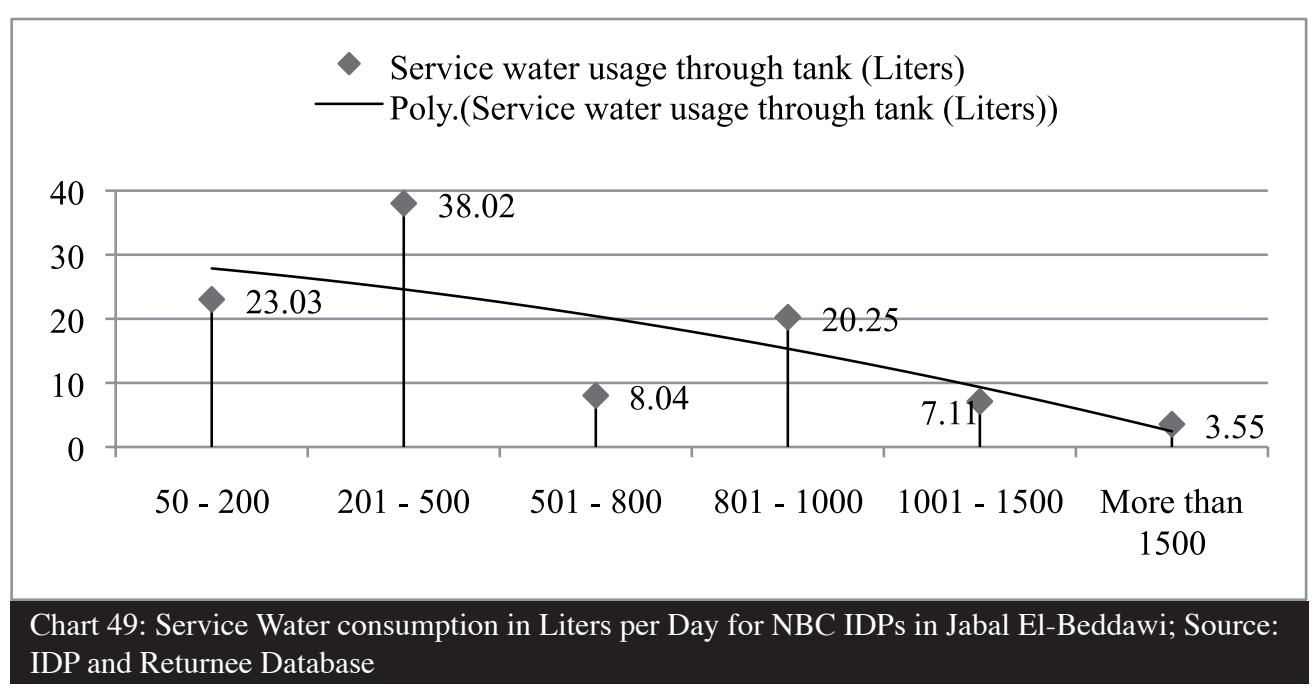

bought, where as $32.9 \%$ declared that their drinking water needs are provided through the UNRWA tanks, and a small minority $(0.61 \%)$ stated they were getting drinking water from other sources.

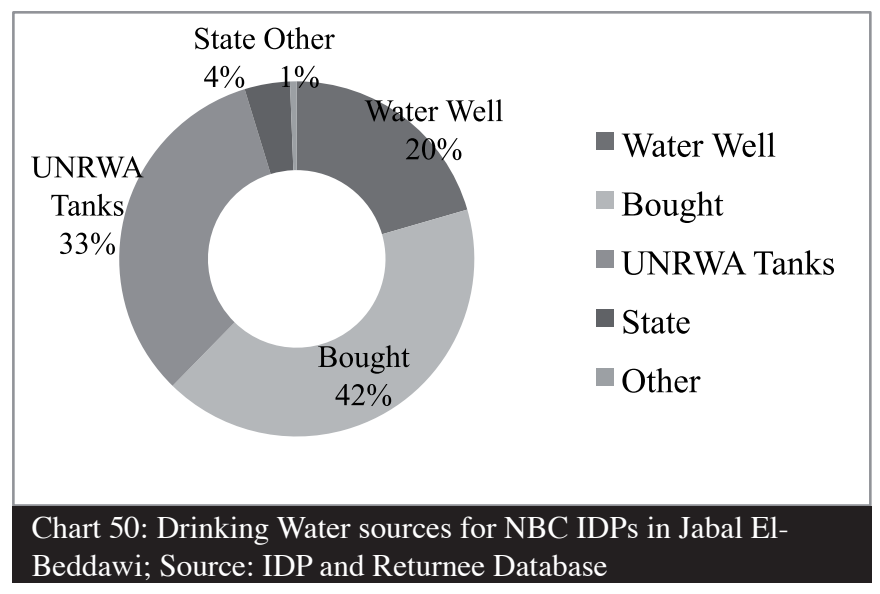




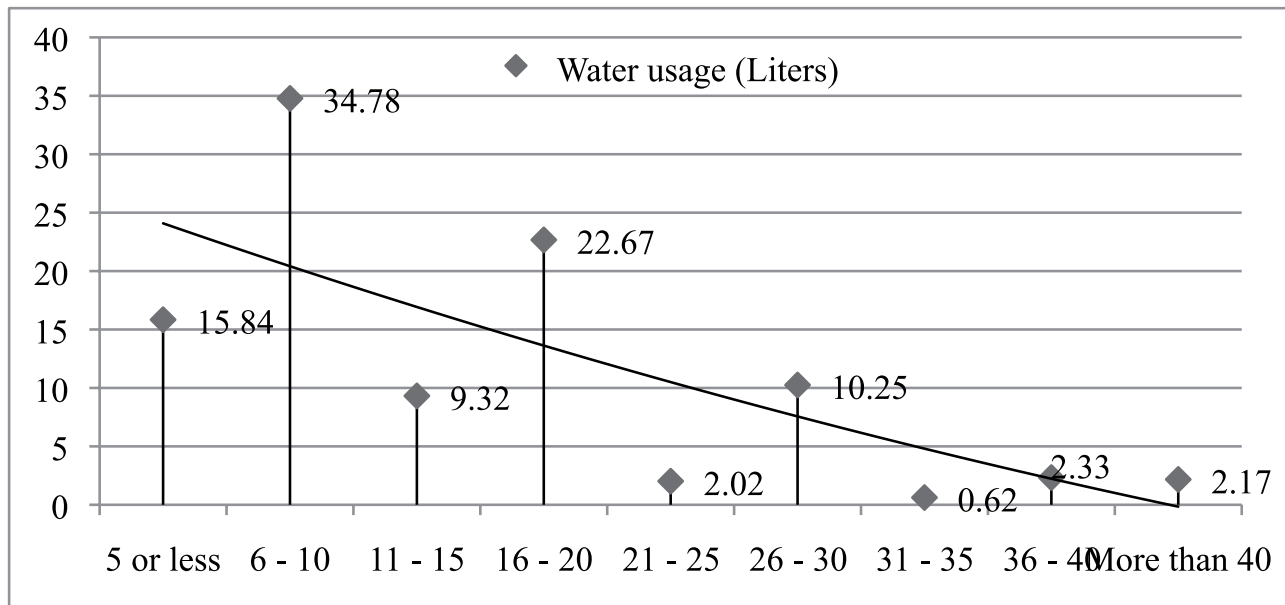

Chart 51: Drinking Water consumption per family per day for NBC IDPs in Jabal El-Beddawi; Source: IDP and Returnee Database

The majority of families (34.78\%) said they consume around 6 to 10 liters of drinking water per day, but a $47.38 \%$ of interviewed families stated that they consume more than 10 Liters per day. 


\section{Returnees and Semi-Returnees in NBC Adjacent Area}

\section{Electricity}

Two main networks, the EDL (Electricite Du Liban) or the State Electricity network and the UNRWA temporary electricity provision characterize electricity in NBC Adjacent Area at the time of the survey. This situation was forced by the destruction of pre-war electricity provision networks, in addition to a process of regularization that is being undertaken in all shelters in the camp with regard to electricity connections.

Electricity reception in NBC Adjacent Area is at a 90\% rate while only $10 \%$ of the population declared having no electricity; as for the electricity sources, 57.23\% of the population declared receiving electricity through the State's Electricity (EDL), while $41.56 \%$ declared receiving electricity through the UNRWA network, and only $1.21 \%$ declared receiving electricity from private sources.

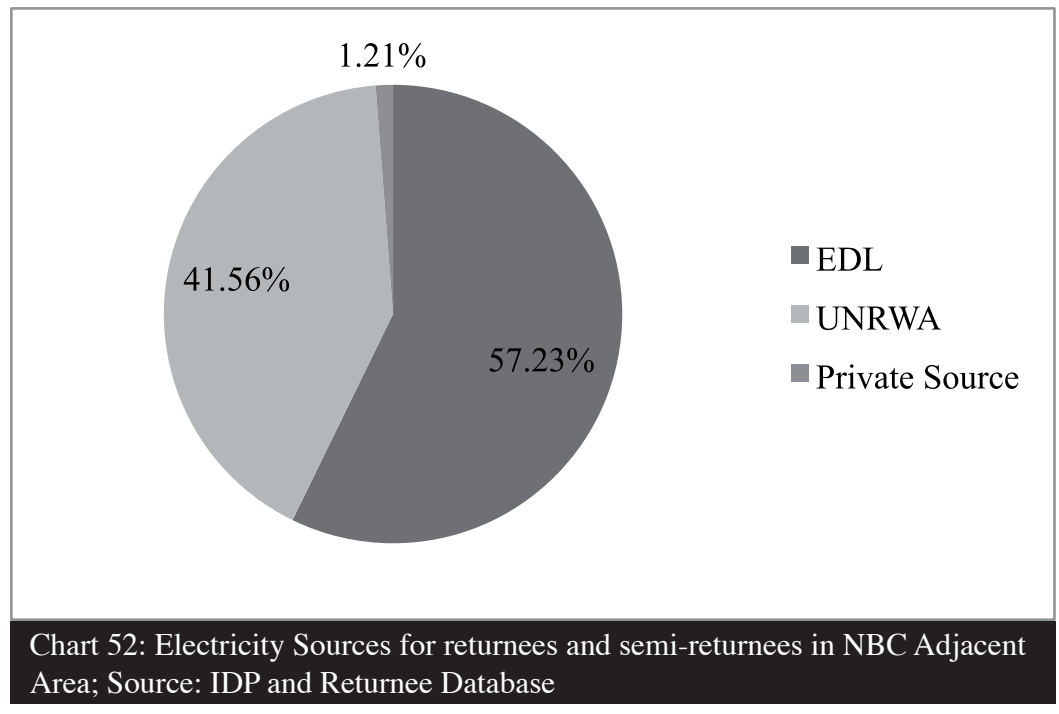

As for electricity coverage, most of the population receiving electricity through the UNRWA network, receive a 8 hours per day coverage, while people who are receiving electricity from EDL, receive about a 12 hour per day coverage with very few exceptions in both cases.

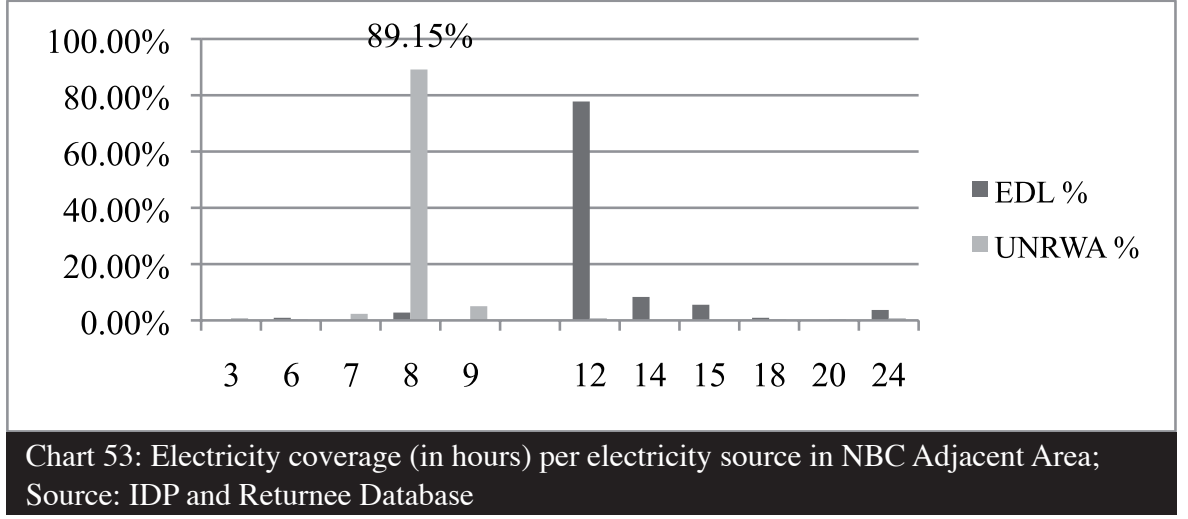


$58.33 \%$ of the population receives $15 \mathrm{~A}$ intensity via the EDL network, and $28.70 \%$ receive $10 \mathrm{~A}$ intensity, while only $7.41 \%$ receive $20 \mathrm{~A}$ intensity, and as for the UNRWA coverage intensity it is at a fixed number, which is $2 \mathrm{~A}$ per household.

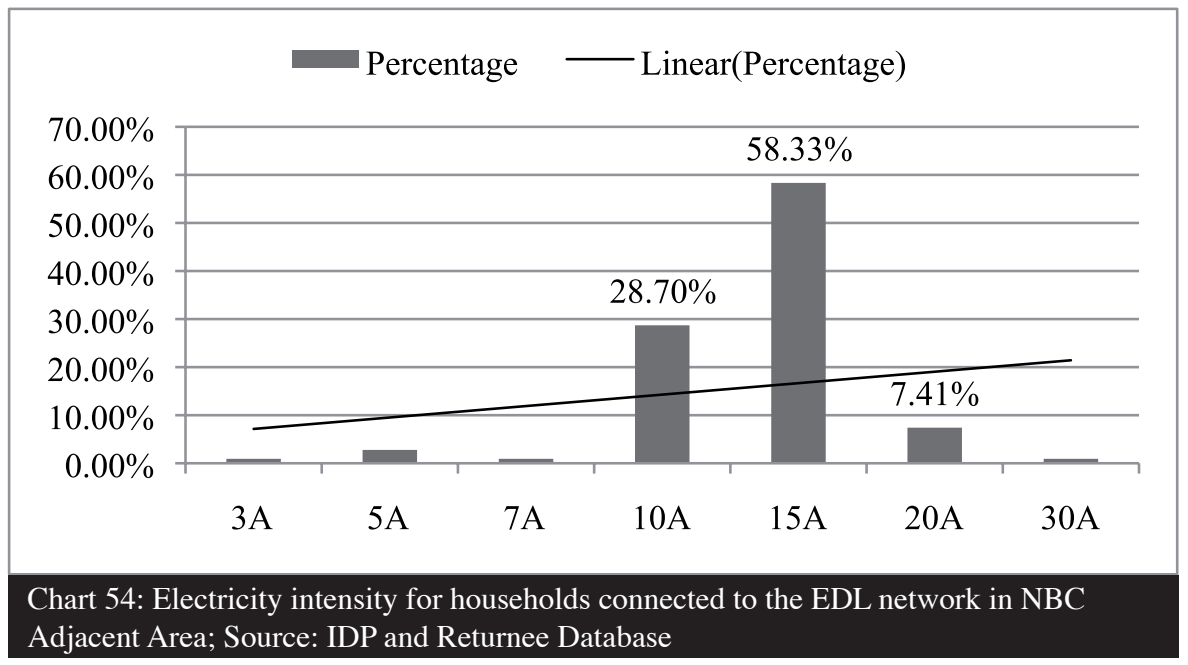

$56 \%$ of the population receiving electricity stated that they have an electricity meter installed, while $44 \%$ said they do no have one installed.

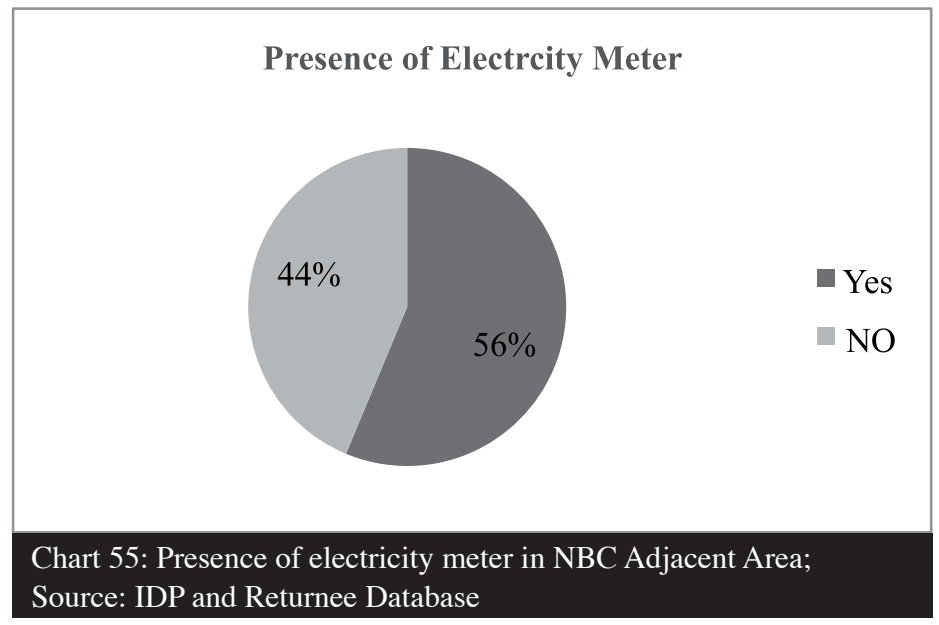

$92.82 \%$ of those who do not have an electricity meter installed, stated that the reason they do not have an electricity meter is that they are currently receiving electricity from UNRWA, while $4.52 \%$ stated that they are planning to install one soon, and $2.66 \%$ stated that the reason they do not have one installed is because it is of a high price.

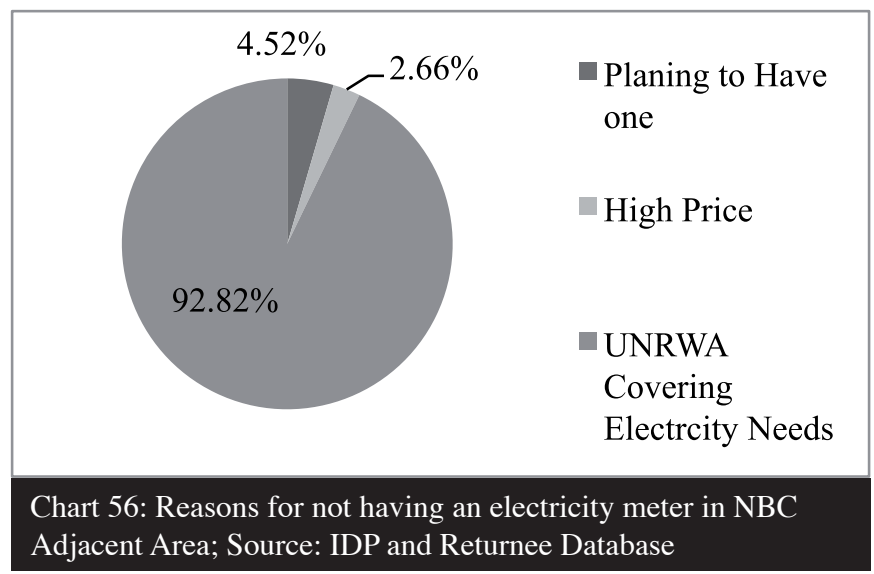


$43.52 \%$ of the population pay a monthly bill for electricity between 31,000 LBP and 75,000 LBP, while $12.04 \%$ pay between 76,000 LBP and 100,000 LBP and $26.86 \%$ pay a monthly bill above 100,000 LBP for electricity and $17.59 \%$ pay a monthly bill below or equal to 30,000 LBP.

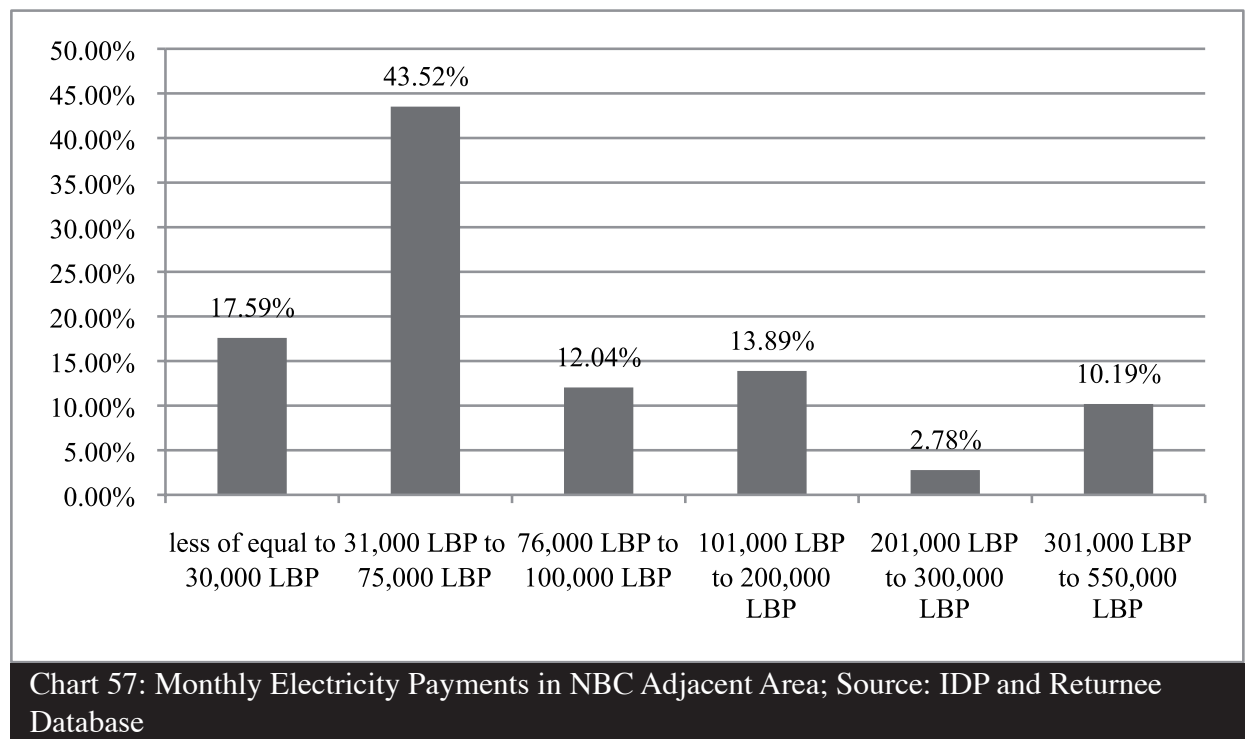

\section{Water:}

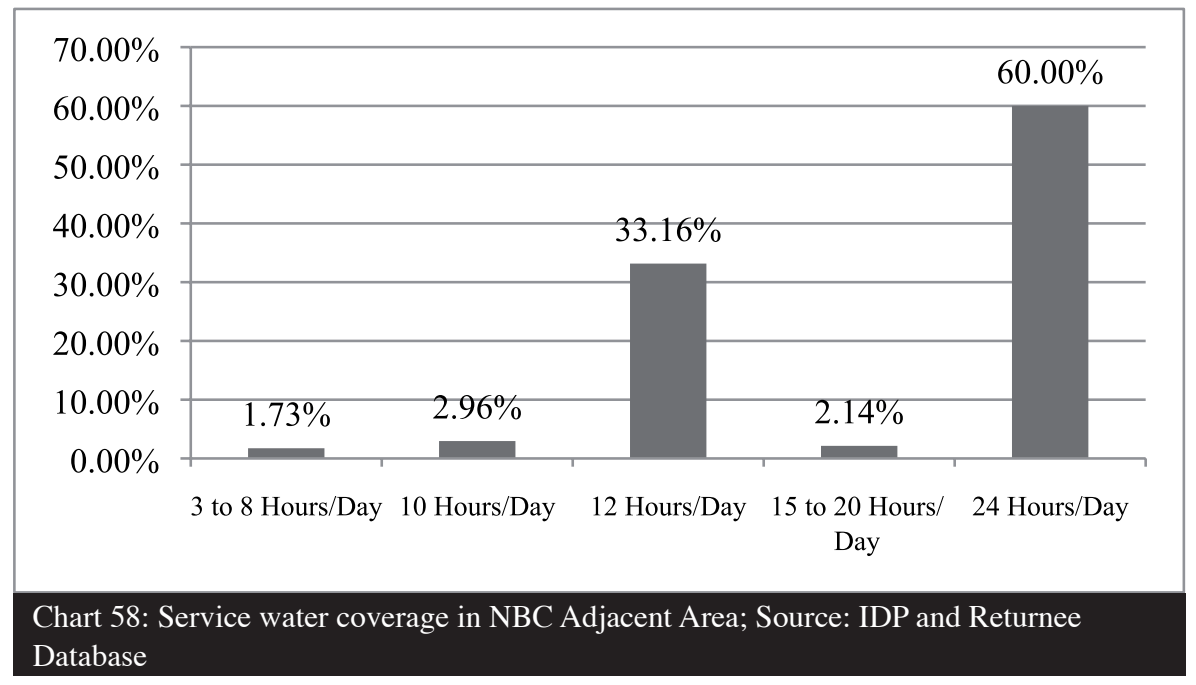

Service water coverage in NBC adjacent area is at 24Hours/Day for $60 \%$ of the population, while $33.16 \%$ stated that they receive water for 12 Hours/Day, while $4.69 \%$ stated that they receive water for 10 Hours/Day or less, and $2.41 \%$ receive water between 15 to 20 Hours/Day As for service water sources, $89 \%$ of the population stated that their water source is the UN- 
RWA water Network, while $1 \%$ relies mainly on water tanks, and 5\% relied both the UNRWA water network in addition to other sources.

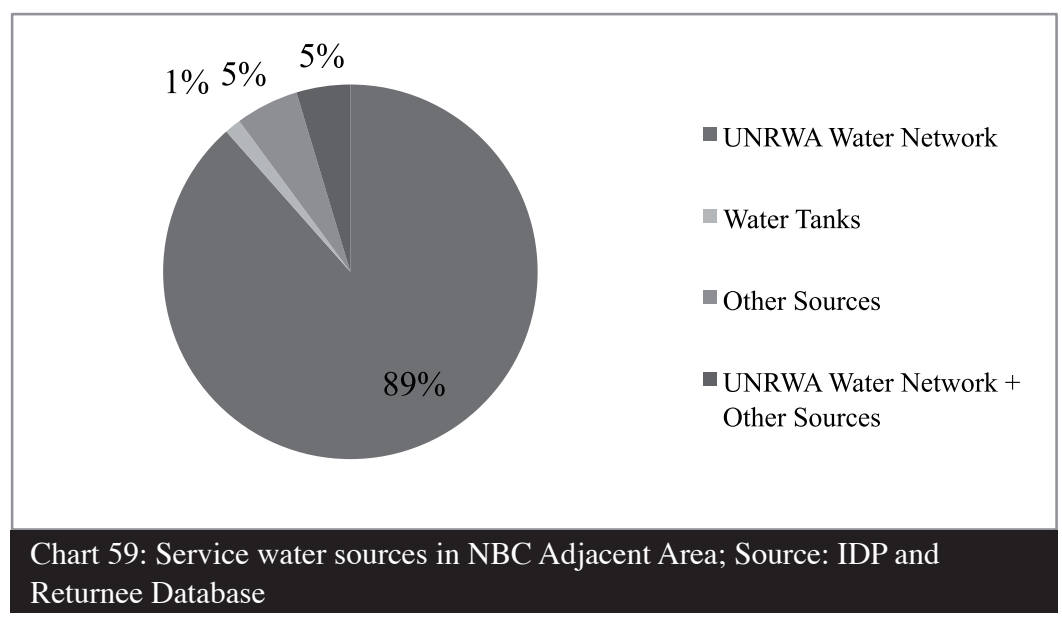

$55 \%$ of the population rely mainly on the UNRWA water network for their drinking water, while $44 \%$ use both the UNRWA water network and other sources, other sources mainly meaning water which is bought from retail shops in the area.

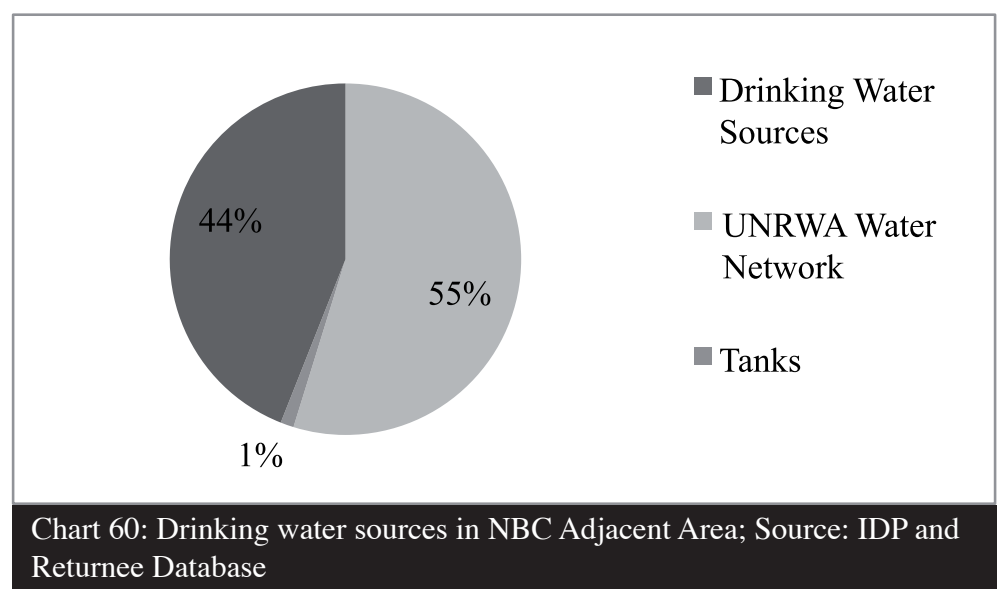

Consumption trends for service water show that $23.96 \%$ of families consume between 150 to 300 Liters per day, while $36.91 \%$ consume between 400 to 750 Liters per day, and around $30.43 \%$ consume more than 800 Liters per day.

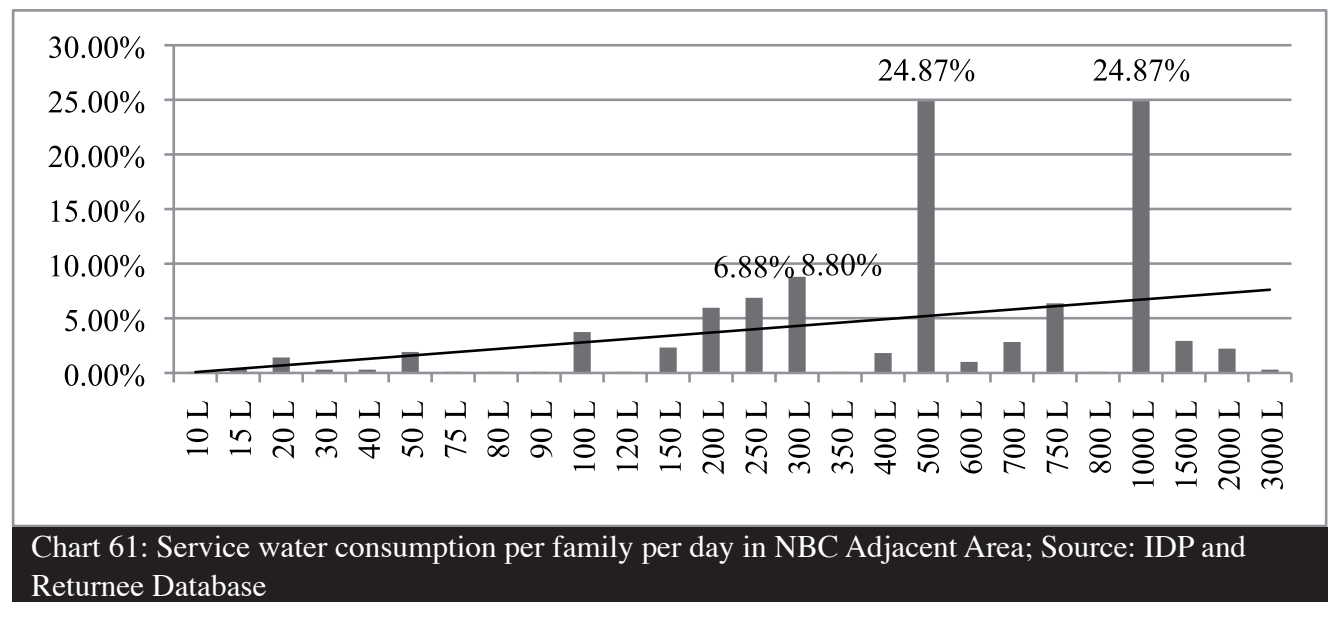




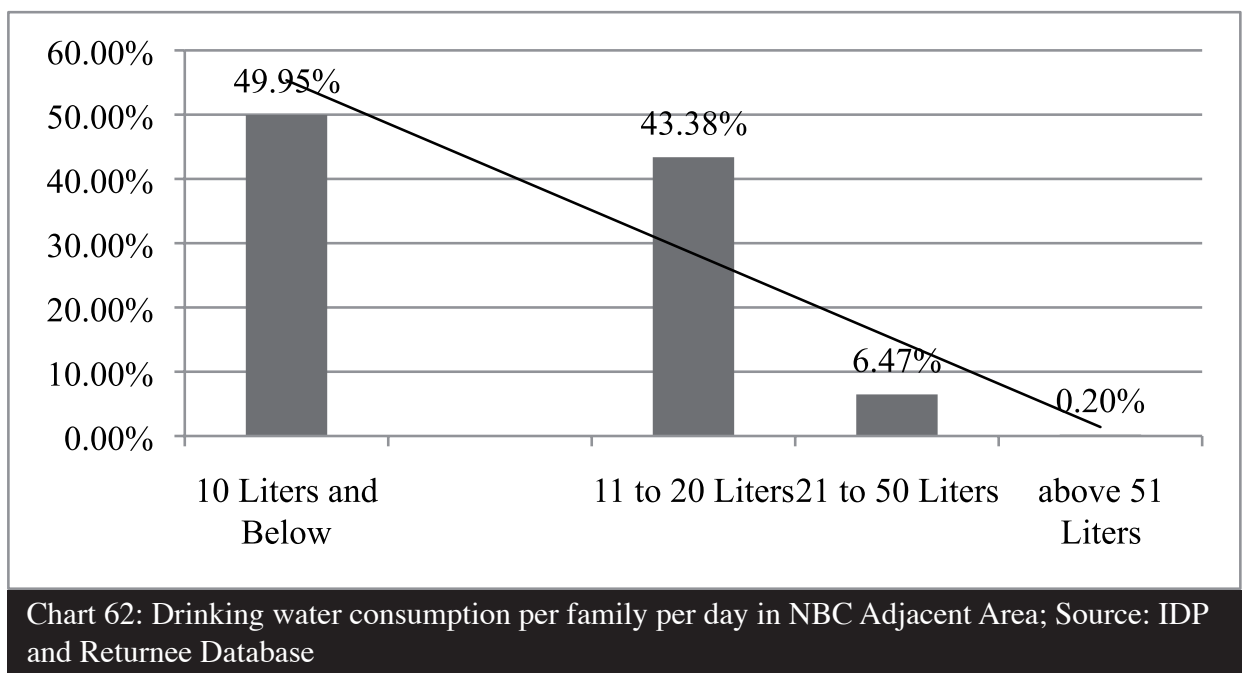

As for drinking water, $49.95 \%$ of the population stated that they consume about 10 Liters/ day or below, while $43.38 \%$ consume between 11 to 20 Liters per day, and $6.47 \%$ consume between 21 to 50 Liters per day, and a $0.20 \%$ consume above 51 Liters per day. 


\section{Comparison of Results}

Electricity coverage between NBC Adjacent Area, Jabal El-Beddawi and Beddawi Camp differ in coverage, as the concentration of coverage for the majority of IDPs in Jabal El-Beddawi is between 10 to 12 hours per day, while for both Beddawi Camp and NBC Adjacent Area, it is for the majority of IDPs and Returnees between 12 and 18 hours per day, with a peaking majority of an average of 16 hours per day for NBC Adjacent Area.

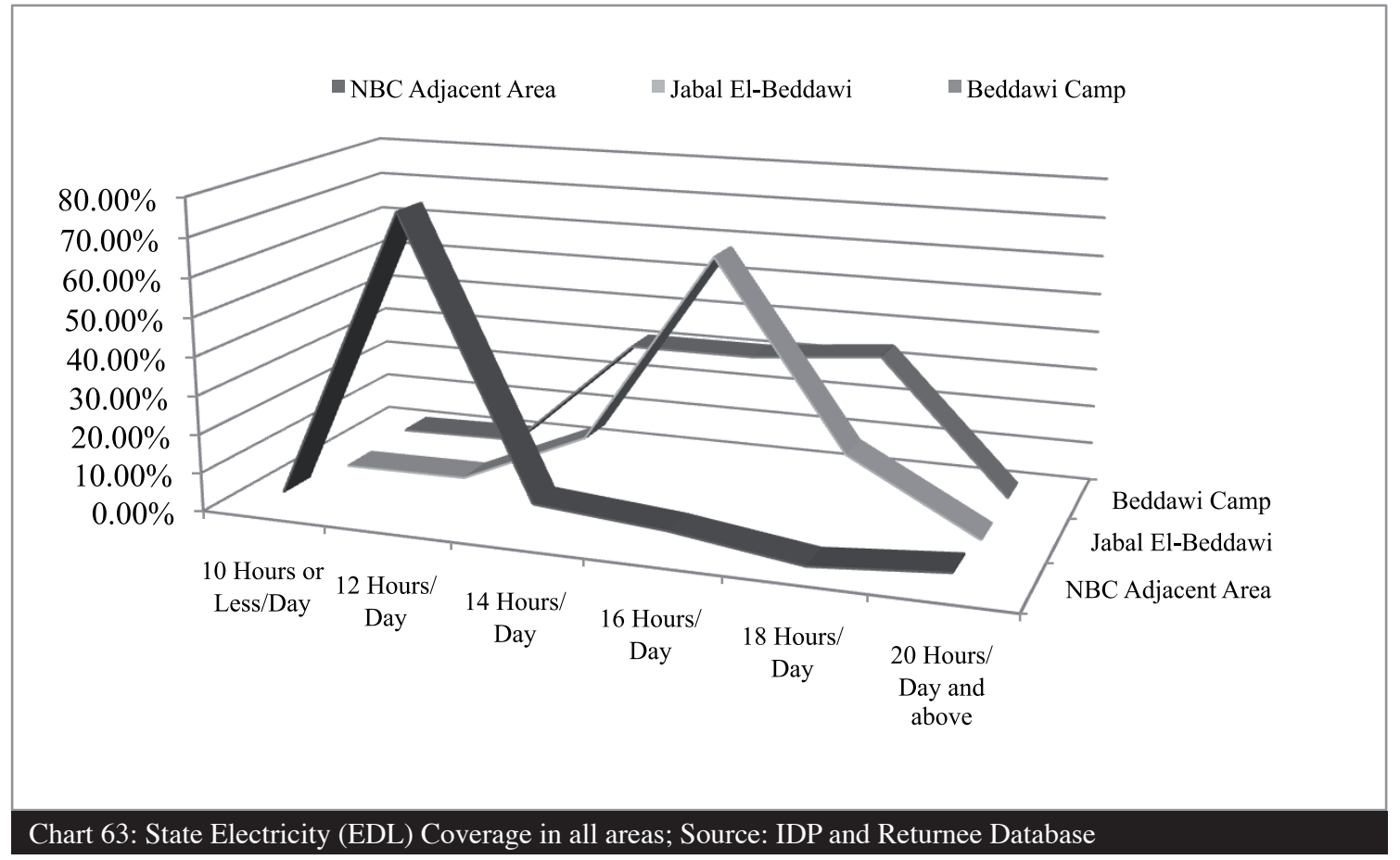

In terms of monthly payments for electricity, we notice big gaps between regions, where in Beddawi Camp the totality of IDPs (100\%) pay $20 \$$ or less for electricity per month (EDL), compared to Jabal El-Beddawi, where around $60.75 \%$ pay more than $20 \$$ per month for electricity, and in Nahr El-Bared, $82.41 \%$ of the population pay more than $20 \$$ for electricity per month.

As we see in the chart below, for NBC Adjacent Area and Jabal El-Beddawi most of the payments are concentrated outside the $20 \$$ or less section, where for Beddawi Camp.

The reason for this discrepancy, is that in Beddawi Camp, a large number of electricity connections are shared between homes, this way the bill somehow reaches a steady flat rate per month, in this case it is about $20 \$$ per month.

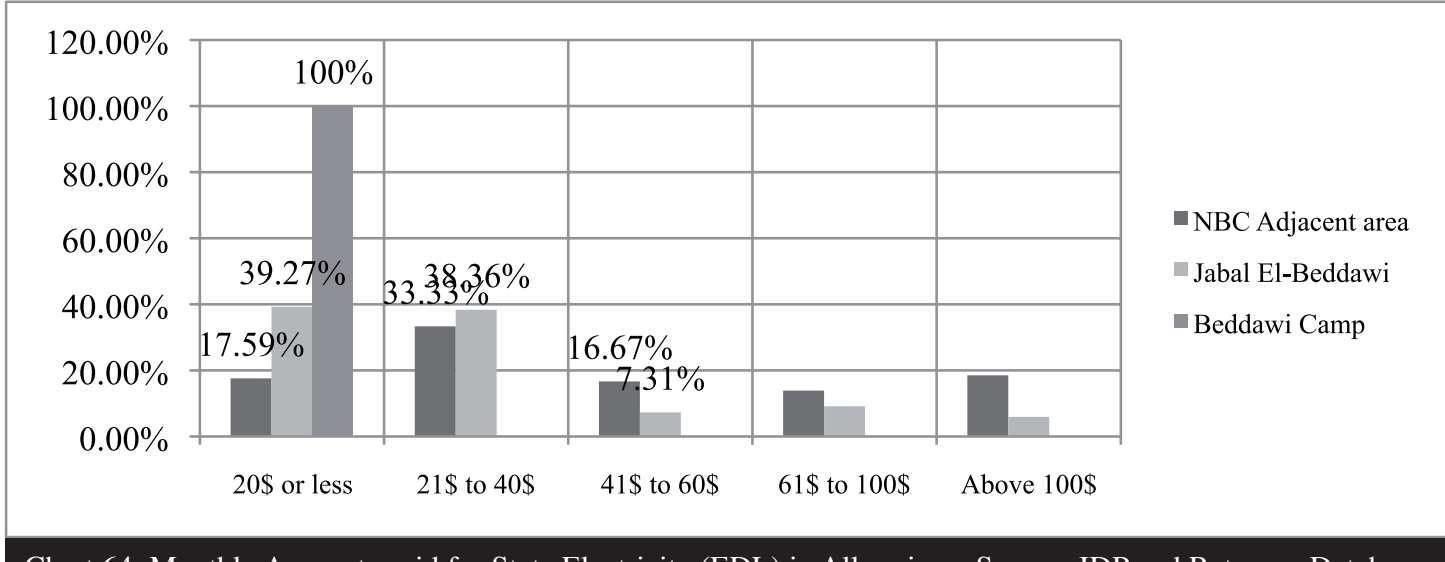

Chart 64: Monthly Amounts paid for State Electricity (EDL) in All regions; Source: IDP and Returnee Database 


\section{VIII- Health Characteristics}

\section{Disability}

The main indicators related to health conditions targeted within the IDP \& Returnee Database Surveys are related to disability and prevalence of chronic diseases.

The rate of Persons with Disability (PwDs) within the NBC IDPs living in Beddawi camp is about $3.45 \%$ of the total population

$57.72 \%$ of PwDs have a mobility related disability, while PwDs with a mental disability constitute $19.57 \%$ of all PwDs. Visual, hearing and speech related disabilities constitute $18.48 \%, 8.15 \%$ and $3.26 \%$ respectively.

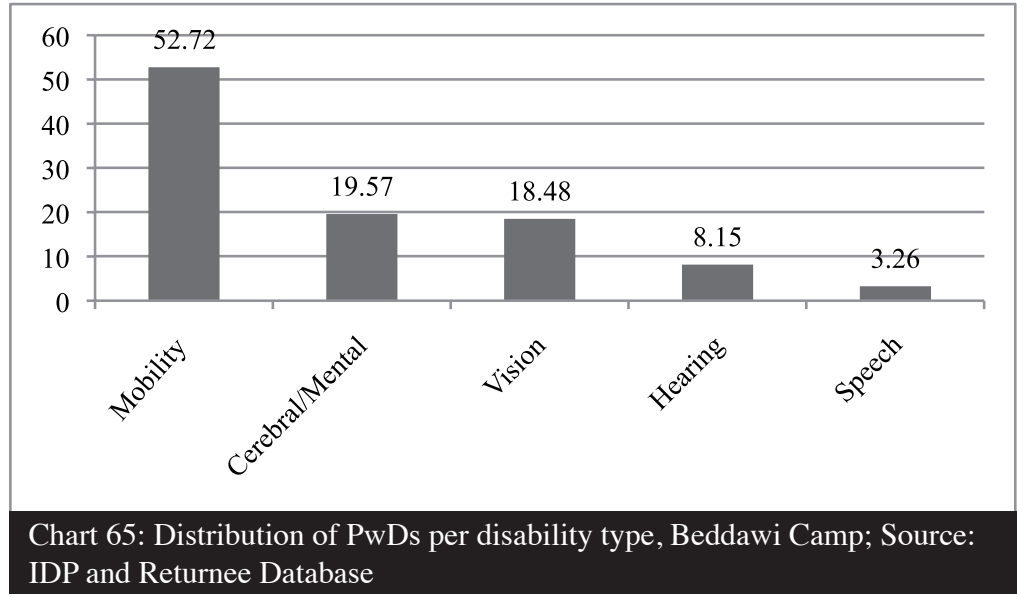

As for NBC IDPs living in Jabal El-Beddawi, the percentage of PwDs compared to the total population is $5 \%$, with the majority of PwDs having mobility related disabilities. Visual related disabilities constitute $23.49 \%$. PwDs with a mental, hearing and speech related disability, constitute $9.4 \%, 8.72 \%$ and $2.68 \%$ respectively.

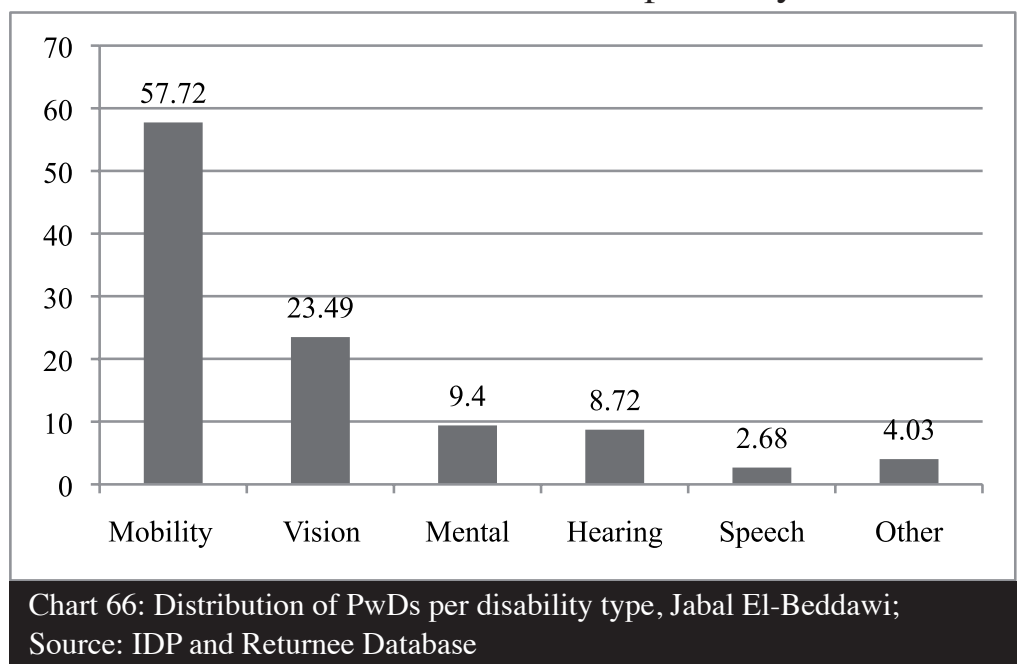


3.8\% of individuals in NBC Adjacent Area are PwDs, with most PwDs (53.29\%) declared having a mobility related disability, while $22.84 \%$ have a visual disability, followed by $11.07 \%$ for mental disabilities and $10.38 \%$ for hearing disabilities and lastly $2.42 \%$ for speech related disabilities. Although it is important to mention that 5.5\% of PwDs have more than one disability.

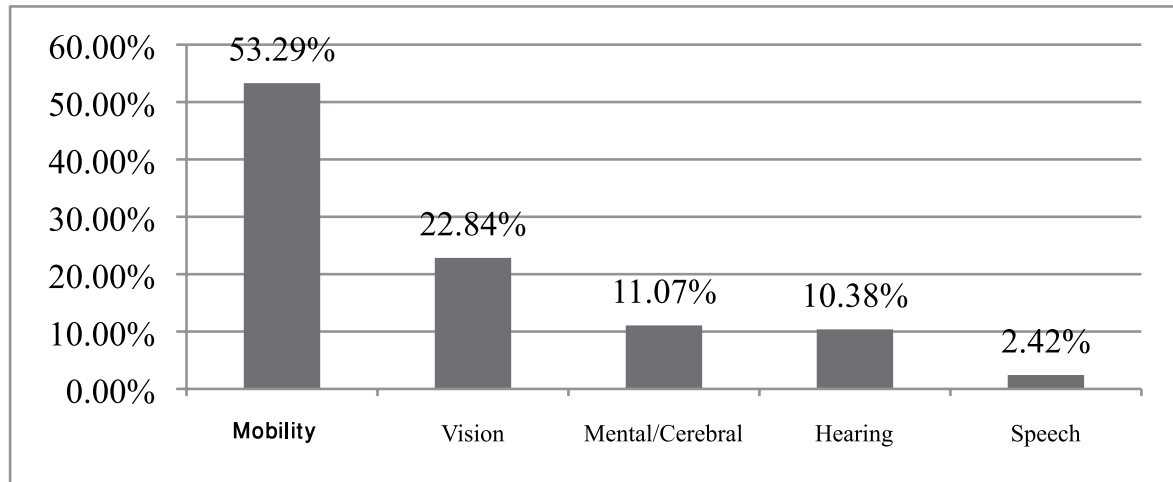

Chart 67: Distribution of PwDs per disability type, NBC Adjacent Area; Source: IDP and Returnee Database 


\section{Chronic Diseases}

$13 \%$ of the IDP population in Beddawi Camp said they had at least one chronic disease.

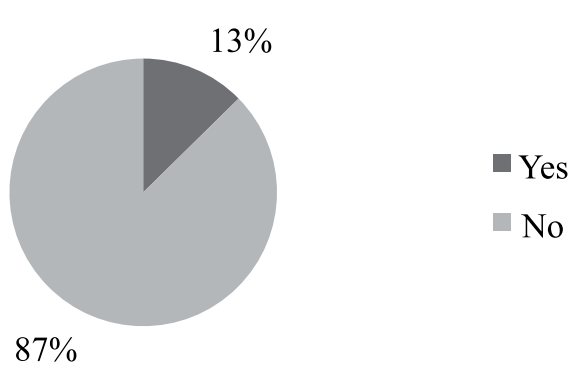

Chart 68: Percentage of chronic diseases per total

population, Beddawi Camp; Source: IDP and Returnee

Database

The majority of people suffering from a chronic disease said they had a cardio-vascular disease, where $29.96 \%$ were suffering from blood pressure related diseases, and $26.77 \%$ from heart diseases.

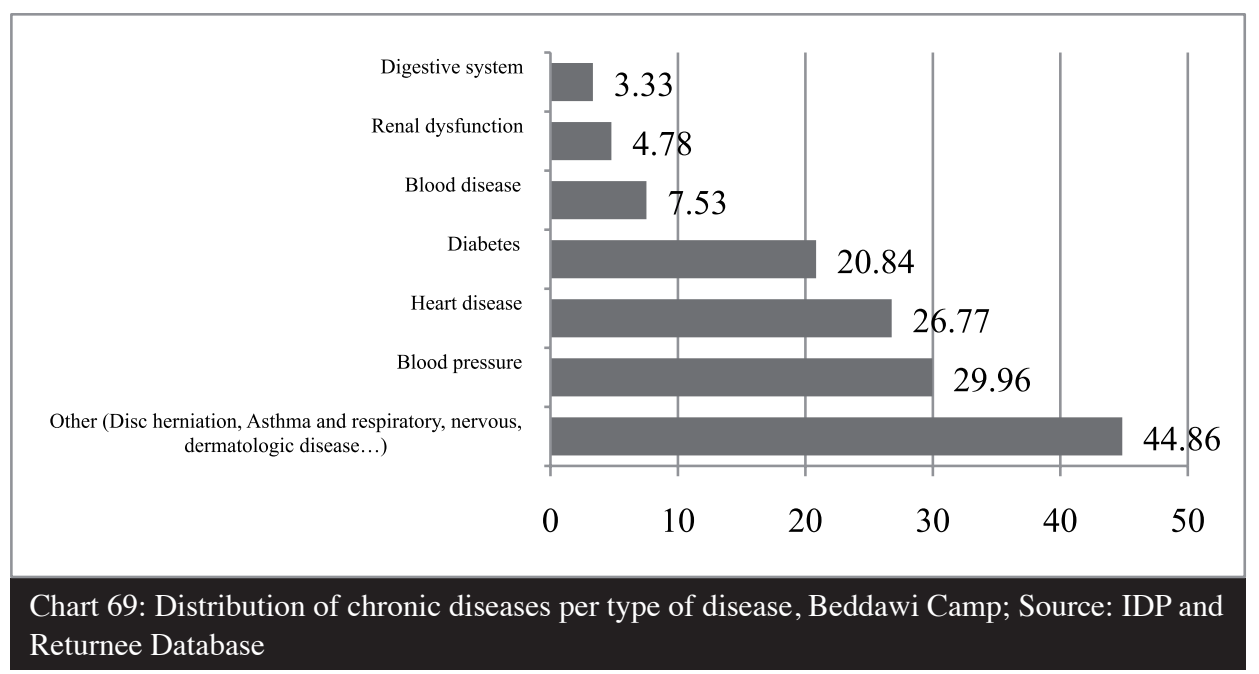

In Jabal El-Beddawi, $13 \%$ of the IDP population said they have at least one chronic disease.

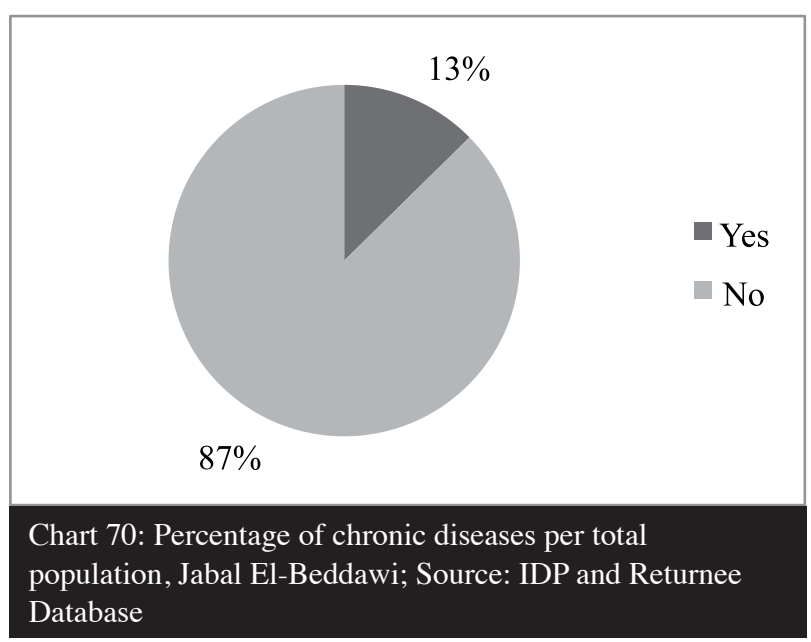


The majority of the people suffering from a chronic disease said they had a cardio-vascular disease, where $39.51 \%$ were suffering of blood pressure, and $18.27 \%$ of heart disease.

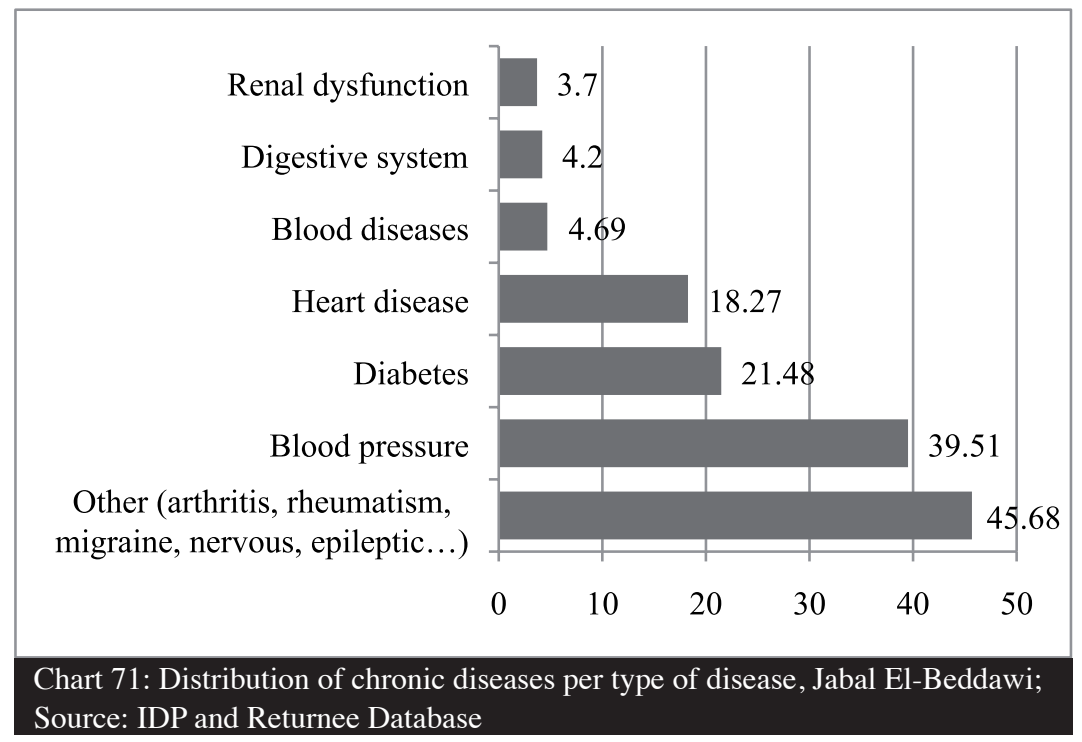

$16 \%$ of the NBC Adjacent Area population said they have at least one chronic disease. Chart 69: Percentage of chronic diseases per number of population, NBC Adjacent Area; Source: IDP and Returnee Database

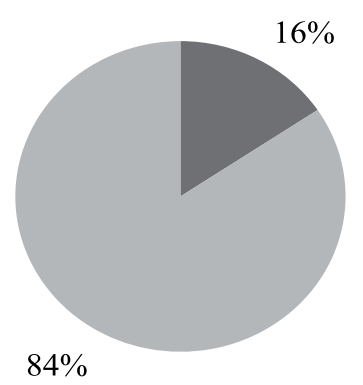

Chart 72: Distribution of chronic diseases per type of disease, Beddawi Camp; Source: IDP and Returnee Database

The majority of people suffering from a chronic disease said they had cardio-vascular diseases, where $29.86 \%$ were suffering of blood pressure, and $18.4 \%$ of heart diseases

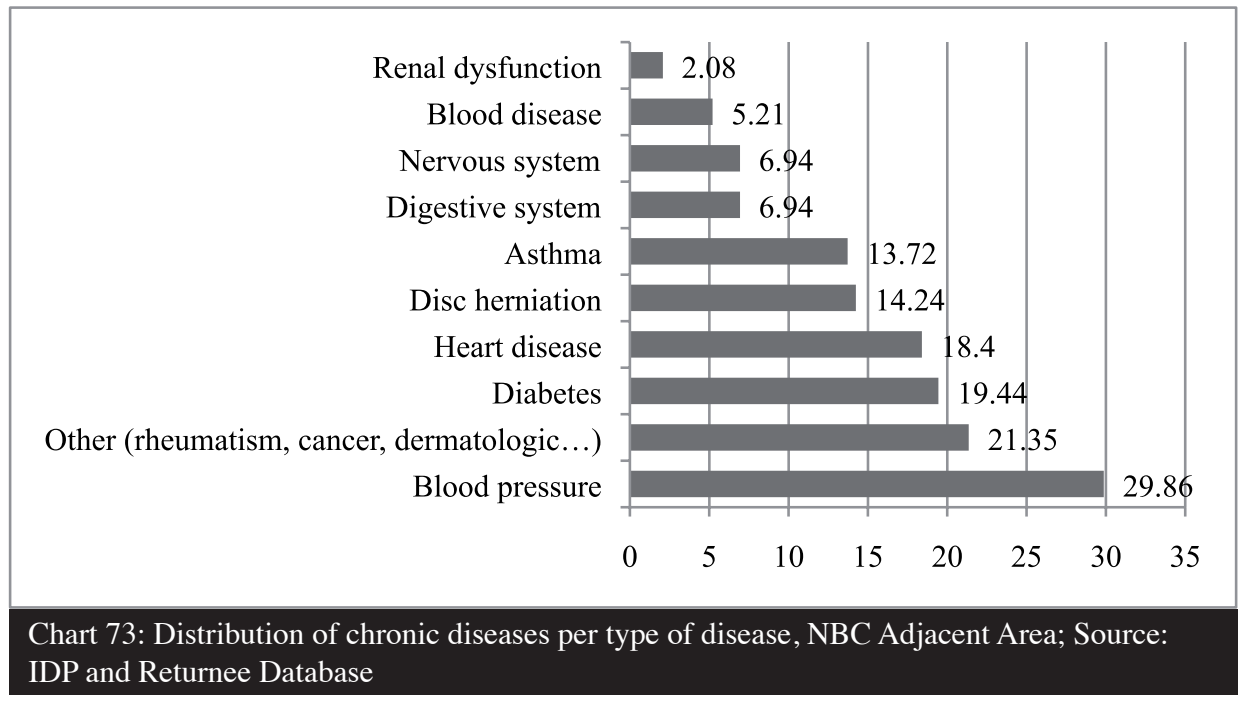




\section{LX-Education}

\section{Education Reception by Age Categories}

Among the surveyed IDP population in Beddawi Camp, aged between 4 and 25 years old, $68.43 \%$ were receiving education, while among the whole population, $35.87 \%$ were receiving education.

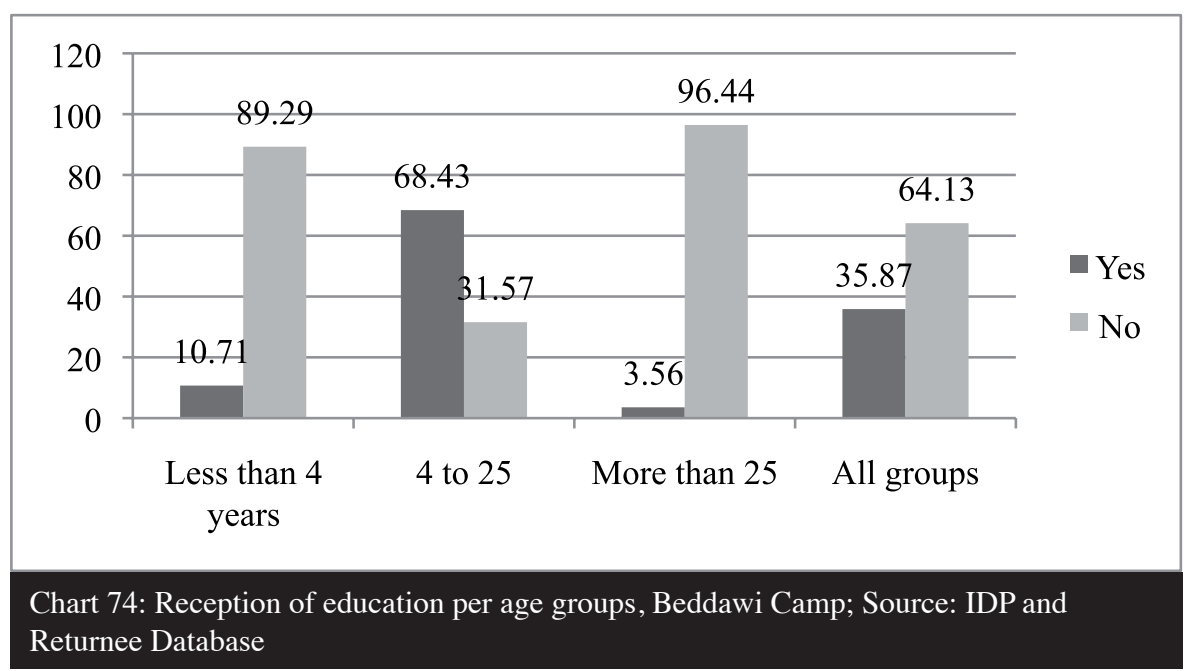

Among the IDP population in Jabal El-Beddawi, $72 \%$ of those aged between 4 and 25 years old, were receiving education, while among the whole population $38.5 \%$ declared currently receiving education.

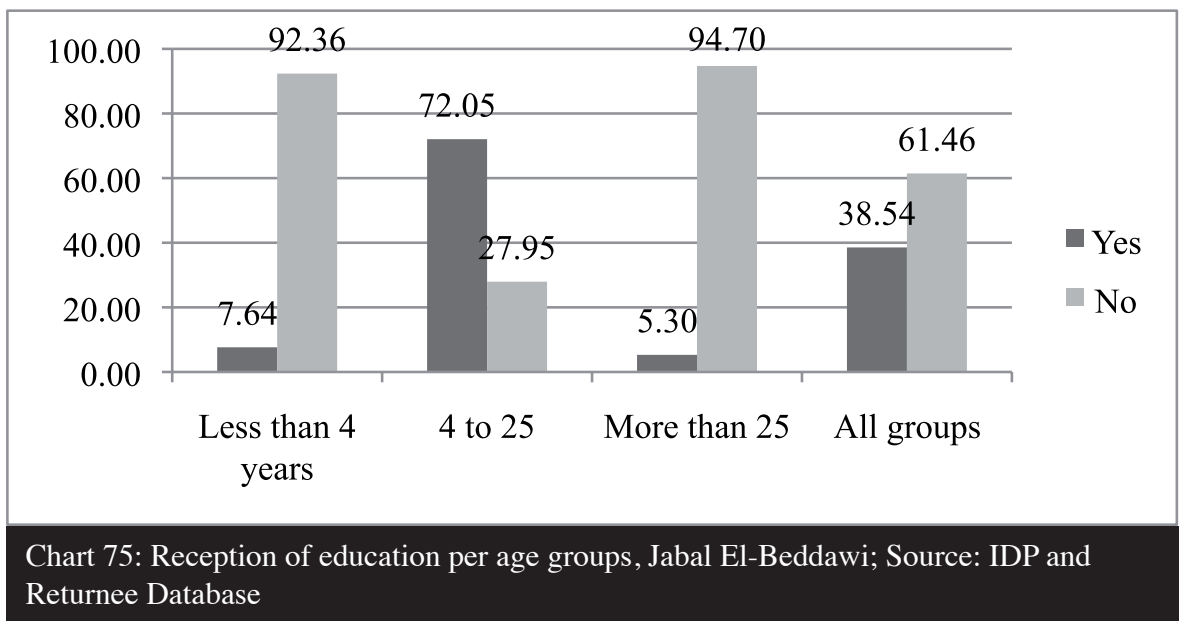


As for returnees and semi-returnees in the NBC Adjacent Area, 34.50\% have attended primary education level, and $30.60 \%$ have attained an intermediary education level, while other levels have a considerably low participation level, secondary education being at $6.70 \%$ and University Education at $5.17 \%$. Illiteracy rate stands at $11.52 \%$.

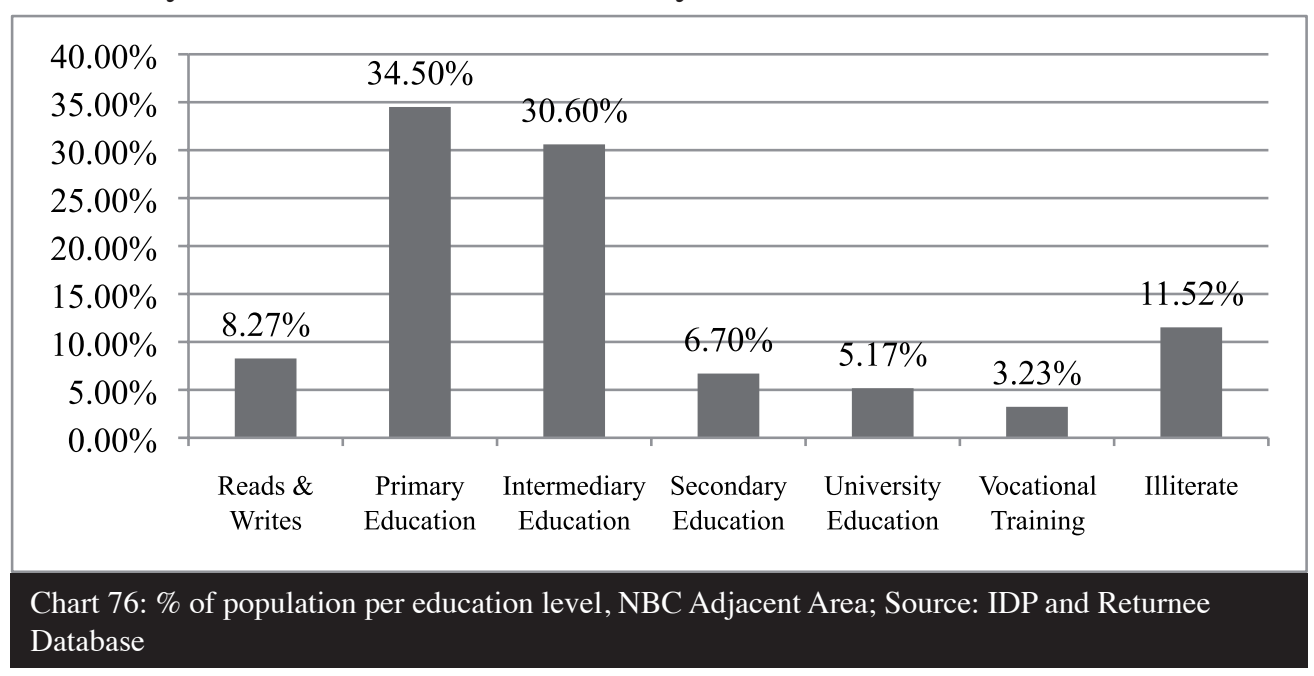

Considering a sample of 7197 individuals form all areas, and looking into the attained education levels compared to sex, we notice that there female illiteracy is higher than male illiteracy by 2.6 percentage points and that female participation in primary education is lower by 3.86 percentage points than their male counterparts. Moreover we witness that female intermediary education is 6.17 percentage points higher than male intermediary education.

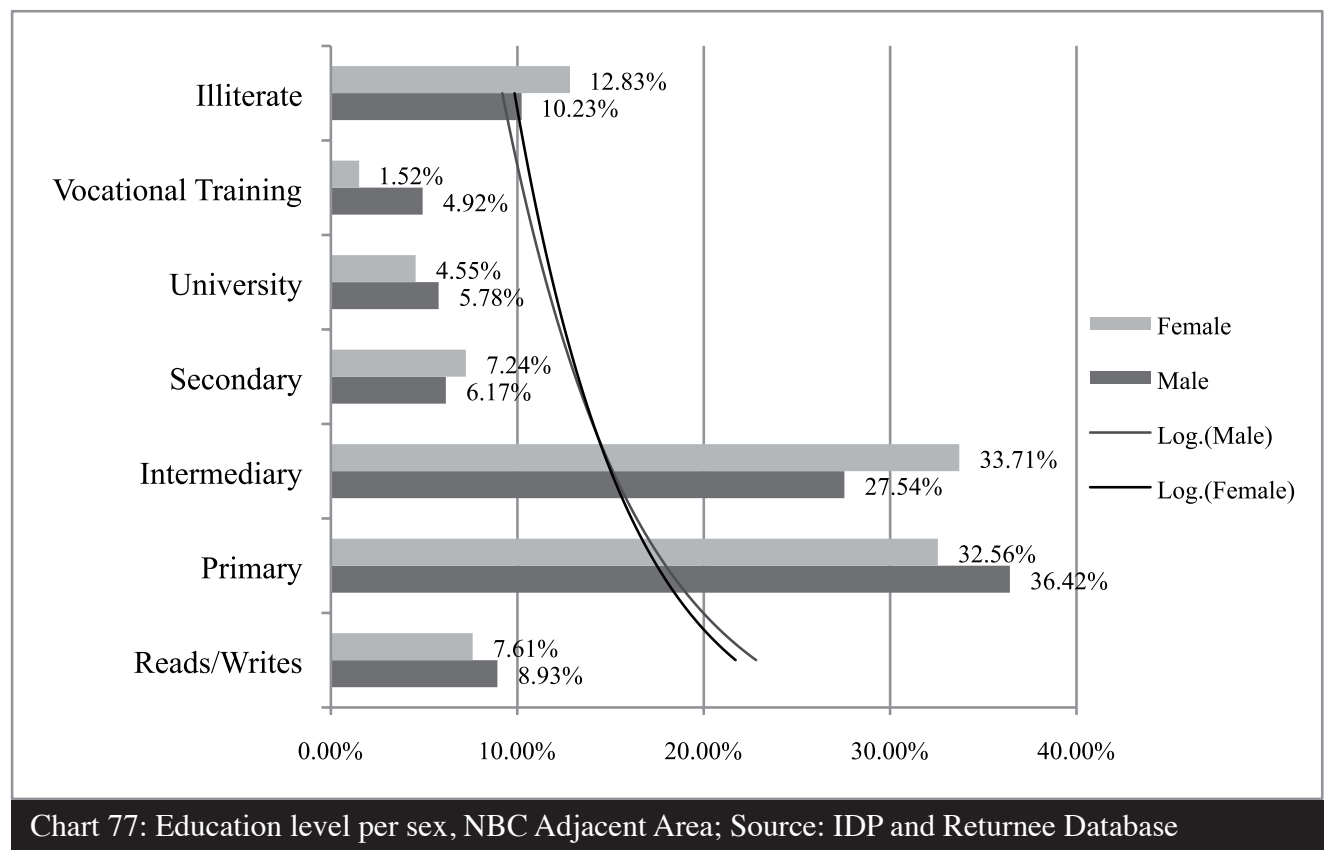

Yet the general trend of participation for both female and male follow the same trend, high participation in primary and intermediary levels and then low participation from secondary up to university levels. It would also be important to mention that female participation in vocational trainings is $69 \%$ lower than their male counterparts. 
These trends show significant gaps and challenges, as $78 \%$ of those who attend intermediary education do not attend secondary education, and can be considered as dropouts. This issue may be related to job market opportunities. Where the job market is not presenting incentives for people with higher education, and jobs available within the market do not require secondary or higher education. Although high dropout rates can be as well related to education quality. 


\section{X-Work and Employment}

\section{Employment and Labor Characteristics}

Considering the IDP population in Beddawi we notice that $30.85 \%$ of the economically active population was working before the war, while after the war only $21.59 \%$ are working. Also $42.54 \%$ of the economically active population declared being not working, this portion of the population increased after the war to reach $51.37 \%$. Those declared as "Not Working" could be individuals who are: either not able to find a job, although actively looking; people who are committed to other activities and are unable to pursue a job (students); or people who are unable to work because of a physical or health condition.

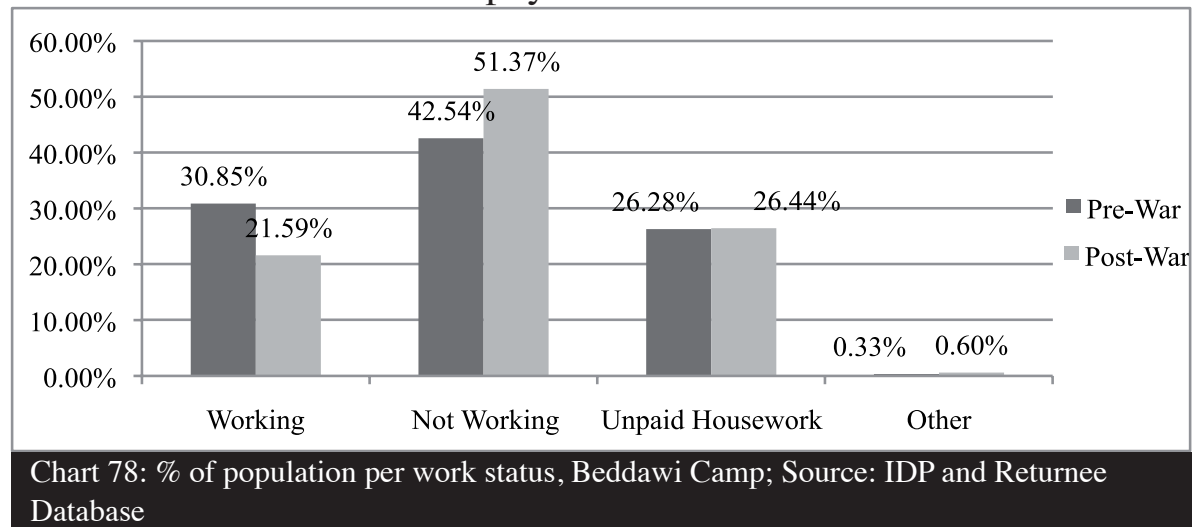

As a result of the war the working population within the NBC IDPs in Beddawi Camp has decreased by $30.02 \%$ while the Non-Working population have increased by $20.76 \%$

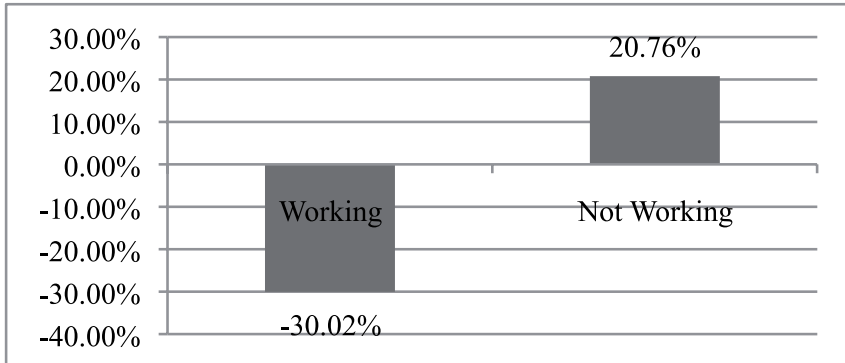

Chart 79: \% of variations in work status after the war, Beddawi Camp; Source: IDP and Returnee Database 
The same trend is found within the IDP population in Jabal El-Beddawi, where $18.87 \%$ of the economically active population was working before the war, but after the war this percentage dropped to $13.74 \%$ while people who are not working, increased from $27.10 \%$ before the war to $31.55 \%$ after the war.

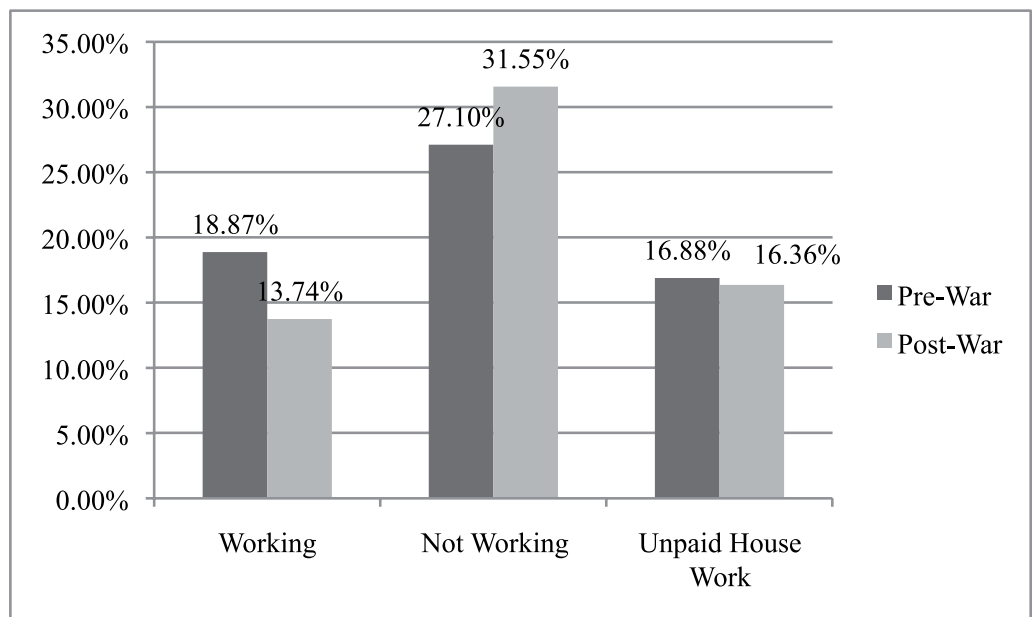

Chart 80: \% of population per work status, Jabal El-Beddawi; Source: IDP and Returnee Database

We notice similar trends in Jabal El-Beddawi as in Beddawi Camp, the working population of NBC IDPs in Jabal El-Beddawi has decreased by $27.18 \%$ and non-working population has increased by $16.43 \%$.

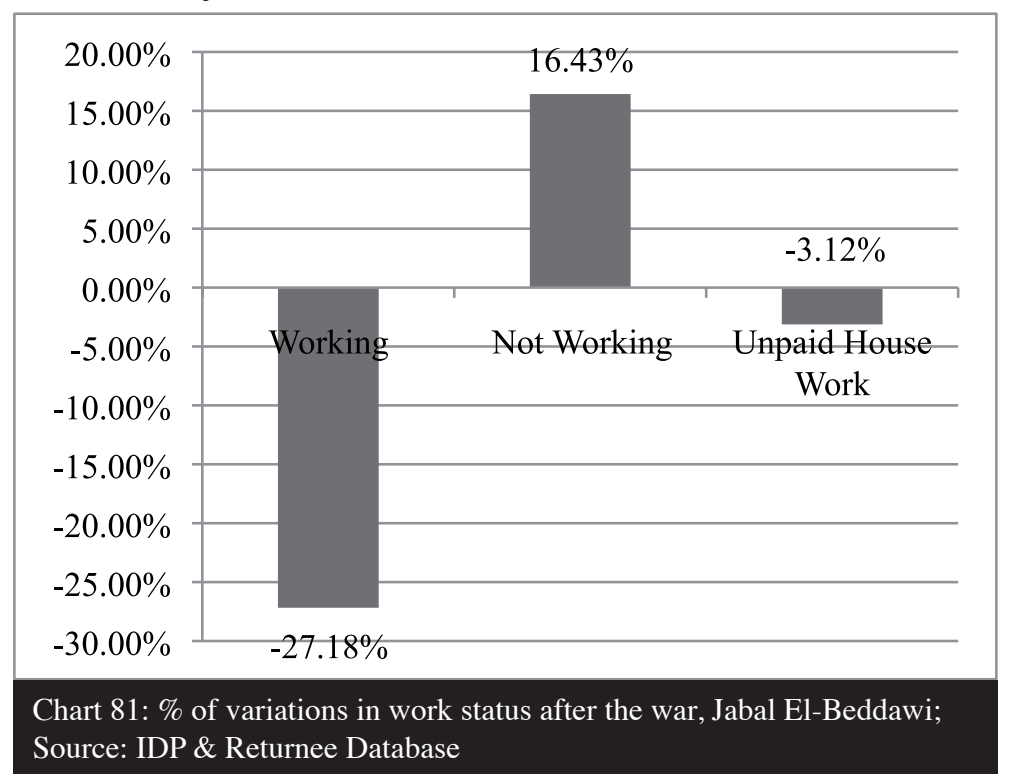

In NBC Adjacent Area, the picture is slightly different. Although the trend of decline in working population numbers does exist, yet it is less grim than figures in Jabal El-Beddawi and Beddawi Camp. This difference can be explained as a result of economic recovery activities and as effect of the return process, as many have re-opened their businesses in the Adjacent Area. And since recovery activities are mostly concentrated in NBC, it is quite logical to see a higher rate of employment in NBC adjacent area compared to displacement areas such as Beddawi Camp and Jabal El-Beddawi.

The working population dropped from $32.44 \%$ before the war to $29.22 \%$ after the war, while the "Unemployed and Looking for a Job" increased from $2.18 \%$ to 5.99\%; while the 
"Unemployed who are not looking for a job" also increased from 6.61\% to 7.28\%; People who are unable to work also increased from $4.83 \%$ before the war to $6.18 \%$ after the war.

It is important to mention that those who are unemployed and not looking for a job should not be dropped out of the unemployment rate as many of them voiced, through the surveys, that they have stopped looking for jobs because they don't seem to find any and lost hope in finding one. Thus it is important for the recovery and humanitarian community to look into unemployment not as a fixed indicator, of who are actively looking for a job, but to also consider that the lack of opportunity might throw a lot of people into despair and to loose hope in finding a job.

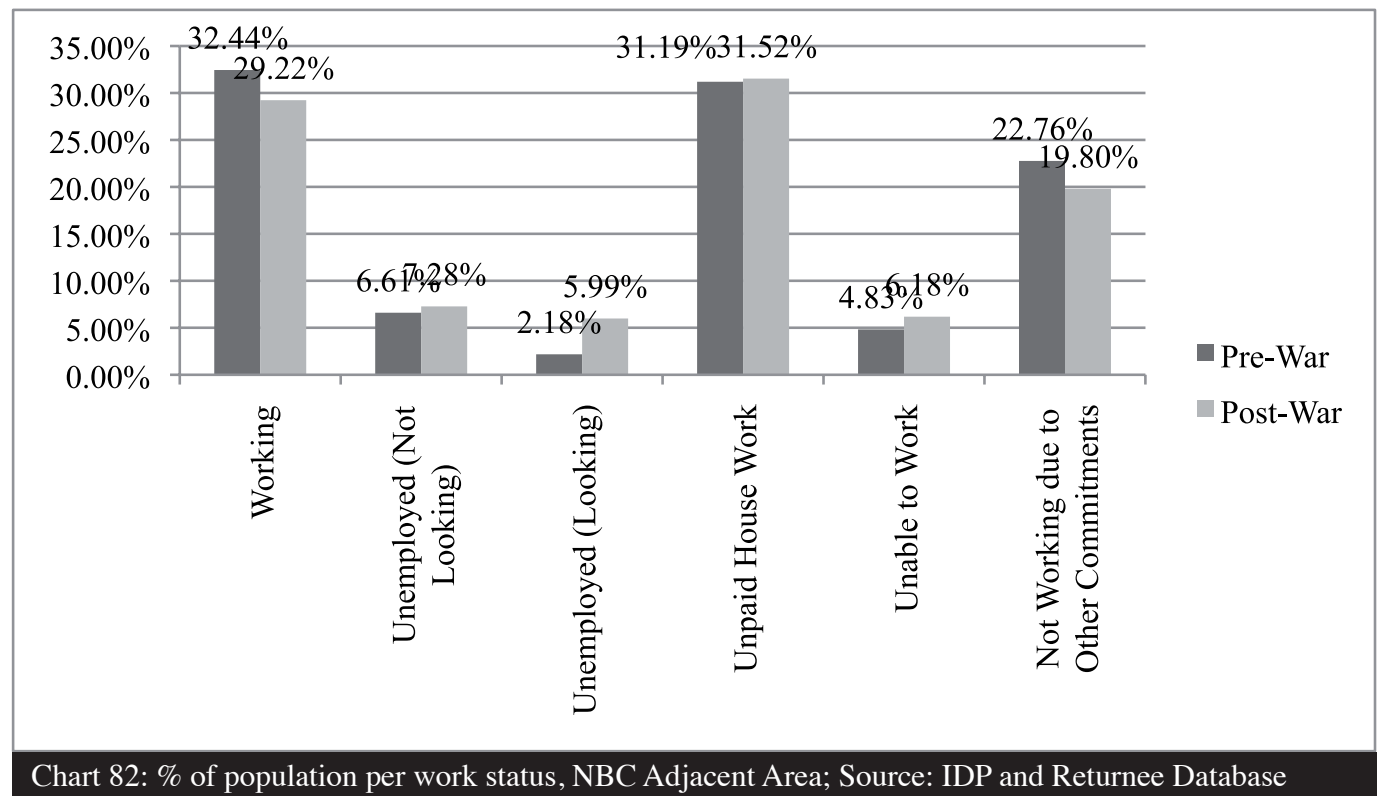

So in a more general picture, the NBC Adjacent Area has $32.44 \%$ of its economically active population working before the war, and $29.22 \%$ after the war, while it had $36.38 \%$ of its economically active population as non-working before the war and $39.25 \%$ after the war.

So the difference in terms of working population decreased by $9.9 \%$ while the non-working population has increased by $7.91 \%$.

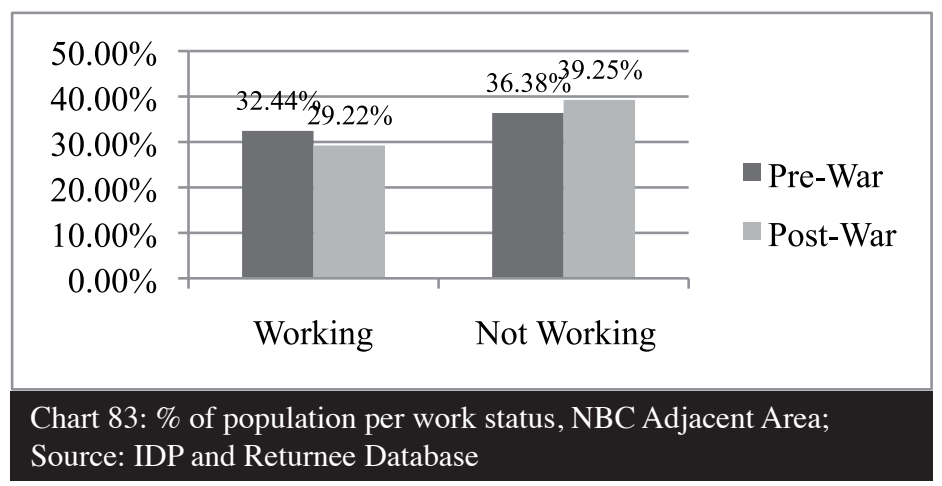

Looking into the employment characteristics between the pre-war and post-war phase for IDPs living in Beddawi Camp, we notice that the harshest impact was on those who owned a business prior to the clashes, dropping from $31.05 \%$ to $9.49 \%$. Daily workers increased from $18.20 \%$ to $35.35 \%$. Another increase is in the number of wage-labor increasing from $28.80 \%$ to $37.41 \%$. While people who worked for themselves, dropped from $21.95 \%$ to $17.74 \%$. 


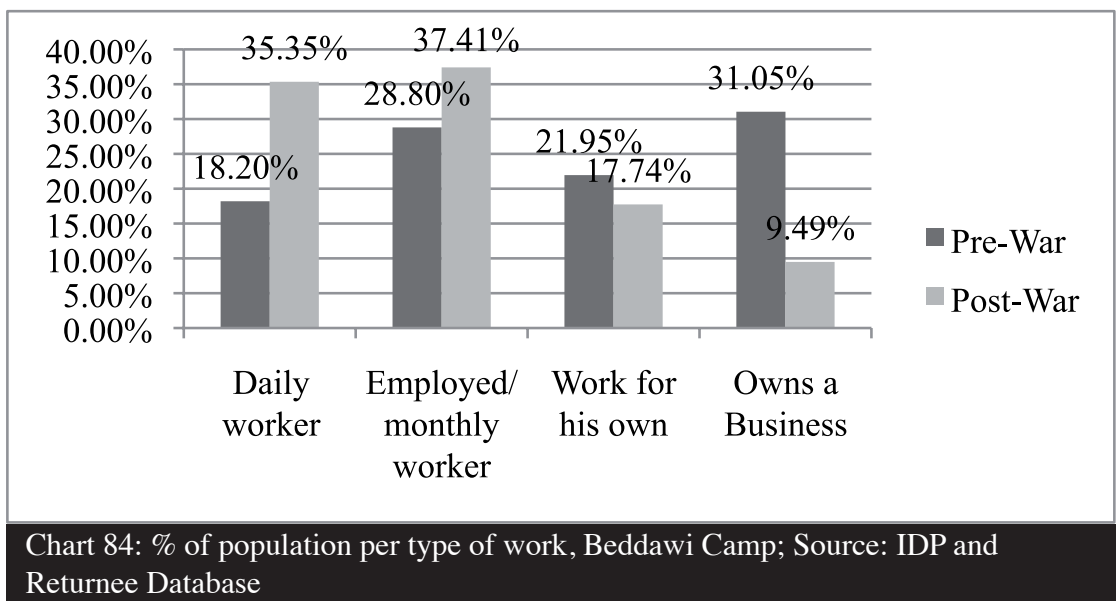

The same trend carries on in Jabal El-Beddawi; people who owned a business were $17.98 \%$ before the war and are $7.82 \%$ after the war. Waged labor increased from $36.52 \%$ to $43.00 \%$ and daily workers increased from $28.10 \%$ to $30.86 \%$.

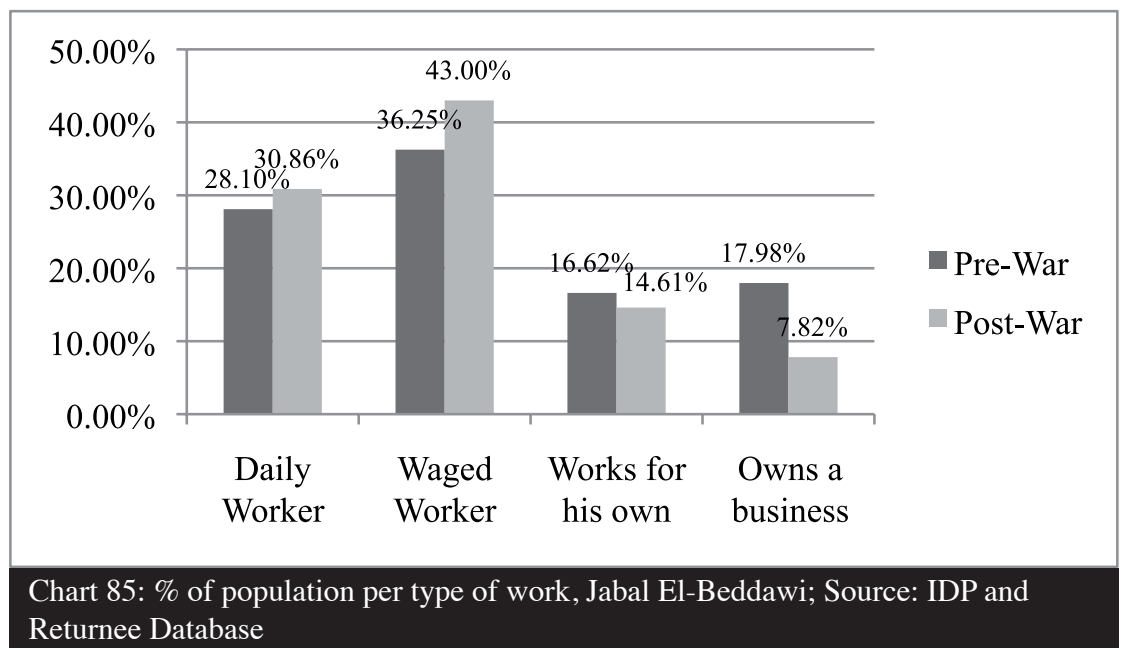

As for the Nahr El-Bared Adjacent Area, the picture is a bit different. Business owners were able to recover and the war impact has been reduced, as business owners formed a $14.11 \%$ before the war and $12.02 \%$ after the war, which is mainly related that business owners in the Adjacent Area are physically able to recover their businesses, and also most of the livelihood

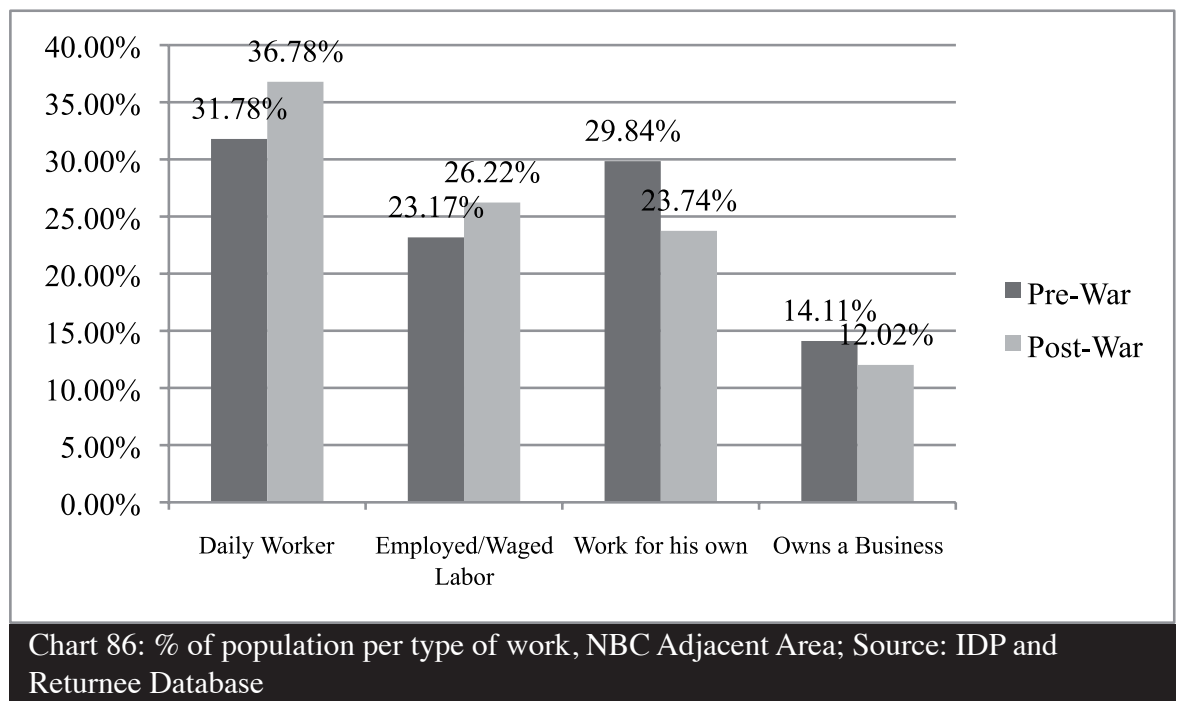


activities are concentrated in the adjacent areas which enable its residents to have a faster economic recovery. Daily workers increased from $31.78 \%$ to $36.78 \%$, the same for waged labor, which increased from $23.17 \%$ to $26.22 \%$ while those who are self-employed decreased from $29.84 \%$ before the war to $23.74 \%$ after the war.

To have a more holistic view we compared the variations between the pre-war and the post war phase in the three regions and noticed that IDP business owners in Beddawi and Jabal El-Beddawi have had recorded lower economic recovery compared to those in NBC Adjacent Area. This recovery gap between regions proves a strong relation between the economic recovery of business owners and return.

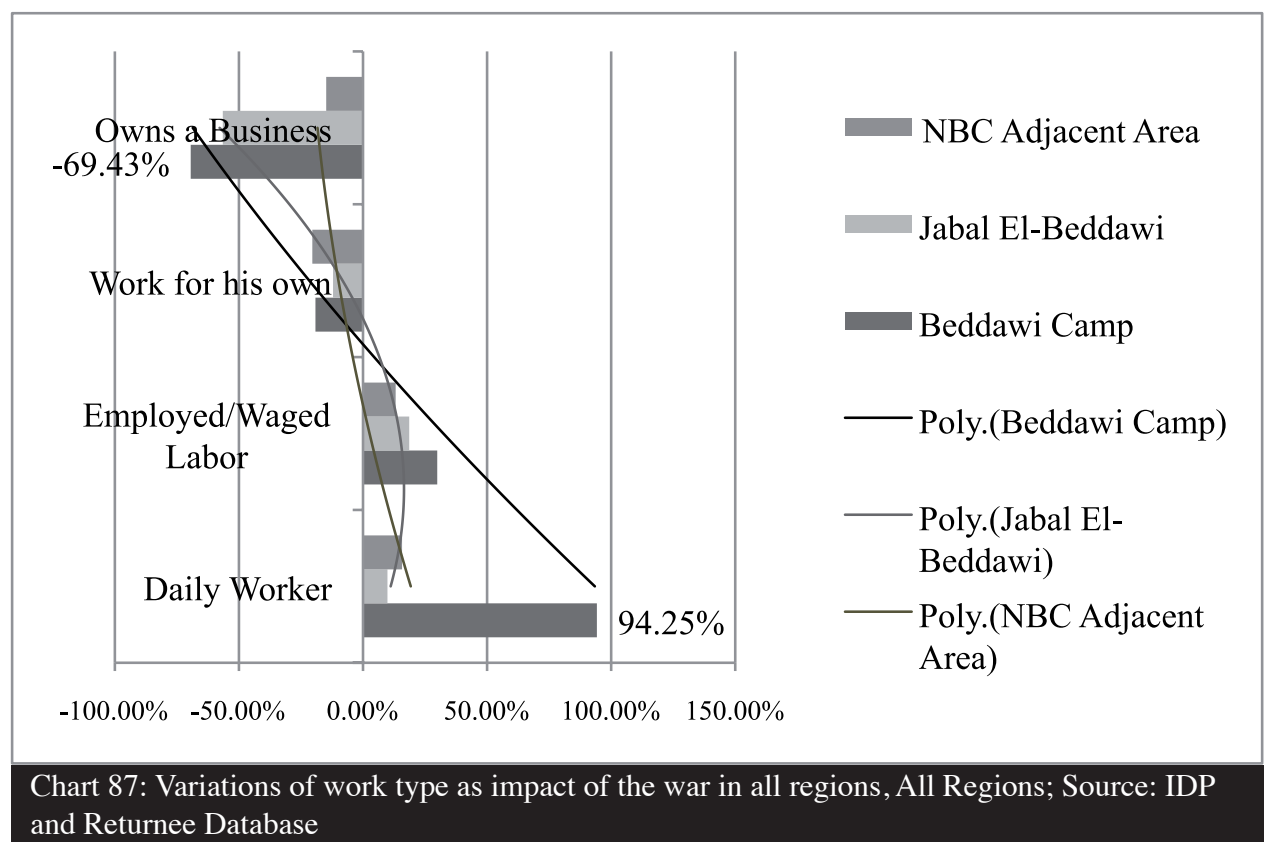

Another trend which would be important to mention, is that there has been a big increase in daily labor in Beddawi camp (94.25\%), while other locations witnessed a more modest increase (9.85\% for Jabal El-Beddawi and $15.74 \%$ for NBC Adjacent Area).

These differences can be interpreted as a result of the high economic activity witnessed in Beddawi Camp during humanitarian operations between 2007 and up to the summer of 2008 . This could have given the incentive for daily labor to increase.

Yet this increase does not necessarily translate into recovery, as daily labor could be the result of temporary opportunities in the market rather than stable and sustainable opportunities. The question that should be addressed here is whether this increase will be able to sustain itself on the longer term?

\begin{tabular}{l|l|l|l}
$\begin{array}{l}\text { Deviations in type of work } \\
\text { relative to pre-war figures }\end{array}$ & Beddawi Camp & $\begin{array}{l}\text { Jabal El- } \\
\text { Beddawi }\end{array}$ & $\begin{array}{l}\text { NBC Adjacent } \\
\text { Area }\end{array}$ \\
\hline Daily Worker & $94.25 \%$ & $9.85 \%$ & $15.74 \%$ \\
\hline Employed/Waged Labor & $29.91 \%$ & $18.62 \%$ & $13.16 \%$ \\
\hline Work for his own (Self-Employed) & $-19.17 \%$ & $-12.08 \%$ & $-20.43 \%$ \\
\hline Owns a Business & $-69.43 \%$ & $-56.50 \%$ & $-14.83 \%$ \\
\hline
\end{tabular}

Table 8: Deviations in type of work in all regions as a result of the war 
Waged labor has increased the most in Beddawi Camp, followed by Jabal El-Beddawi, while in the NBC Adjacent Area it recorded the least increase. This could be possibly related to higher economic opportunities in Beddawi and Jabal El-Beddawi that in NBC Adjacent Area. Such increase in economic activity could be interpreted as a result of the of businesses in Beddawi Camp and in Jabal El-Beddawi to employ more people since their market has grown due to displacement and concentration of relief and humanitarian activities during 2007 and 2008.

While businesses in NBC Adjacent Area are mostly run by one person, and due to limitations on movement, their market share is smaller, thus they tend to have low levels of employment 


\section{Income Characteristics}

The average decrease in income in Beddawi camp is of $188.23 \$ /$ month/working person between the pre-war period and the post-war period.

\begin{tabular}{l|l|l|l|l} 
Beddawi Camp & $\begin{array}{l}\text { Number of } \\
\text { persons }\end{array}$ & $\boldsymbol{\%}$ & $\begin{array}{l}\text { Total difference of } \\
\text { income/month (\$) }\end{array}$ & $\begin{array}{l}\text { Average difference of income/ } \\
\text { month/working person (\$) }\end{array}$ \\
\hline Decrease & 555 & 74.70 & -165448 & -298.10 \\
\hline Increase & 127 & 17.09 & 25594 & 201.53 \\
\hline Unchanged & 61 & 8.21 & 0 & 0 \\
\hline Total & 743 & 100 & -139854 & -188.23 \\
\hline
\end{tabular}

Table 9: Variations in Income for IDPs in Beddawi Camp

In Jabal El-Beddawi, considering those IDPs who were working and still working after the war, the average decrease of income is of $192.3 \$ / \mathrm{month} /$ working person between the prewar period and the post-war period.

\begin{tabular}{l|l|l|l|l} 
Jabal El-Beddawi & Number of persons & $\%$ & $\begin{array}{l}\text { Total difference of } \\
\text { income/month }\end{array}$ & $\begin{array}{l}\text { Average difference of } \\
\text { income/month/work- } \\
\text { ing person }\end{array}$ \\
\hline Decrease & 321 & 67.72 & -104988.80 & -327.07 \\
\hline Increase & 73 & 15.40 & 13684.50 & 187.46 \\
\hline Unchanged & 80 & 16.88 & 0 & 0 \\
\hline Total & 474 & 100 & -91304.30 & -192.3 \\
\hline
\end{tabular}

Table 10: Variation in INcome for IDPs in Jabal El-Beddawi

As for the NBC Adjacent Area, the following table shows, that it is more frequent to find people having low income after the war than before it. And less frequent to find people with high monthly income, after the crisis than before it. The decrease is mainly concentrated in medium and high-income categories while an increase is recorded in the low-income categories.

\begin{tabular}{l|l|l|l}
$\begin{array}{l}\text { NBC Adjacent Area } \\
(\text { LBP })\end{array}$ & Before war (\%) & After war (\%) & Differences (\%) \\
\hline $250000-299000$ & 19.79 & 30.80 & 11.01 \\
\hline $300000-349000$ & 16.22 & 21.88 & 5.65 \\
\hline $350000-399000$ & 7.29 & 8.48 & 1.19 \\
\hline $400000-449000$ & 13.99 & 13.24 & -0.74 \\
\hline $450000-499000$ & 7.29 & 5.51 & -1.79 \\
\hline $500000-549000$ & 11.76 & 6.40 & -5.36 \\
\hline $550000-750000$ & 10.42 & 5.21 & -5.21 \\
\hline More than 750000 & 13.24 & 8.48 & -4.76 \\
\hline Total & 100 & 100 & 0 \\
\hline
\end{tabular}

Table 11: Variations in Income for Returnees and Semi-Returnees in NBC Adjacent Area 


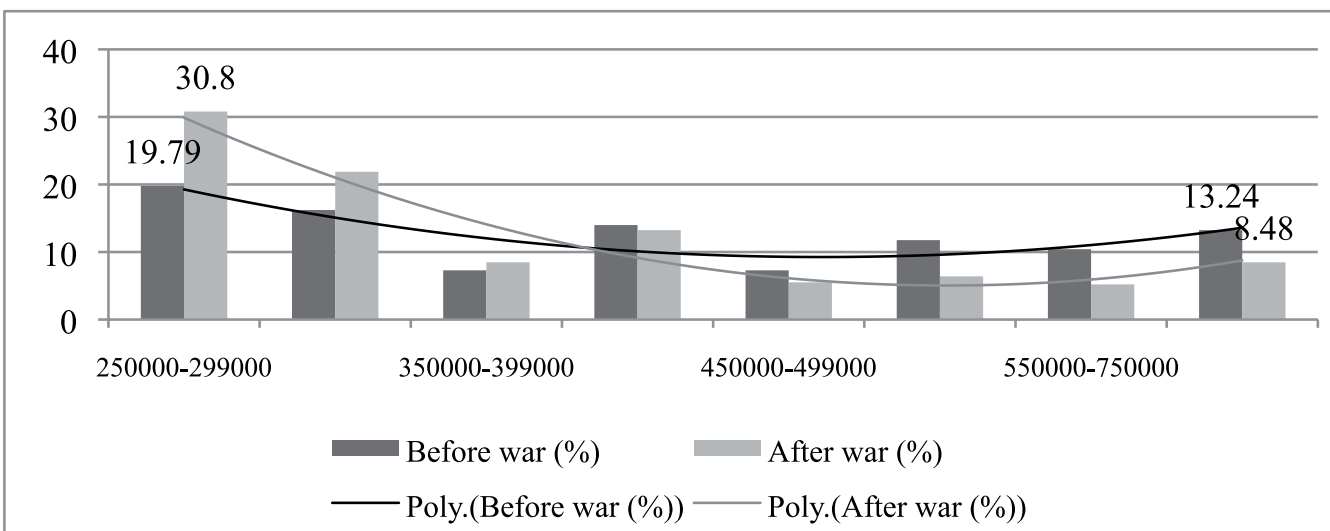

Chart 88: Variations of income as impact of the war, NBC Adjacent Area; Source: IDP and Returnee

Database

These trends show a re-organization of income in the low-paid jobs and migration out of medium and high-paid jobs. This can be a direct effect of job losses, but the main question at hand here is whether this trend will flip during the recovery period or will it become a more permanent trend in the economy of NBC? 


\section{Gender and Employment}

For Gender and Employment we will be only looking at NBC Adjacent Area, considering that the context of NBC has more stable labor participation characteristics.

Labor participation levels for both men and women stand approximately the same between the pre-war period and the post-war period. There is a slight increase in female labor participation and a slight drop in male participation.

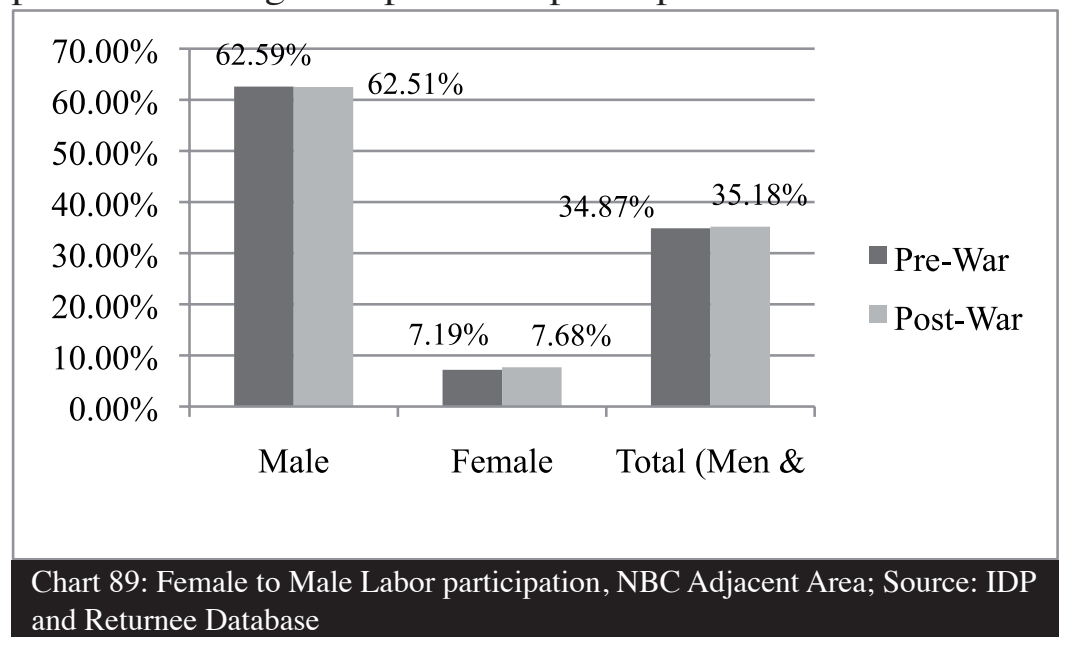

Female labor participation is at $7.68 \%$ after the war, compared to $62.51 \%$ for their male counterparts, the general participation rate is $35.18 \%$. There is a significant gap between male and female labor participation, men have $87 \%$ more chances in job opportunities that women, with a ratio of 8 working men per 1 working women.

\section{Pre-War}

If we consider the relation the labor force before the war, we notice that for men, $59.20 \%$ declared to be working, compared to only $5.62 \%$ for women. Most economically active women are unpaid labor involved mainly in housework. Which shows that there are very low incentives for women to access the workplace.

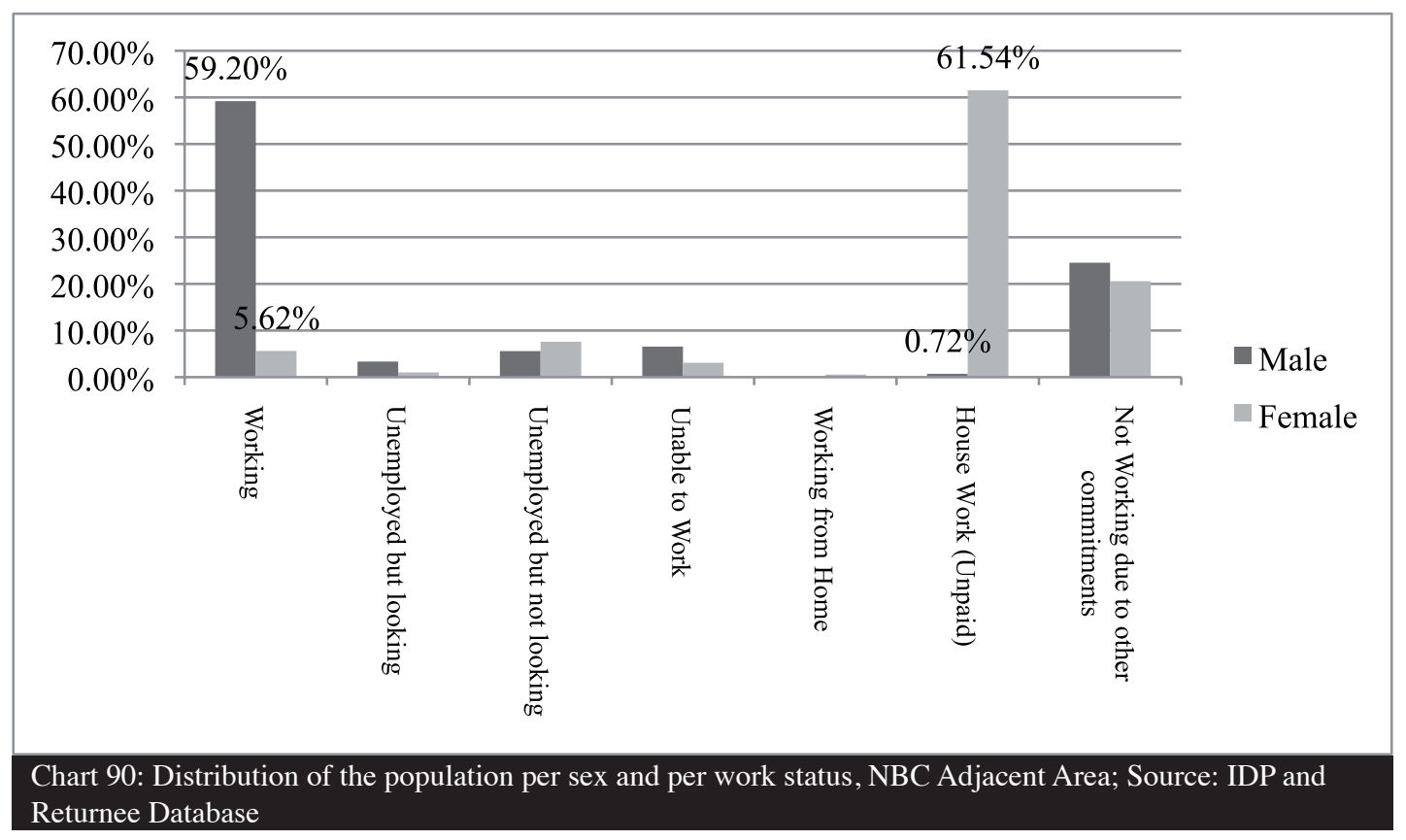


In terms of income, a considerable majority of women $(68.57 \%)$ receive monthly between 250,000 and $349,000 \mathrm{LBP}$, compared to a majority $(64.35 \%)$ of men receiving more than 349,000 LBP per month.

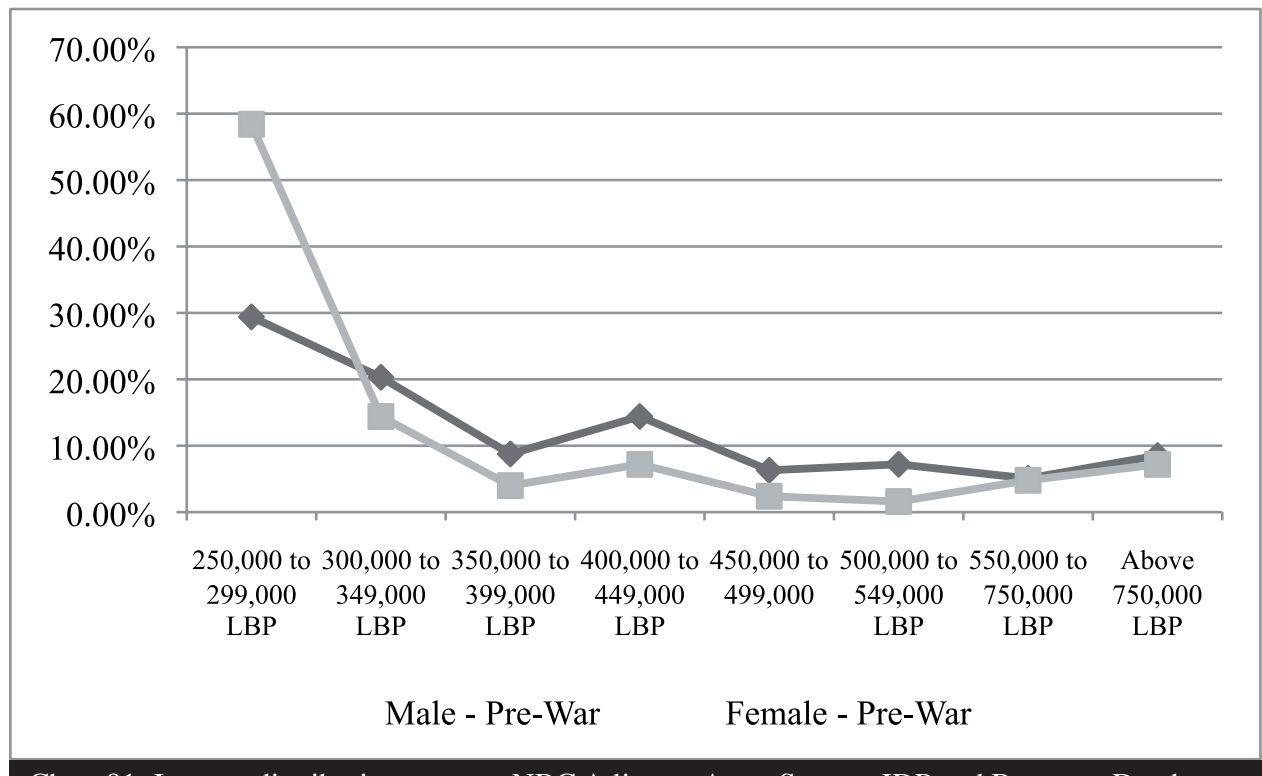

Chart 91: Income distribution per sex, NBC Adjacent Area; Source: IDP and Returnee Database

\section{Post-War}

If we look at the relation the labor force after the war, we notice a bit of a sharper trend in terms of the distribution of economic participation, and again most men (52.46\%) are working, while most women are housewives (63.17\%).

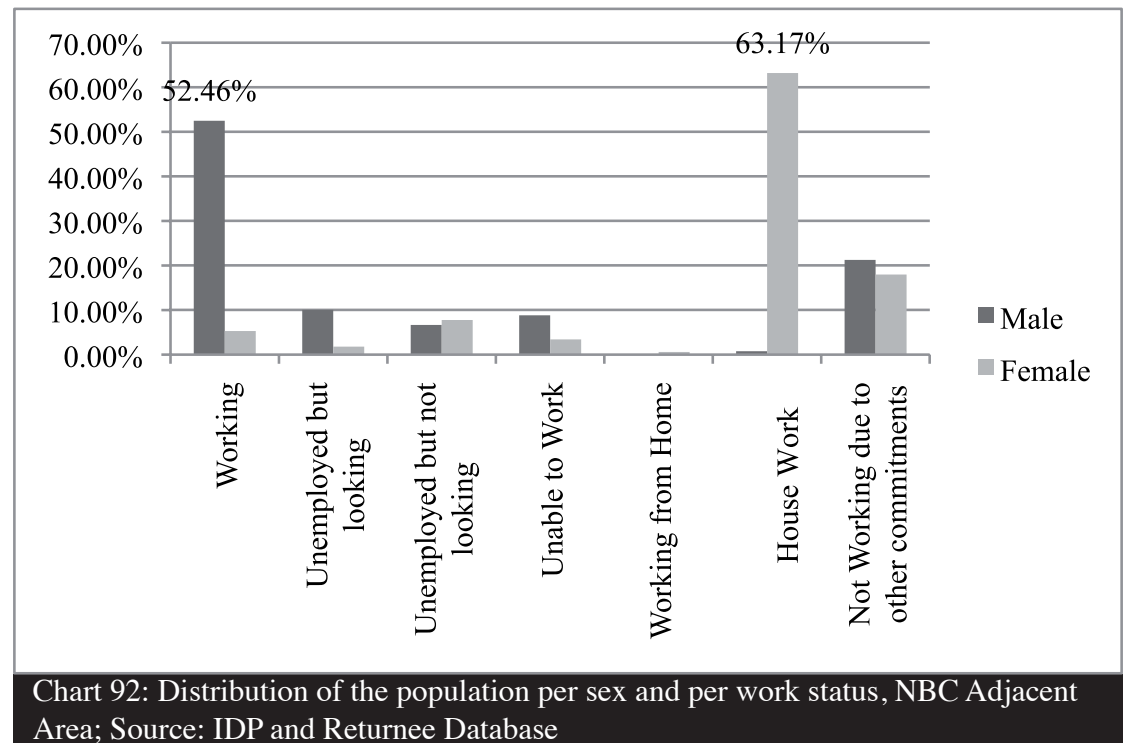


The impact of the war on women in terms of income has been negative in the low-income category and in the high-income category, $-5.18 \%$ (below 350,000 LBP) and $-15.97 \%$ (above 500,000 LBP) respectively; while in the medium-income level there has been a considerable increase of women (62.82\%). As for men the impact of the war was negative in the low and medium income categories, while it is positive for the high-income category.

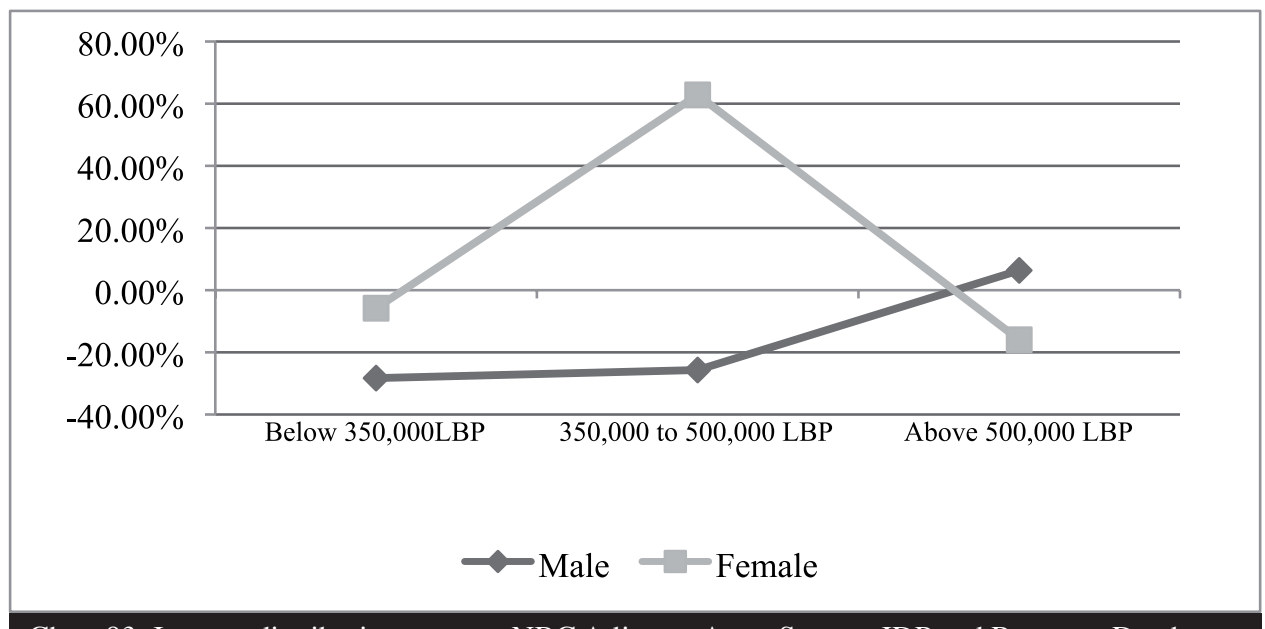

Chart 93: Income distribution per sex, NBC Adjacent Area; Source: IDP and Returnee Database 


\section{Education and Employment}

\section{Pre-War}

$40.13 \%$ of those who have attained a primary level education are working compared to $35.83 \%$ of those who have attained university education. $31.11 \%$ of those who have attained intermediary education are working compared to $26.91 \%$ of those who have attained secondary education. Based on these figures we can assume that the labor market is more hospitable towards those who have primary education and university education while it is less hospitable for those who have intermediary and secondary education. $28.89 \%$ of those who have had vocational training are reported as working.

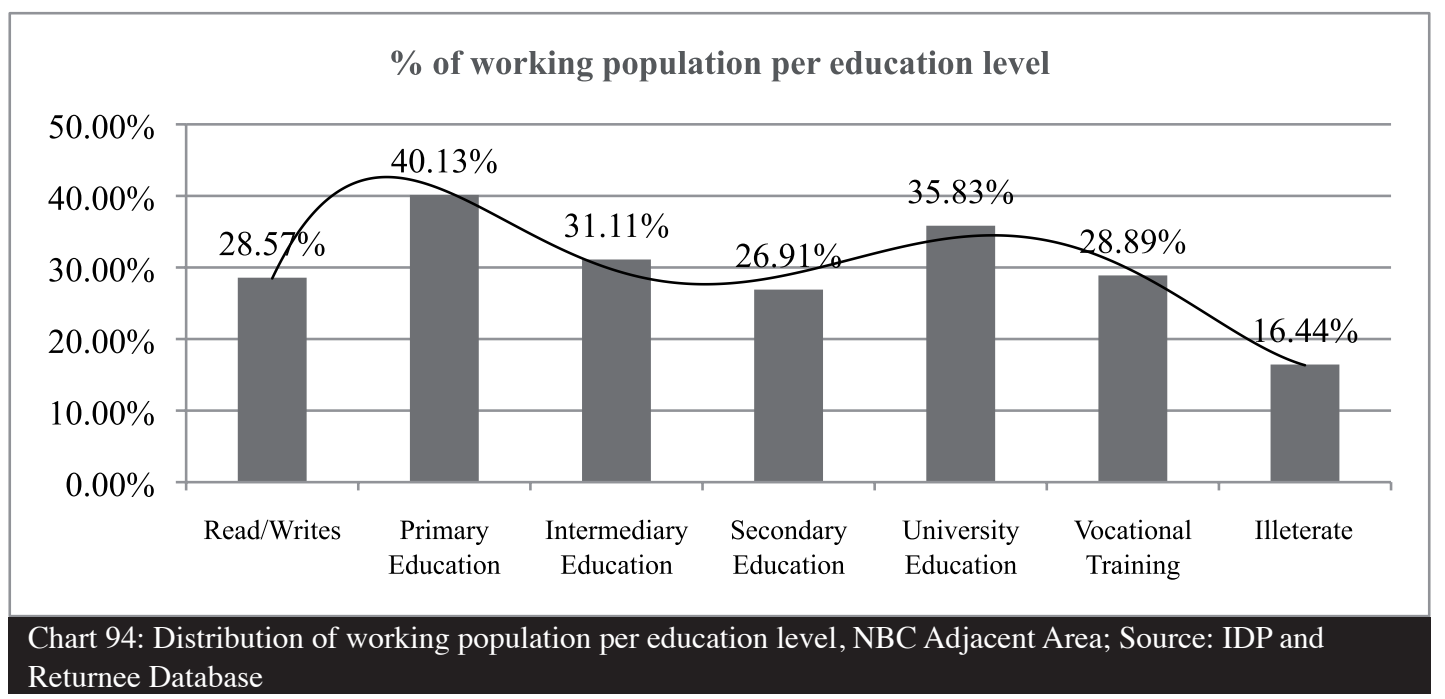

In terms of income, those who have attained secondary and university education have the best performance in terms of income, $68.97 \%$ of those who have attained university education receive more than 500,000 LBP as monthly wage, and $53.10 \%$ of those who have attained secondary education. Those who have attained vocational trainings rank third, $45.54 \%$ have a monthly wage above 500,000 LBP

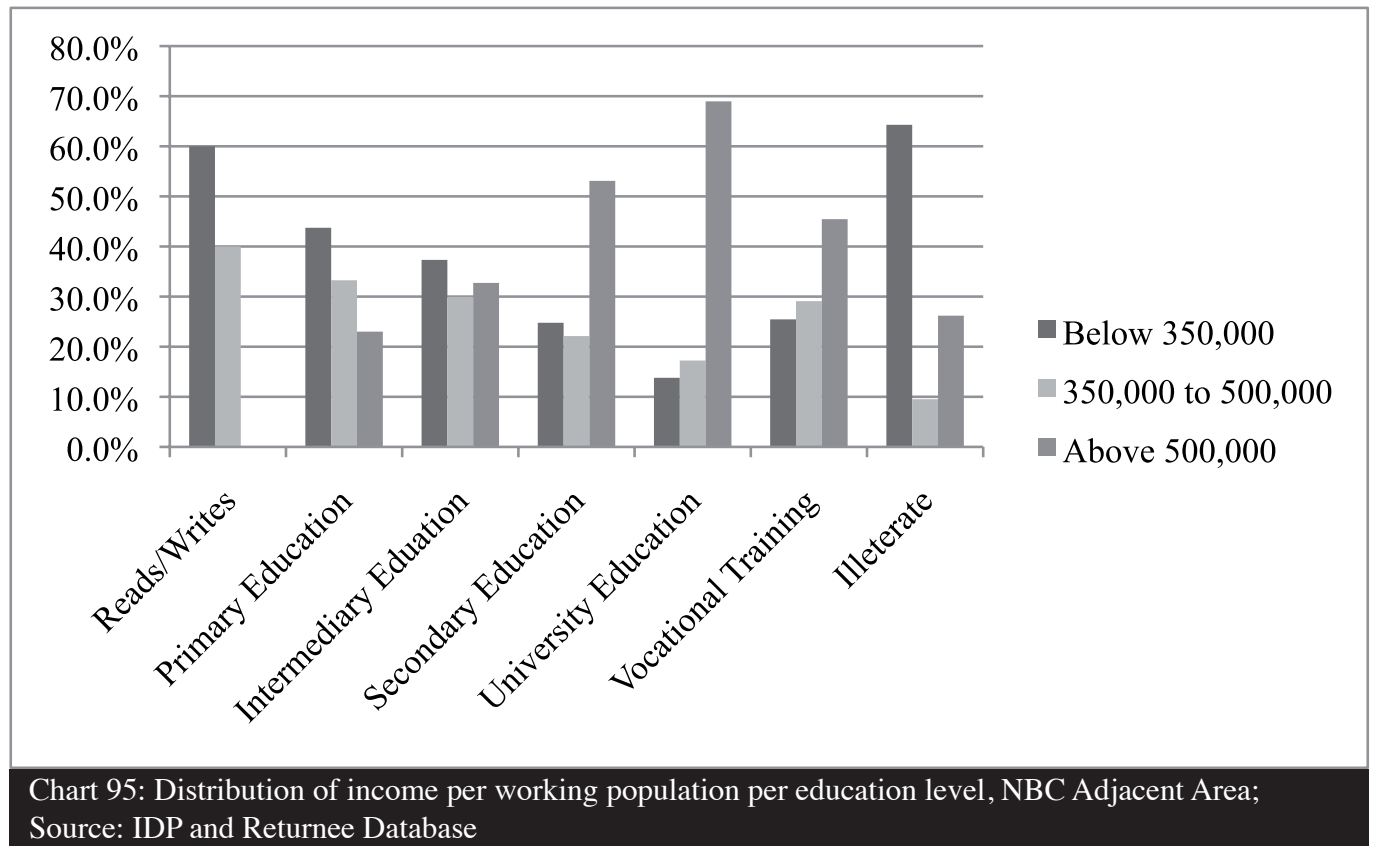




\section{Post-War}

After the war, we can notice a considerable drop in medium-level wages (350,000 to 500,000 LBP) in all categories, and a considerable rise in low-level wages; those who have university education had the least impact on their income levels.

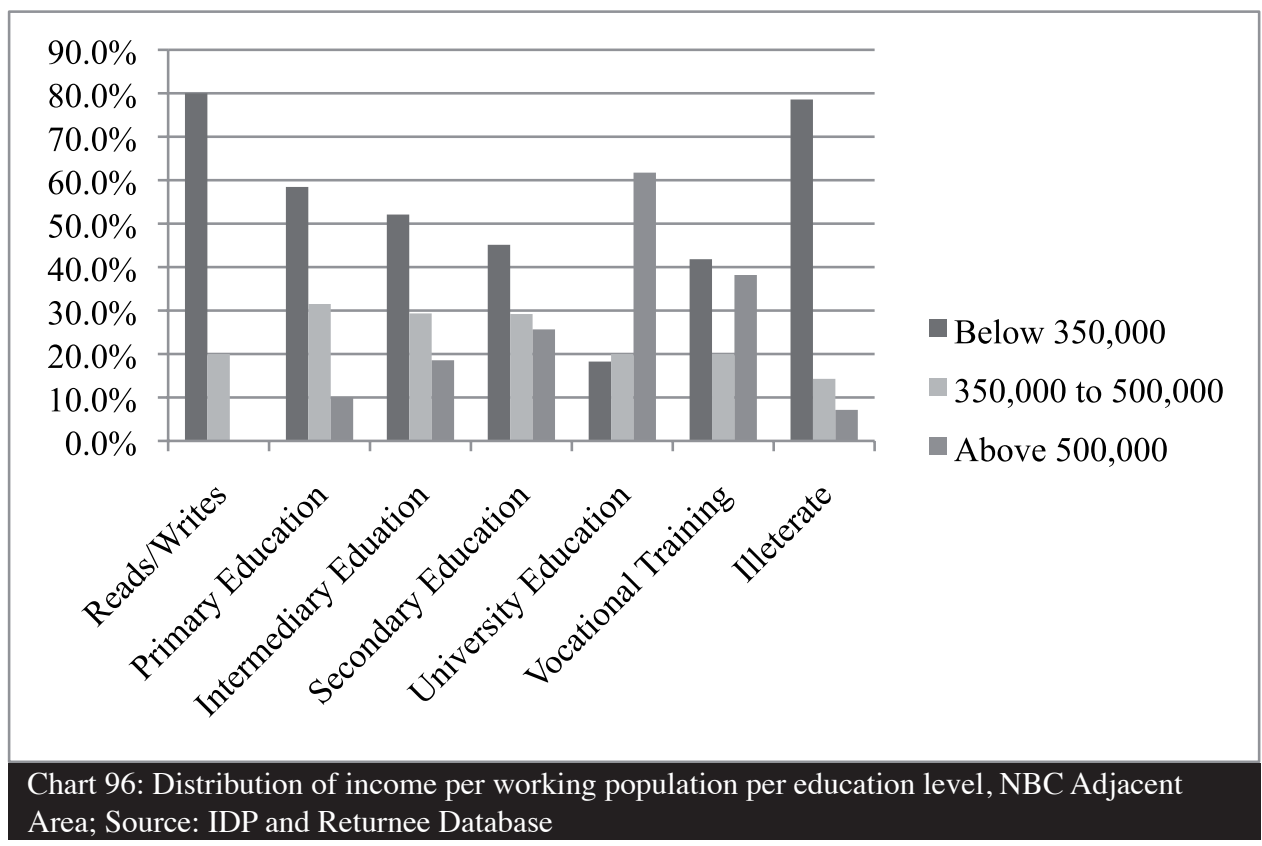

Looking at income variations from before and after the war we notice that the category for primary, intermediary and secondary education have witnessed the highest decrease in the number of those who receive more than 500, 000LBP, 56.34\%, $43.29 \%$ and $51.67 \%$ respectively. Persons who have university education and vocational training witnessed a more modest drop in the number of those who receive above 500,000 LBP.

We notice a rise in the numbers of those receiving below 350,000 LBP in all categories, which signifies a trend of drop in wages for most of the population.

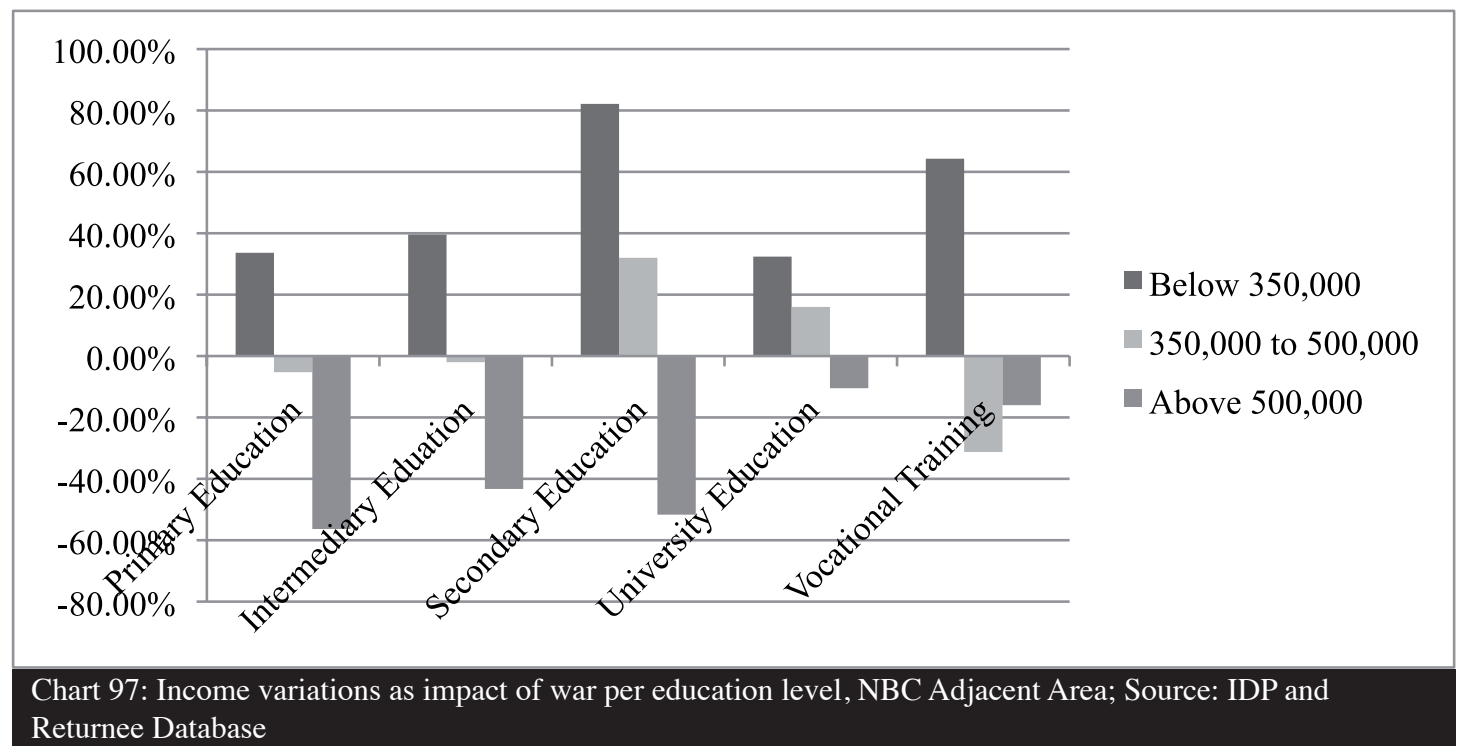




\section{XI-Businesses in Nabr El-Bared}

\section{General Characteristics of SMEs}

A total of 892 businesses were assessed for their situation before and after NBC crisis. Majority of businesses are operational (83.88\%) and a majority of businesses are accessible $(96.7 \%)$.

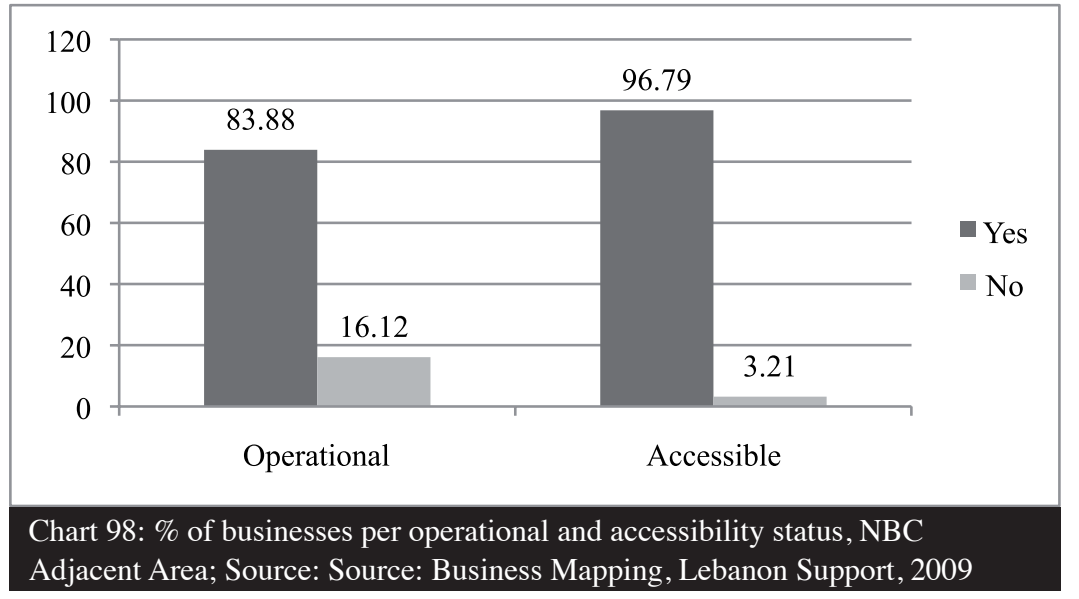

In terms of safety, $88.7 \%$ of businesses are categorized under "Safe" while $10.06 \%$ are partially unsafe, and $1.13 \%$ are considered unsafe.

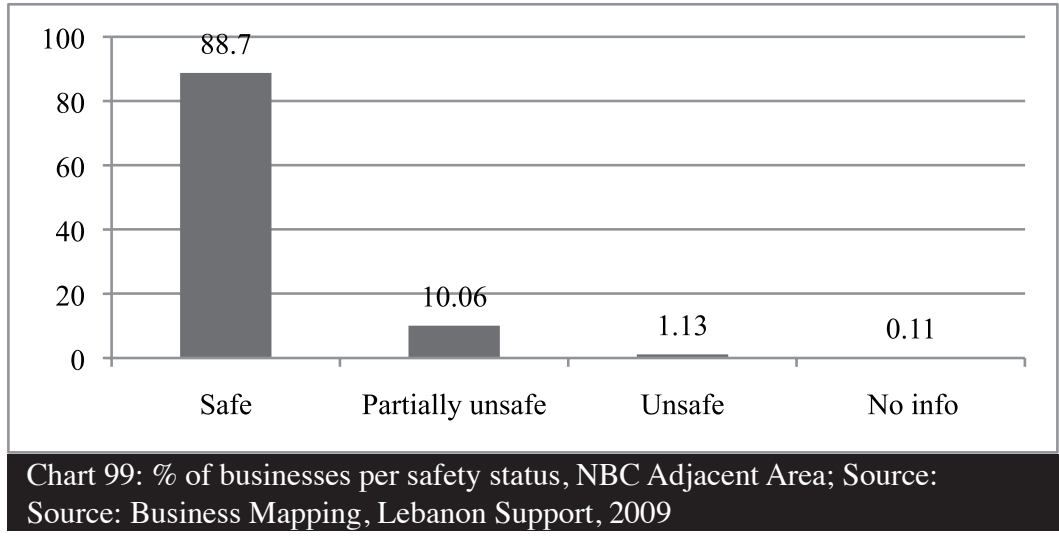

Almost half of the businesses (49\%) are rented, while in $14 \%$ are provided for free.

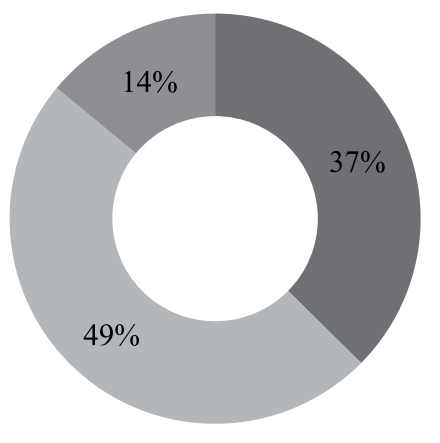

- Owner

Renter

Provided for free 
While damaged businesses represent $87 \%$ of the cases, based on the response of the interviewees, only $13 \%$ had organizational assistance while in most cases (76\%) they had to rely on themselves in terms of repairs.

93\% of business owners in NBC are also residents of the camp. Moreover, $83.76 \%$ of business owners/operators are male compared $16.24 \%$ for female business owner/operators. The majority of business owners/operators are aged between 40 to 45 years; the mean age is at $41.35 \%$.

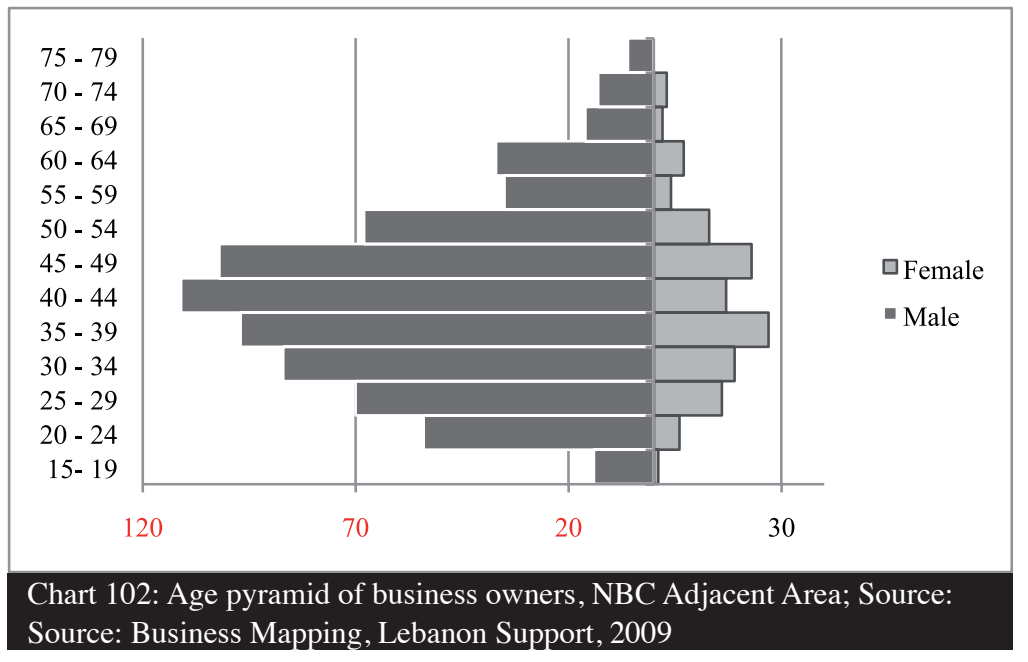

The majority (44.51\%) has reached the intermediary (complementary) level of education and only $0.35 \%$ has a master's degree. $16.53 \%$ have attained secondary education, and only 7.32 have attained university education

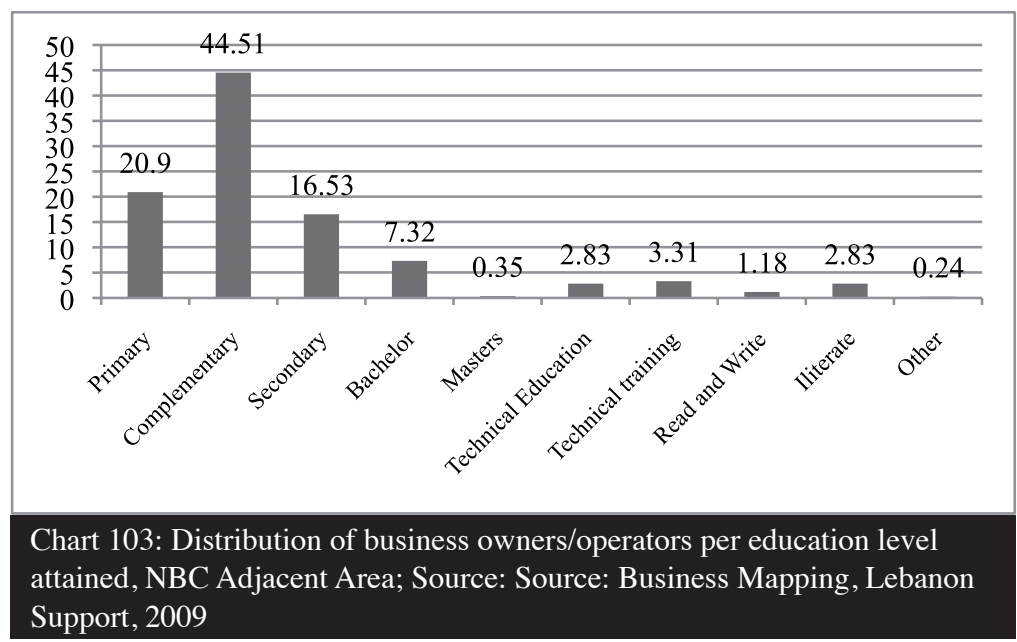

The mean number of dependents is 6.89 persons/business, with a maximum of 30 persons/ business.

\begin{tabular}{l|l} 
& Number of dependants for their livelihood \\
\hline Mean & 6.89 \\
\hline Median & 6 \\
\hline Minimum & 0 \\
\hline Maximum & 30 \\
\hline
\end{tabular}

Table 12: Average number of economically dependant on business owner 


\section{Levels of Employment and Income}

The majority of the businesses (63.67\%) are operated by the owner/operator, followed by businesses with one to two workers in addition to the owner/operator. In general, businesses at NBC are small businesses and have low levels of employment.

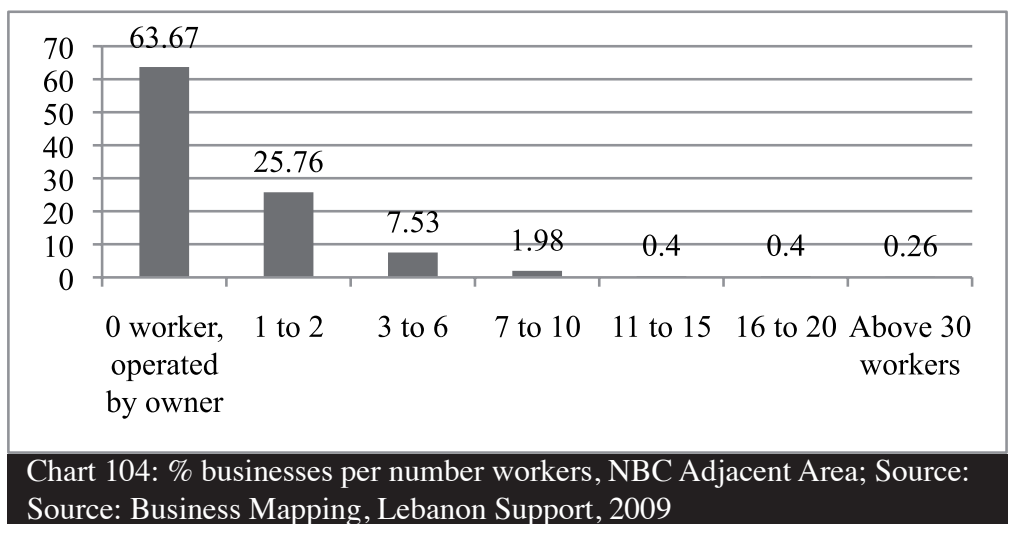

Most workers in businesses are males, and only $15 \%$ of businesses employ one or more female workers, while $86 \%$ employ one or more male workers.

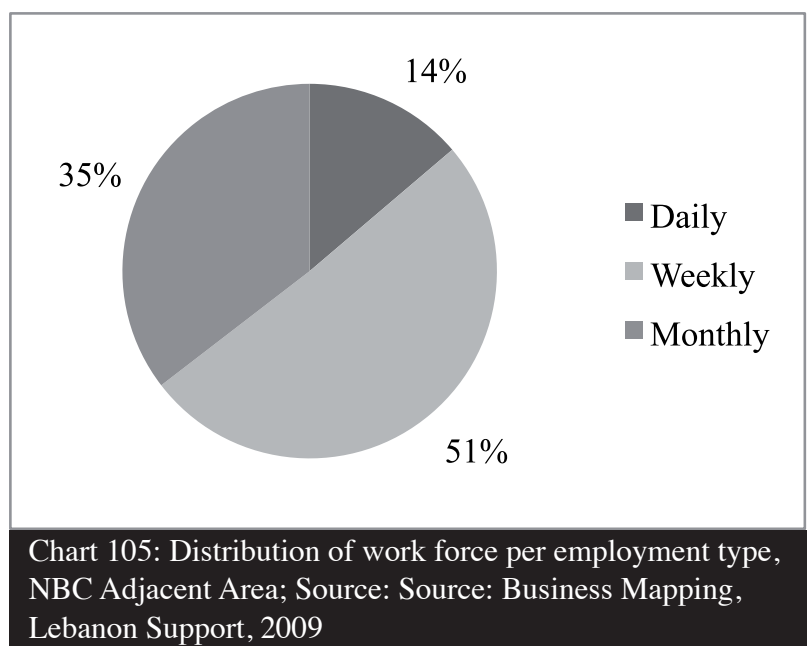

Workers are employed in half $(51 \%)$ of the cases on weekly basis, while monthly workers are only employed in $35 \%$ of the cases.

The majority of businesses have 1 to 2 weekly basis workers, while more than 10 workers are reserved in majority for the daily basis workers;

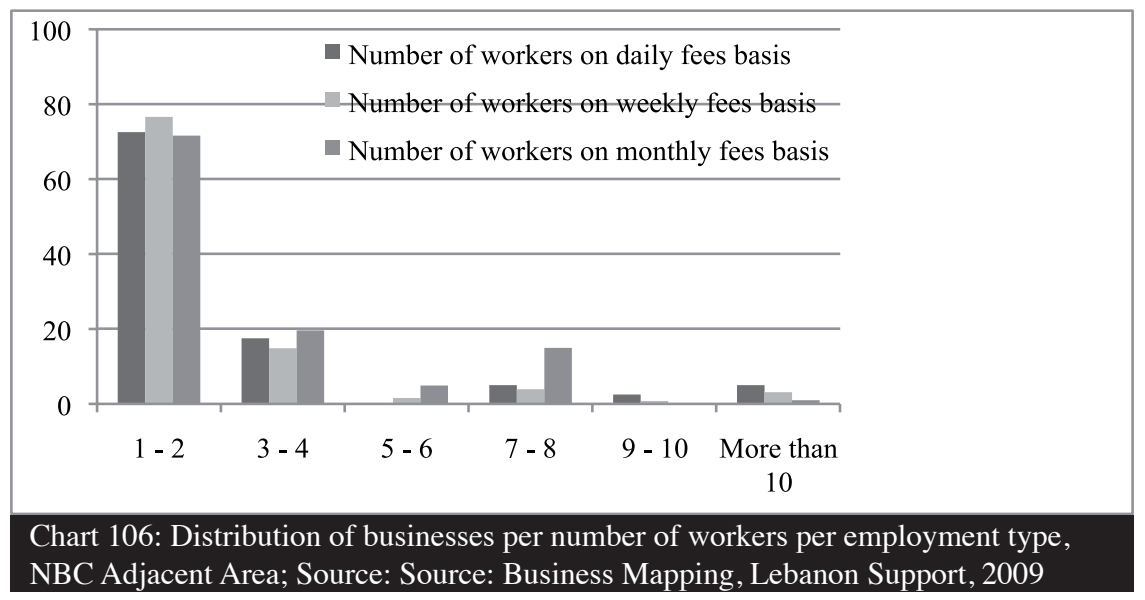


Most daily workers (59.46\%) in businesses receive between 10,000 LBP and 20,000 LBP per working day.

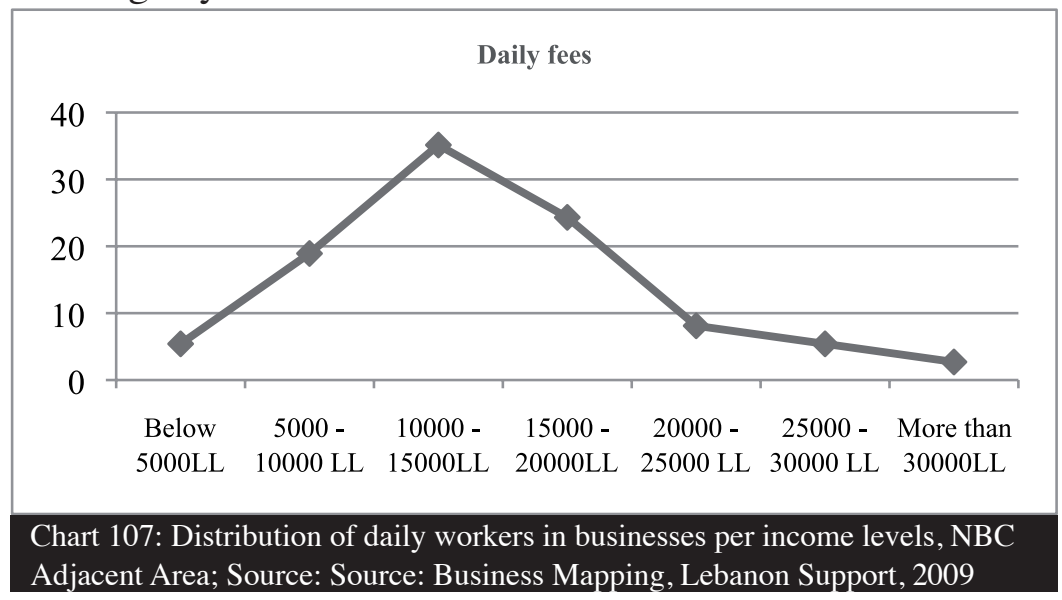

Most weekly workers (56.25\%) in businesses receive a weekly pay between 45,000 LBP and 100,000 LBP per working week.

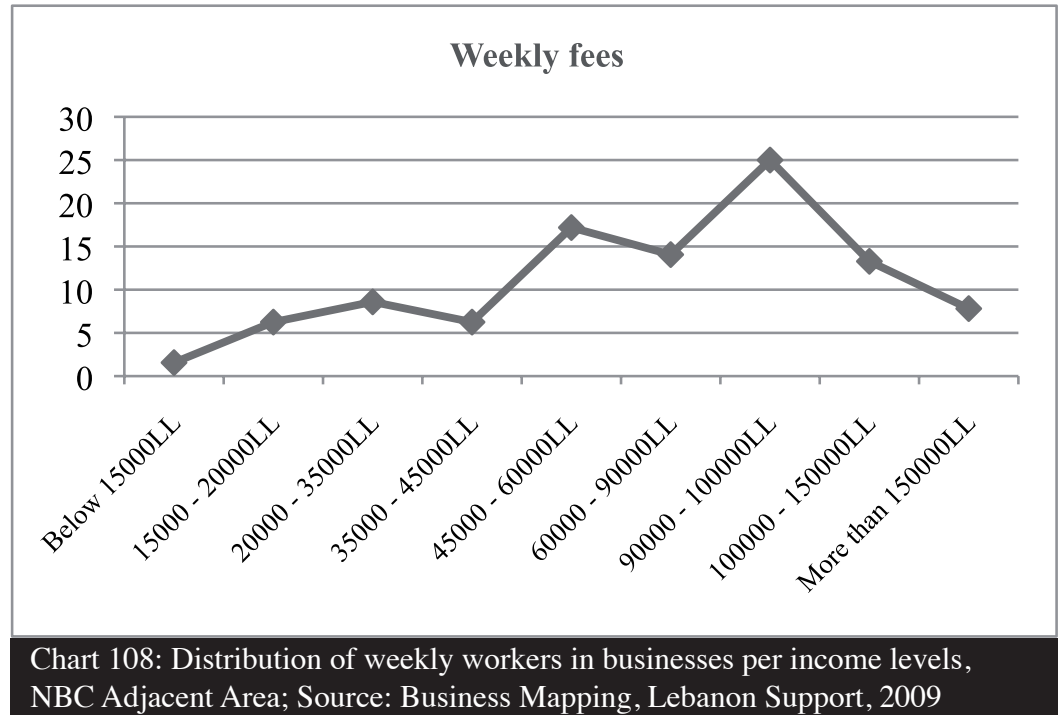

Most monthly workers (79.2\%) in businesses receive between 100,000 LBP and 750,000 LBP per month.

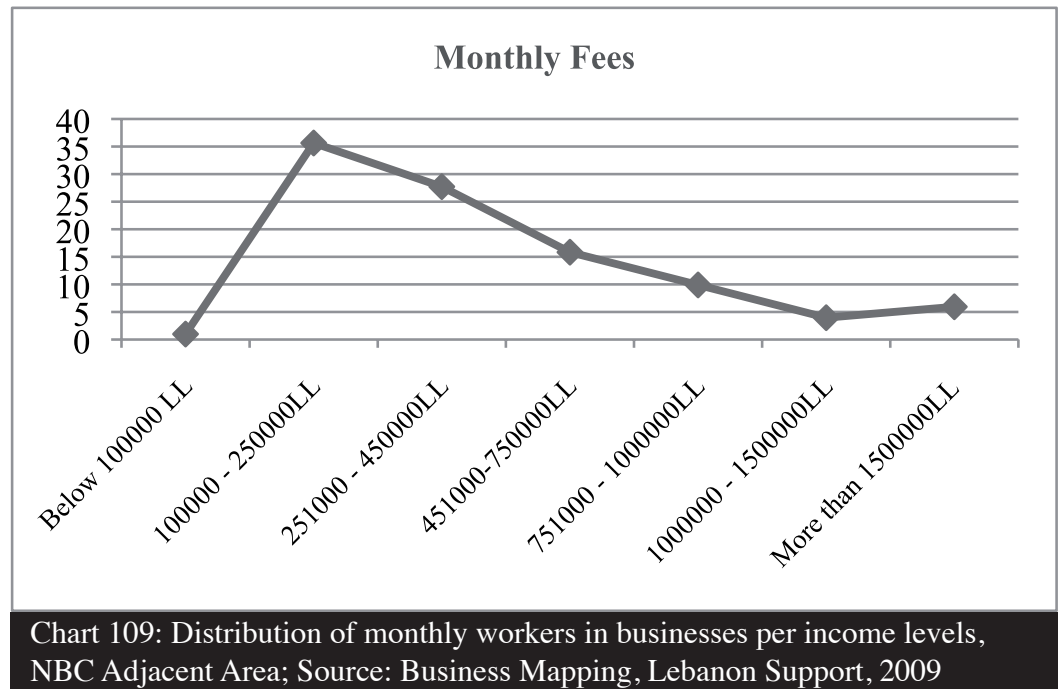




\section{Obstacles to Growth}

The majority (72\%) of businesses stated that they are encountering a budget deficit.

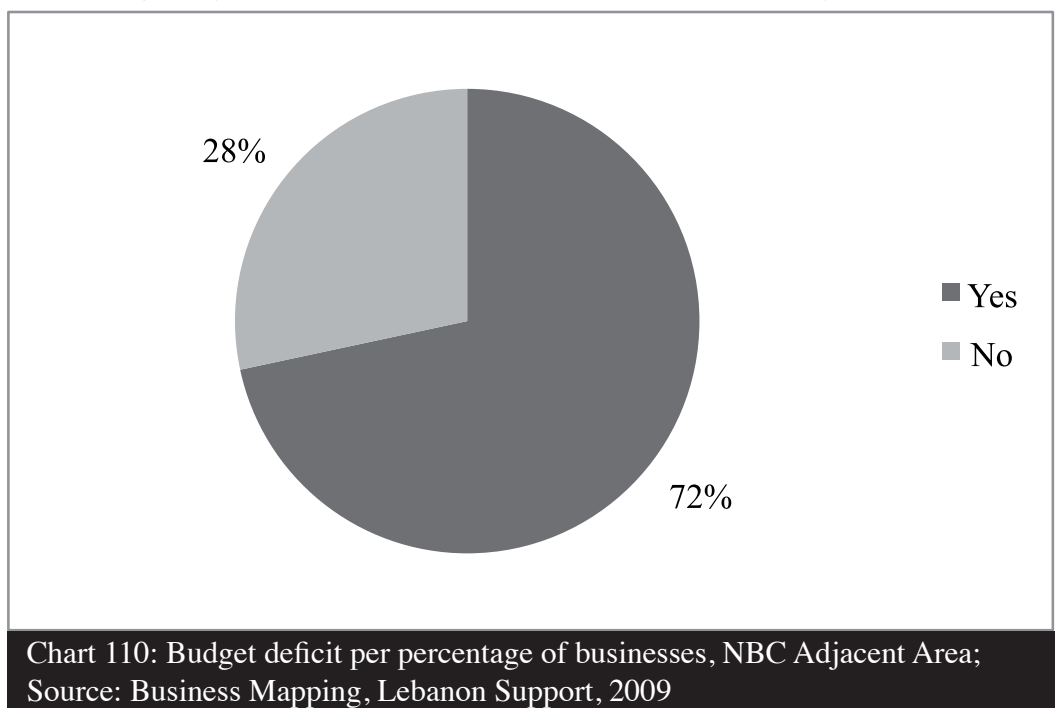

Receiving grants seems to be more frequent than loans, as respectively $18.3 \%$ of the surveyed population stated they received grants while only $2.2 \%$ stated to have received a loan. But however, the majorities ( $>80 \%$ ) didn't receive any grants or loans. Grants in the majority of cases $(61 \%)$ are offered as in Kind and not as in form of money.

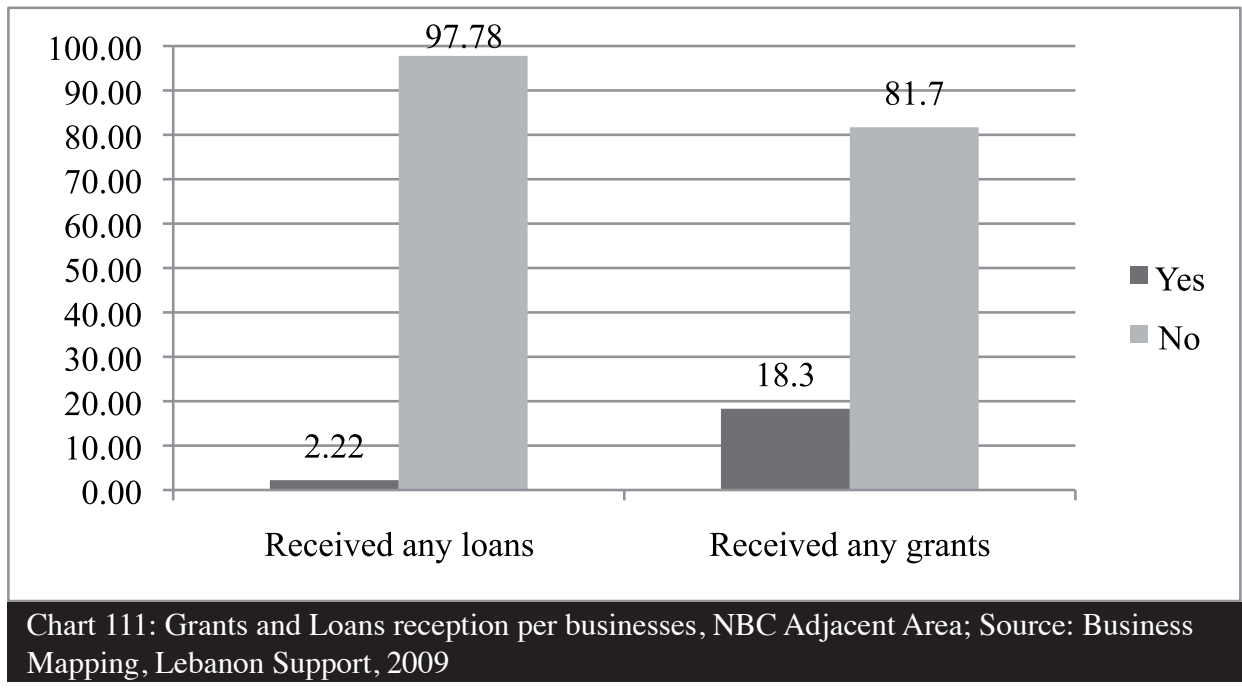

The majority (64\%) confirmed having noticed a rise of prices during the previous month. 
The difficulty that the biggest majority (97.64\%) encounters is Army/Security barriers; while the major obstacle/problem or cause that's stopping their business from growing is the provision supplies.

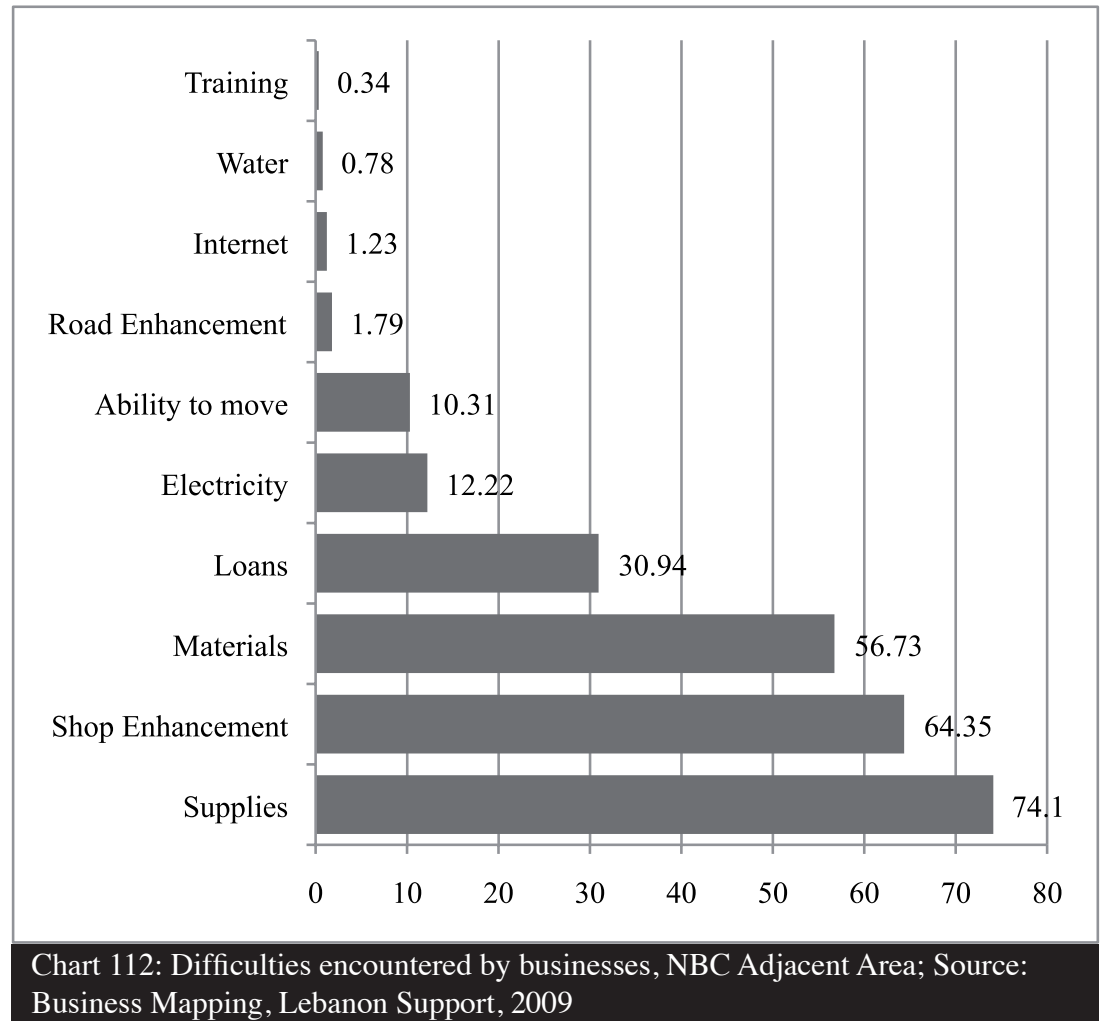

When asked if they were willing to change their business, only $3 \%$ said they were.

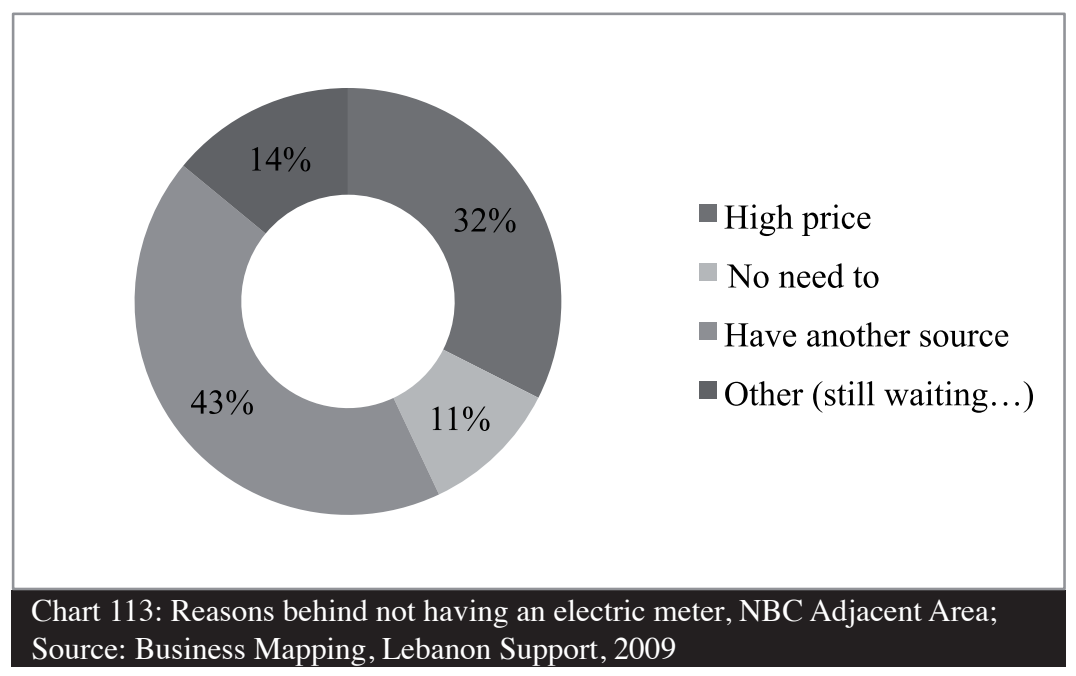

Almost half of the surveyed population (49\%) does not have an electric meter.

And the reason for not having one is for the majority that they had another source while $32 \%$ stated that the main reason for not getting an electric meter is due to its high price. 


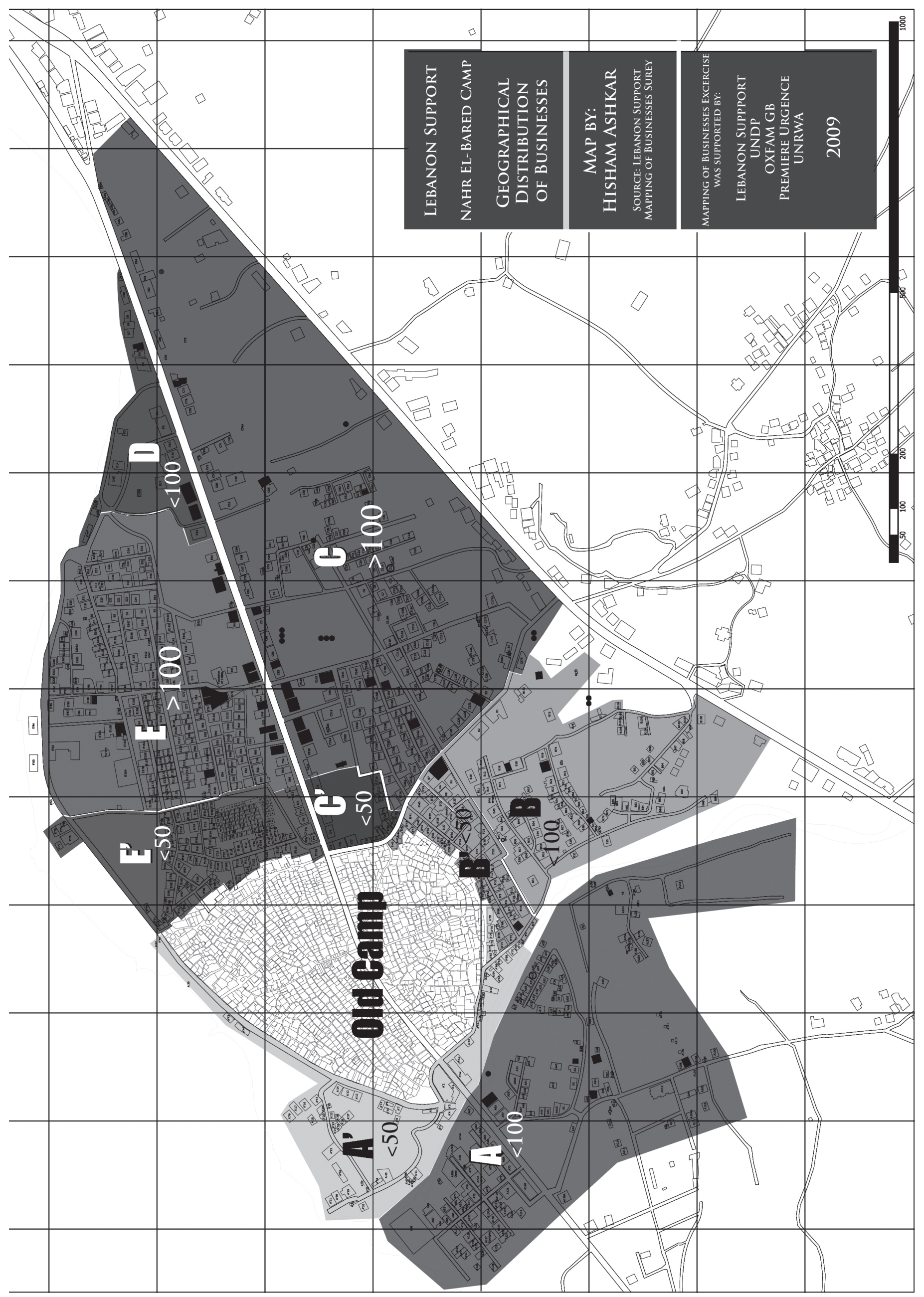


OTHER RESOURCES AND PUBLICATIONS RELATED TO NAHR EL-BARED CAN BE FOUND ON:

LEBANON SUPPORT'S EMERGECNY AND RECOVERY INFORMATION SYSTEM (ERIS) 